\title{
Effects of fear of dental pain and information type on fear and pain responding during endodontic treatment
}

\author{
John T. Sorrell \\ West Virginia University
}

Follow this and additional works at: https://researchrepository.wvu.edu/etd

\section{Recommended Citation}

Sorrell, John T., "Effects of fear of dental pain and information type on fear and pain responding during endodontic treatment" (2003). Graduate Theses, Dissertations, and Problem Reports. 1890.

https://researchrepository.wvu.edu/etd/1890

This Dissertation is protected by copyright and/or related rights. It has been brought to you by the The Research Repository @ WVU with permission from the rights-holder(s). You are free to use this Dissertation in any way that is permitted by the copyright and related rights legislation that applies to your use. For other uses you must obtain permission from the rights-holder(s) directly, unless additional rights are indicated by a Creative Commons license in the record and/ or on the work itself. This Dissertation has been accepted for inclusion in WVU Graduate Theses, Dissertations, and Problem Reports collection by an authorized administrator of The Research Repository @ WVU.

For more information, please contact researchrepository@mail.wvu.edu. 
Effects of Fear of Dental Pain and Information Type on

Fear and Pain Responding during Endodontic Treatment

\author{
John T. Sorrell \\ Dissertation submitted to the \\ Eberly College of Arts and Sciences at \\ West Virginia University in partial fulfillment of \\ the requirements for the degree of
}

Doctor of Philosophy

in

Psychology

\author{
Daniel W. McNeil, Ph.D., Chair \\ Lindsey L. Cohen, Ph.D. \\ Richard T. Gross, Ph.D. \\ Julie Hicks Patrick, Ph.D. \\ Jeannie A. Sperry, Ph.D. \\ Department of Psychology
}

Morgantown, West Virginia

2003

Keywords: Fear of Pain, Dental Pain, Information, Anxiety, Coping

Copyright 2003 John T. Sorrell 


\author{
ABSTRACT \\ Effects of Fear of Dental Pain and Information Type on \\ Fear and Pain Responding during Endodontic Treatment \\ John T. Sorrell
}

Fear of pain is an important factor within dental settings. Information is an effective method of enhancing predictability about aversive events during dental and medical procedures and can decrease fear and pain during treatment. Therefore, the effects of fear of dental pain and information type on fear and pain responding during endodontic treatment were examined. Experiment 1 included 268 undergraduate students to develop an informational videotape and a knowledge inventory designed to enhance predictability about root canal treatment and measure dental knowledge across 3 domains (oral hygiene, root canal procedure, and pain during root canal treatment). Results suggest that videotape information can enhance predictability; the knowledge inventory demonstrated the ability to detect content specific changes in dental knowledge. In Experiment 2, there were 104 endodontic patients from 2 clinics in West Virginia who viewed one of three informational videos prior to treatment; fear and pain behavior were recorded. Results from Experiment 1 were replicated in Experiment 2 using a clinical sample. Furthermore, results from Experiment 2 did not suggest differential effects of information type on fear and pain responding. Significant main effects of time emerged, indicating that fear and pain decreased after the procedure compared to any other time during treatment. These experiments demonstrate that although pain predictability can be enhanced using videotape information, endodontic patients may not be necessarily better served by receiving one type of information compared to another (e.g., procedure vs. pain-relevant) immediately prior to treatment. It is possible that the oral hygiene video functioned as a distraction from fear and pain and the information about pain sensitized patients to be vigilant of painful experiences, essentially offsetting potential positive fear and pain reduction effects of the pain information and overall negating differential effects. Due to methodological limitations, however, the possibility of distraction and sensitization will need to be addressed in future research. Clinically, these studies support the use of videotape information with root canal patients; practitioners should consider patient characteristics (e.g., fear of pain and anxiety sensitivity) when giving certain types of information. 


\section{Acknowledgements}

I would like to extend my warmest appreciation and gratitude to my dissertation chair, Daniel W. McNeil. His hard work and commitment helped foster the progression and completion of this study, and his support throughout the project has been instrumental. Many thanks also to the rest of my committee: Lindsey L. Cohen, Richard T. Gross, Julie Hicks Patrick, and Jeannie A. Sperry. Their suggestions and support have helped me achieve this developmental milestone. A special thanks to Jeannie and Rick for modeling what it takes to be a great psychologist.

Kevin and Janet Vowles have supported me throughout my graduate training and especially during the time of my dissertation. They helped me manage the tough parts of graduate school, and they have made the good times the most memorable and cherished of the entire experience. Thank you for all the wonderful times and the many more to come in the future.

The support of my family, Robert, Sheri, Madison, Joey, Denise, Connor, Vince, and Tara, has meant so much to me during the past 2 years while working on my dissertation. I do not believe I could have accomplished as much as I have without them. To my new family, James, Martine, Dominique, and Matou Ferretti, thank you for believing in me. And to my parents, Robert and Catherine, thank you for your love, tenderness, and encouragement.

To my wonderful companion and most cherished friend, Sophie, thank you, from the bottom of my heart, for showing me what really matters in life. Words cannot describe how thankful I am for the support you have given me during the past three and a half years. I look forward to every day of the rest of our lives together.

I also would like to thank the WVU Eberly College of Arts and Sciences, WVU Department of Psychology Alumni Fund, WVU School of Dentistry, University Health Associates Research Fund, and American Association of Endodontists Foundation for helping to fund this project, as well as several individuals who put time and energy into helping to make this project happen: Jeff Barns, John Coletti, Richard Crout, Sarah Foster, Lori Gochenour, Matt Gregory, Johnna Guzzi, Russell Jackson, Jennifer Kianko, Sheila Price, Nhu Quach, Nicole Siegwarth, Brad Stalnaker, Frank Stevens, and Rich Swartzwelder. 
Table of Contents

\section{Title Page}

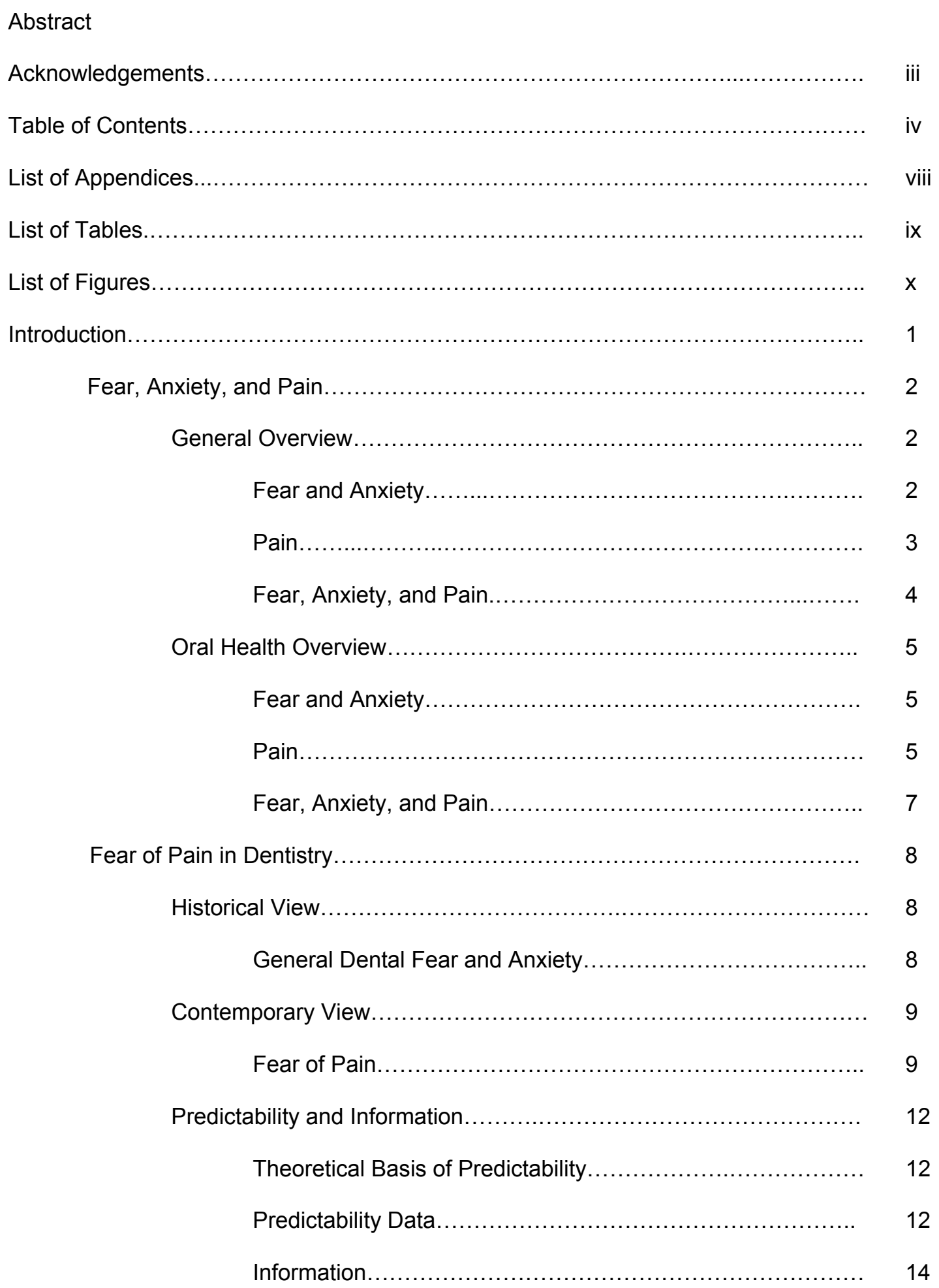


Summary and Critique.................................... 18

Statement of the Problem................................................. 19

Endodontic Treatment: Brief Description............................... 20

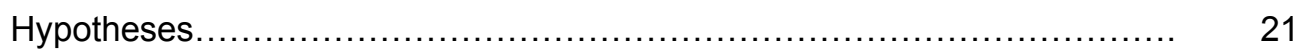

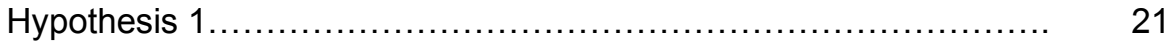

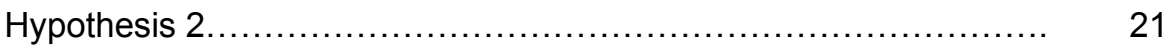

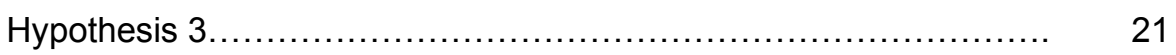

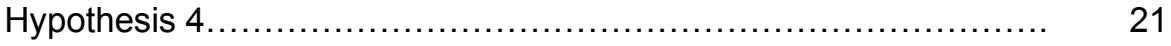

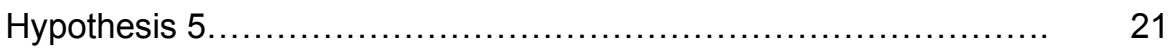

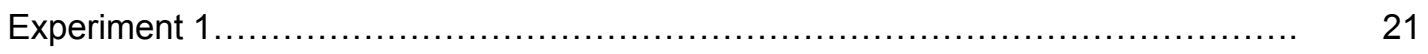

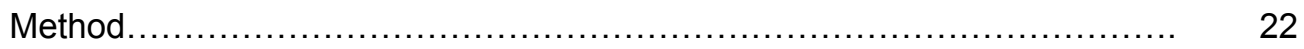

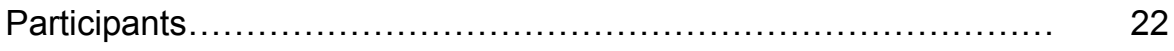

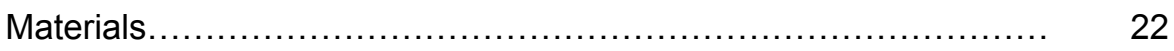

Oral Hygiene Video...................................... $\quad 22$

Root Canal Procedure Video........................... 22

Fear of Dental Pain Video............................ $\quad 22$

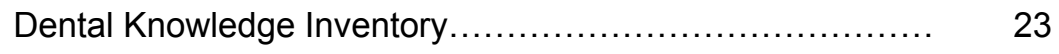

Demographic Questionnaire............................. $\quad 24$

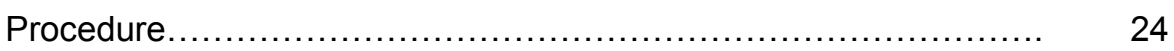

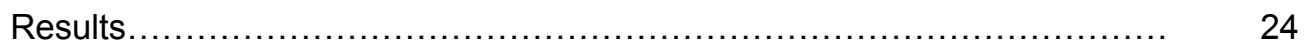

Discussion...................................................... 25

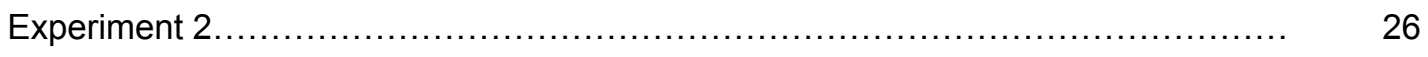

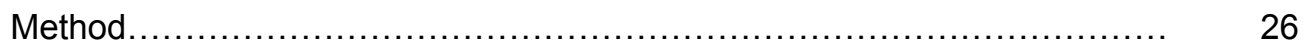

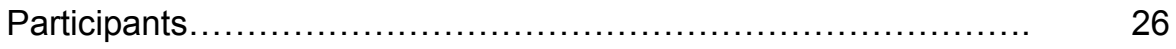

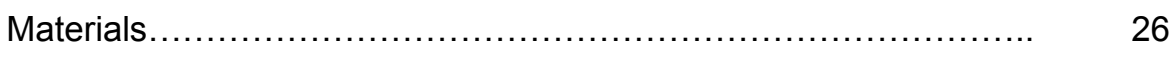

Informational Videos.................................. 26

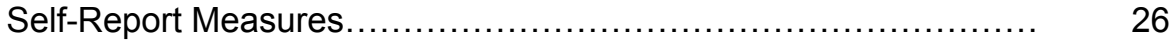


Fear of Pain Questionnaire ............................... $\quad 26$

Dental Fear Survey................................... $\quad 27$

Anxiety Sensitivity Index............................. 27

Miller Behavioral Style Scale.............................. 28

Dental Knowledge Inventory.............................. $\quad 28$

Additional Measures............................................... 28

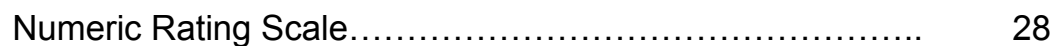

Polar Heart Rate Monitor................................. $\quad 29$

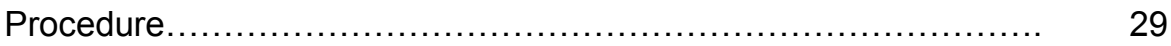

Data Analytic Approach........................................ $\quad 30$

Power Analysis.................................................... 30

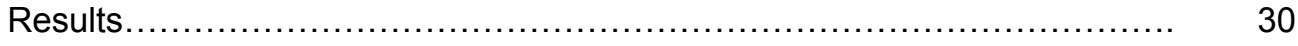

Manipulation Check........................................ $\quad 30$

Analyses by Hypotheses......................................... 31

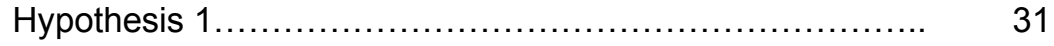

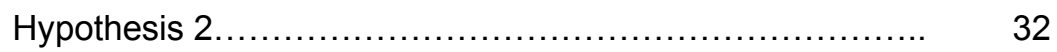

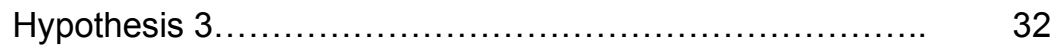

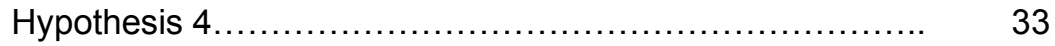

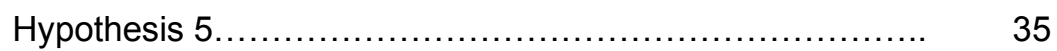

Discussion ................................................................... 36

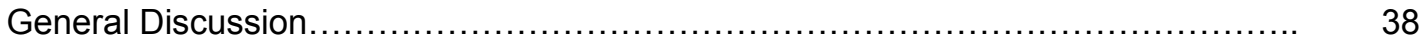

Major Findings and Confirmed Hypotheses.............................. 39

Replication of Previous Research................................ $\quad 39$

Extension of Previous Research................................... 41

Major Finding and Unsupported Hypotheses............................ 42

Fear, Pain, and Information Type............................... 42

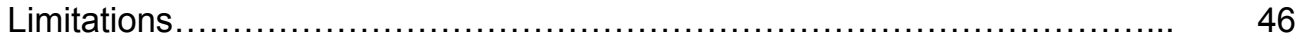




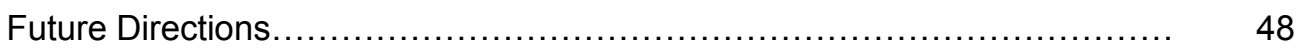

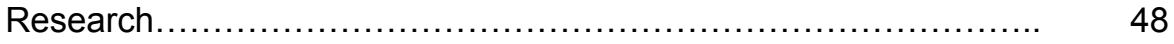

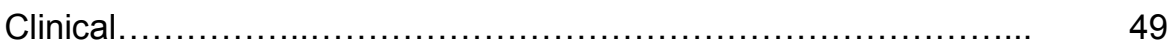

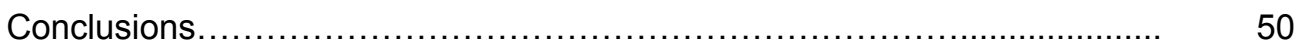

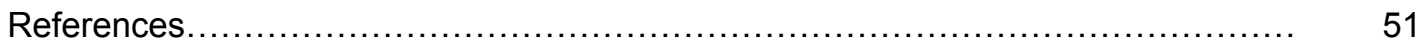

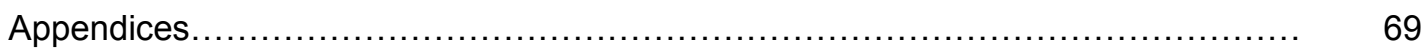

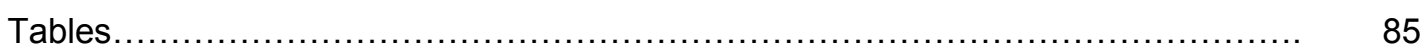

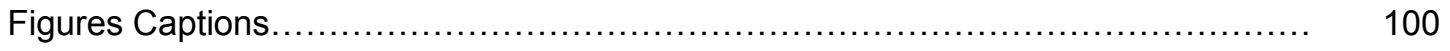

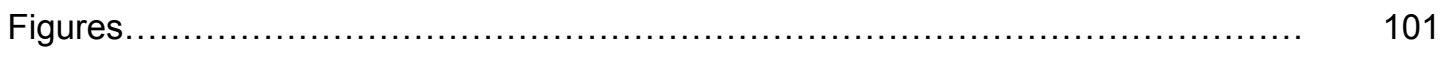




\section{List of Appendices}

1. Oral hygiene video: "Taking care of your teeth and gums."

2. Endodontic procedure video: "Root canal."

3. Fear of dental pain video: "Reducing fear about pain in root canal therapy."

4. Dental knowledge inventory.

5. ANOVA table for pre- and post-video scores on the DKI in Experiment 1.

6. Numeric rating scale.

7. Procedural flow.

8. ANOVA table for pre- and post-video scores on the DKI in Experiment 2

9. ANOVA table for verbal reports of fear.

10. ANOVA table for verbal reports of pain.

11. ANOVA table for heart rate change scores.

12. ANOVA table for fear memory.

13. ANOVA table for pain memory. 
List of Tables

1. Demographic summary for participants in Experiment 1.

2. Video content analysis.

3. Means and standard deviations for pre- and post-video DKI subscale scores in Experiment 1.

4. Demographic summary for participants in Experiment 2.

5. Means and standard deviations for pre- and post-video DKI subscale scores in Experiment 2.

6. Means and standard deviations for verbal reports of fear in Experiment 2.

7. Means and standard deviations verbal reports of pain in Experiment 2.

8. Means and standard deviations for heart rate change values.

9. Means and standard deviations for worst fear during treatment and worst fear remembered at follow-up.

10. Means and standard deviations for worst pain during treatment and worst pain remembered at follow-up.

11. Means and standard deviations for the four self-report measures used in Experiment 2.

12. Correlations among demographic variables, self-report measures, and fear and pain ratings before treatment.

13. Summary of hierarchical regression analysis for variables predicting dental fear.

14. Summary of hierarchical regression analysis for variables predicting verbal reports of fear before treatment.

15. Summary of hierarchical regression analysis for variables predicting verbal reports of pain before treatment. 
List of Figures

1. Mean scores on DKI subscales across groups in Experiment 1.

2. Mean scores on DKI subscales across groups in Experiment 2.

3. Mean verbal reports of fear for Experiment 2.

4. Mean verbal reports of pain for Experiment 2.

5. Mean heart rate change scores for Experiment 2.

6. Mean verbal reports of fear experienced during treatment and remembered at follow-up.

7. Mean verbal reports of pain experienced during treatment and remembered at follow-up. 


\section{Effects of Fear of Dental Pain and Information Type on \\ Fear and Pain Responding during Endodontic Treatment}

Fear and pain as general constructs have been widely investigated, both in regard to chronic medical problems and acute medical procedures. Fear of pain has received increasingly greater attention as research and clinical foci when considering patients' overall health care experiences. Fear of dental pain, however, has received relatively less investigation and clinical attention compared to fear of pain in other health care areas such as chronic musculoskeletal pain (e.g., Crombez, Vlaeyen, Heuts, \& Lysens, 1999; Vlaeyen \& Linton, 2000). As fear of dental pain begins to be more closely examined, it is recognized as a significant problem that often acts as a barrier to dental treatment (Chadwick, 2002). Persons who avoid routine examinations and emergency dental procedures as a result of such fear can experience significant oral health problems (e.g., Kloffon, 1988). Furthermore, general systemic health problems such as cardiovascular disease (e.g., Deshpande, Khan, \& Genco, 1999; Graves, Jiang, \& Genco, 2000) and respiratory infection can result from the spread of bacteria in blood that develops from poorly maintained oral health (Mojon, 2002). Fear of dental pain can not only compromise patients' health but its effects on patient behavior (e.g., avoidance) also can significantly decrease the productivity, efficiency, and financial stability of the facilities that provide treatment (Vowles et al., 2001). Therefore, the negative effects of fear of dental pain are evident at an individual as well as a societal level of analysis.

Given the importance of fear of pain as a global problem (e.g., Anaise \& Mann, 1982;

Kunzelmann \& Dunninger, 1990; Newman \& Gift, 1992; Schuurs, Duivenvoorden, Thoden van Velzen, \& Verhage, 1980; Sullivan \& Neish, 1998; Widstrom \& Martinsson, 1980; Weinstein, 1990), multiple theoretical approaches and methodologies have been employed to study fear of pain in general (e.g., Lethem, Slade, Troup, \& Bentley, 1983; Rhudy \& Meagher, 2000, 2001; Vlaeyen, Kole-Snijders, Boeren, \& van Eek, 1995; Vlaeyen \& Linton, 2000; Waddell et al., 1993) and fear of dental pain in particular (e.g., Arntz \& Schmidt, 1989; Corah, 1988; Kent, 1983, 1984, 1985; Klepac, McDonald, Hauge, \& Dowling, 1980; Horst \& de Wit, 1993; Litt, 1996; McNeil, Au et al., 2001; Sorrell \& McNeil, 2003; Vassend, 1993). Despite the growth of research related to fear of dental pain, only recently has there been a critical review and integration across investigations in this field of study (Sorrell \& McNeil). Such a review has uncovered areas in fear of dental pain research that would benefit from further investigation. Among those areas, 
and the main topic of the present study, is predictability. More specifically, how can predictability be enhanced during dental treatments to reduce fear and pain responding? Information about pain, for example, has been found to be helpful for chronic pain patients (e.g., Burton et al., 1999), but the data is mixed for dental patients (Miller, Combs, \& Stoddard, 1989). Furthermore, several unanswered questions remain about predictability and how it may facilitate treatment for some patients and not others (Arntz \& Schmidt, 1989; Sorrell \& McNeil). Therefore, the purpose of this study was to better understand how using information to enhance predictability affects fear and pain responding during root canal treatment.

To further introduce this area of research (and the present study), relevant constructs will be reviewed (i.e., fear, anxiety, and pain) in general and in dentistry. Second, research on fear of dental pain will be highlighted in an effort to illustrate the accumulation of data in this area of investigation. Third, predictability and information research in dentistry will be reviewed to illustrate the current state of the problem.

Fear, Anxiety, and Pain

\section{General Overview}

Fear and anxiety. Fear and anxiety have significant familial concordance rates and often are discussed in terms of a diathesis-stress model in which one may have a biological predisposition or genetic vulnerability to develop an anxiety disorder (Barlow, 2002). Although an anxiety disorder may develop in the absence of biological predispositions or an environmental stressor, according to this diathesis-stress model, it is not until triggering events are encountered that disorders emerge. Fear and anxiety are multidimensional emotional states characterized by changes in physiological arousal, catastrophic thoughts, emotional responses, as well as behavioral avoidance and escape responding (Barlow, 1991, 2002; McNeil, Turk, \& Ries, 1994; Rhudy \& Meagher, 2000, 2001). Although there are similarities among these responses, fear is considered to be a basic (cross-cultural), fundamental emotional response to immediate danger. In contrast, anxiety is vague, imprecise, and associated with less differentiated physiological arousal and is more of an apprehension of a future threat (e.g., Barlow, 1991, 2002; McNeil, Vrana, Melamed, Cuthbert, \& Lang, 1993; Zinbarg, 1998). Craske (1999) distinguishes fear and anxiety as a basic emotional response and generalized mood state, respectively. Craske argues that emotions such as fear are less cognitive, mature prior to mechanisms required for memory, and can be evoked by noncognitive events, while moods such as anxiety can be maintained 
much longer than emotions and lack distinct physiological response patterns (Craske; Davidson \& Ekman, 1994; Izard, 1992).

It would be more precise, for example, to say that increased heart rate, blood pressure, and skin response, and quick retreat out of the path of an imminent threat such as a speeding truck are characteristic responses of fear. Minimal to moderate increased physiological arousal, general nervousness, and ruminating thoughts about poor performance on an exam for a college student, however, would be responses more characteristic of anxiety. Taken together, fear and anxiety overlap in terms of their multidimensional aspects, yet they are very different with regard to how the underlying dimensions are affected by immediate or future, uncertain threat (e.g., Barlow, 1991, 2002; Eccleston, 1994; Lang, 1968, 1971; McNeil, Lejuez, \& Sorrell, 2001; Rachman, 1991; Seligman, 1971).

Pain. Pain also is a multidimensional construct characterized by physiological reactivity, cognitive appraisal, and overt behavioral responses (e.g., Cleeland, 1986; Hadjistavropoulos \& Craig, 1994; Melzack \& Wall, 1965; Turk \& Monarch, 2002; Turk \& Rudy, 1987). Traditional medical models of disease (e.g., biomedical model) have been unidimensional (Eifert, Lejuez, \& Bouman, 1998) and suggest that responses such as pain are secondary to the ailment, are less important, and should remit when the disease is removed or "cured" (Turk \& Monarch, 2002). Thus, the approach asserts that if the insult or disease is removed, the pain also will be reduced or removed otherwise psychological factors are to blame for the maintenance of pain (i.e., psychosomatic). Research indicates that such a psychogenic approach is inaccurate and does not shed light on the processes underlying pain-related experiences and concomitant emotional distress (Abram, 1993; Lacroix \& Barbaree, 1992; Turk \& Rudy, 1987). Therefore, recent accounts of pain have made a shift in emphasis toward multidimensional models (e.g., biopsychosocial model), both in their conceptualization (e.g., Turk \& Monarch) and treatment (e.g., Hadjistavropoulos \& Craig, 1994; Keefe, et al., 2002). With regard to conceptualization, Melzak and Wall (1965) were among the first to discuss pain as a multidimensional experience, which focused on sensorydiscriminative, motivational-affective, and cognitive-evaluative components of pain. The gate control theory states that pain signals are modulated in the spinal cord by physiological and psychological mechanisms such as mood and affect regulation.

The International Association for the Study of Pain also supports a multidimensional definition of pain with its endorsement of the following pain definition: "An unpleasant sensory and emotional 
experience associated with actual or potential tissue damage, or described in terms of such damage“ (IASP, 2002, p. 209). Defined in this manner, pain is an experience reported by an individual. Thus, if a patient reports having pain in the absence of physical tissue damage, the pain may or may not be attributed to psychological factors; but the pain, nevertheless, is real. The opposite also is true; a patient may experience tissue damage and not necessarily experience pain along with it (i.e., analgesia).

Given the multifaceted conceptualization of pain described above, multidimensional pain treatments have been developed and found to be very effective. Mayer and Gatchel (1988), for example, describe a structured treatment program (based on a sports medicine approach) for chronic pain that involves the integration of multiple disciplines (e.g., physical therapy, psychology, medical management, and occupational therapy). The result is a treatment team that collectively cares for a patient and targets multiple aspects of the patient's pain experience (e.g., biological, psychological, and social). Another multifaceted treatment for pain patients is that described by Keefe and colleagues (2002). The group therapy they describe for patients with chronic pain targets three main goals: pain coping skills training, education about pain, and providing social support. In this way, patients learn various cognitive, behavioral, and physiological strategies to manage their pain. Treatment approaches such as this have been used repeatedly and demonstrate significant clinical improvements in patient functioning (e.g., Fritz, George, \& Delitto, 2001; McCracken \& Gross, 1998; McCracken, Gross, \& Eccleston, 2002).

Fear, anxiety, and pain. The nature of the relation between fear and pain is due in part to historical and contemporary conceptualizations of these states (Gross \& Collins, 1981), which has led to the multidimensionality of pain. As such, there has been considerable focus on how fear, anxiety, and pain interact to formulate the pain experience (e.g., IASP definition of pain). For instance, higher processes (e.g., emotions and cognitive variables) have been shown to moderate nociceptive and peripheral activity in formulating the experience of pain (Arntz \& Schmidt, 1989; Wall \& Melzack, 1994). With such studies there has been disagreement in how fear and anxiety affect pain, and vice versa (e.g., Al Absi \& Rokke, 1991; Arntz, Dreessen, \& De Jong, 1994; Eccleston, 1994; Williams, 1996). Fear and anxiety have been found to both increase and decrease pain responding, or to be secondary to other constructs (e.g., attention). When the relevance of fear towards pain is considered, there are more consistent effects such that pain-relevant fear exacerbates pain (Al Absi \& Rokke) while pain-irrelevant fear may function more as a distraction, and thus decrease pain (Arntz, Dreessen, \& Merckelbach, 1991; 
Arntz, Dreessen, \& De Jong). Research continues to examine the effects of fear and anxiety on pain within experimental psychopathology research and clinical arenas to elucidate understanding with regard to additional factors such as aversiveness that affect the influence of fear and anxiety on pain (e.g., Vowles, McNeil, Sorrell, \& Lawrence, 2003).

Oral Health Overview

Fear and anxiety. Fear and anxiety appear to be a frequent part of the dental experience. In fact, dental fear is one of the most frequently reported fears in "typical" adults (Jerremalm, Jansson, \& Ost, 1986) and continues to be a problem for both patients and practitioners (Feinmann \& Madland, 1999). For instance, a patient may be fearful of what might happen in the dental chair (e.g., Arntz, van Eck, \& Heijmans, 1990; Sullivan \& Neish, 1998) or a dentist may be apprehensive to put an anxious patient through a painful dental procedure (e.g., Kent, 1983, 1984, 1985). For fear and apprehension to be considered a significant problem, however, patients must show consistent avoidance or a strong, disabling fear reaction towards dental situations that result in disruption of functioning (e.g., delayed necessary treatment). Generally, fear and anxiety of dental situations results in increased rates of avoidance behavior, physiological reactions, verbal reports of distress, and pain reports (e.g., Corah, 1988; Horst \& de Wit, 1993; Vassend, 1993). In extreme instances, fear and anxiety of dentistry have contributed to the avoidance of necessary dental treatment, which eventually led to progressive infection, and ultimately to patient death (Kloffon, 1988). Systemic health problems could be prevented from routine oral hygiene maintenance and/or treatment of periodontal disease (Mojon, 2002). For those who experience dental fear of problematic proportions, women more often seek psychological treatment relative to men (Klepac, Dowling, \& Hauge, 1982), anxious responding decreases with age (Vassend, 1993), and behavioral treatments such as systematic desensitization have been shown to be successful interventions (Klepac, 1975).

Pain. As with general conceptualizations of pain, dentistry traditionally has examined pain from an undimensional, biomedical model. Perhaps the similar conceptualizations of pain across general medicine and dentistry is due to the fact that much of the sensory and autonomic nerve activity in oral mucosa and dental tissues are similar to that found elsewhere in the human body (Byers \& Burgess, 2001). Oral mucosa and teeth, however, have special functions (e.g., detection of material entering the mouth, reflexes related to swallowing, and enamel support) that affect the specific types of sensory 
innervations and the pain characteristics of these tissues (Byers \& Burgess). Extensive innervations of oral mucosa include nociceptive, polymodal, mechanoreceptive, thermosensitive, and chemosensitive sensory fibers to provide a wealth of sensory information for oral functioning and reflexes. The uniqueness of mucosa results in a denser array of sensory innervations in the mouth relative to other surface-covering tissues, potentially making this region of the body more sensitive to stimulation (see Byers \& Burgess; Fine, 1985 for detailed reviews). Thus, although the mouth is similar in many ways to other areas of the body, it also has many unique physiological aspects, which make it potentially more sensitive to stimulation (including pain) and more vulnerable to pain problems and aversive conditioning.

Within dentistry, chronic pain often is associated with temporomandibular disorders (TMD) whereas acute pain can be associated with any number of procedures (e.g., root canal treatment) or types of infections (e.g., dental caries or "cavities"). TMD includes a collection of disorders characterized by orofacial pain, masticatory dysfunction, or both, and they can involve disc displacement, muscle disorders, problems with the temporomandibular joint, or any combination thereof. Interestingly, there is evidence that significant overlap exists between psychopathology and TMD (Kight, Gatchel, \& Wesley, 1999), suggesting an association between physical and psychological stress and problems with the mandibular musculature.

Dentists traditionally have used medically oriented pain-reduction techniques, as opposed to fearor anxiety-reduction, as a central component of dental treatment with fearful patients. Accordingly, the treatment of pain in dentistry largely has revolved around medications (Surgical Update, 1987). Peripherally-acting (e.g., non-steroidal anti-inflammatory drugs [NSAID] such as ibuprofen) and centrallyacting (e.g., codeine and oxycodone) analgesics function by blocking local humeral factors and neural transmissions at the nerves and by altering pain perception and subsequent reaction in the brain, respectively. For optimal control of acute pain with minimal side effects for most dental outpatients, NSAID analgesics are recommended one hour prior to oral surgery as opposed to narcotic-containing analgesics (Dionne, 1992; Surgical Update, 1987). Exclusively focusing on pain signals at the site of origin by using medication neglects the well-established importance that emotional factors have regarding pain, which may account for a $15 \%$ failure rate of local anesthetics used with dental patients (Wong, \& Jacobsen, 1992) and the fact that $26 \%$ of anesthetized dental patients have been found to experience moderate to severe pain during treatment (Vassend, 1993). 
Fear, anxiety, and pain. With more acceptance of multimodal influences on dental pain behavior (e.g., Fine, 1985), fear and anxiety have received increased individual and collective attention in dental research. Investigations studying the effects of fear and anxiety on dental pain show that increases in these emotional responses are associated with greater pain (e.g., Eli, Bar-Tal, Fuss, \& Silberg, 1997; Jerremalm, Jansson, \& Ost, 1986; Kent, 1984; Klepac, 1975; Klepac et al., 1982), increased verbal reports of experienced pain (e.g., Arntz et al., 1990; Kent, 1985), and greater degrees of catastrophizing and distress (e.g., Sullivan \& Neish, 1998). There are, however, some studies that show contrary results. Klepac, McDonald, Hauge, and Dowling (1980) found that high and low dentally-fearful college students did not initially differ in pain threshold or tolerance assessed during tooth pulp stimulation or during electrical stimulation to the forearm. Only later, retrospectively, did participants with high fear rate tooth shock more painful. Therefore, as in the general fear and pain arena (e.g., Al Absi \& Rokke, 1991; Arntz et al., 1994; Eccleston, 1994; Rhudy \& Meagher, 2001), the effects of fear and anxiety on dental pain are highly dependent on the relevance of the fear to the pain; dental-relevant fear tends to increase pain while dental-irrelevant fear functions more as a distraction and blunts pain responding.

Distraction from painful health care procedures has been the focus of many research programs (e.g., Cioffi \& Holloway, 1993; Cohen et al., 1999; Johnson, Breakwell, Douglas, \& Humphries, 1998; Johnson \& Petrie, 1997; Seyrek, Corah, \& Pace, 1984) and a broad accumulation of data has resulted. Research suggests encouraging results that support using distraction with patients (e.g., Cohen et al., 1999; Cohen, Blount, \& Panopoulos, 1997; Frere, Crout, Yorty, \& McNeil, 2001). Conceptual explanations of why distraction works include the importance of cognition as mediating the pain experience and the limited capacity available for focusing attention on different stimulus events (McCaul \& Malott, 1984). Johnson and colleagues (1998), for example, found that tasks that require attention to external cues (e.g., warmth of a thermal probe) have more impact on reducing pain than either a positive or neutral imagery task. Consistent results have been found using distraction strategies such as a comedy video and videogame among amalgam restoration patients (Seyrek, Corah, \& Pace, 1984) and a virtual reality system among dental prophylaxis patients (Frere et al., 2001).

Furthermore, a substantial amount of what is known about the efficacy of distraction has come from the child literature. Using distraction with children during medical procedures reduces observed distress for most children (Kleiber \& Harper, 1999), including infants as young as 2 months old (Cohen, 
2002). Medical personnel and parents can coach children to watch cartoon videos as a distraction to effectively reduce distress during medical procedures (Cohen, Blount, \& Panopoulos, 1997). There are many factors such as parental encouragement, however, that may influence whether or not children use distraction as a strategy during dental procedures (see Albino, 2000 for a review). Additionally, cognitive development can significantly limit the degree to which a young child uses distraction and other coping strategy during medical procedures (Reissland, 1983). Some research from the adult literature on distraction suggests that distraction can be worse for patients (e.g., Cioffi \& Holloway, 1993) in that a "rebound effect" can result. This effect is especially true for those with chronic pain. Specifically, pain is prolonged by attempts to distract or suppress thoughts that accompany aversive stimulation and such strategies may negatively influence the interpretation of subsequent somatic, painful events (Cioffi \& Holloway).

Taken as a whole, distraction likely functions differentially based not only on the type of pain (e.g., chronic vs. acute) and the type of goal (e.g., short-term pain tolerance vs. long-term pain management) but also on the type of patient population (e.g., pediatric vs. adult). Thus, coping strategies that involve distraction may be better suited for acute pain episodes or painful procedures rather than for chronic pain problems (e.g., Johnson \& Petrie, 1997). Eccleston (1994) posits that distraction tasks demand attention and are effortful and fatiguing. The energy and mental resources depleted by distraction may impair the ability of someone with chronic pain to engage in otherwise helpful, pain reducing behaviors (Eccleston).

Fear of Pain in Dentistry

\section{Historical View}

General dental fear and anxiety. Fear of pain in dentistry has been encompassed under the much broader category of general dental fear and anxiety (cf., McNeil \& Berryman, 1989). Contributions by psychologists to the understanding of dental fears have historically taken the form of psychodynamic speculations regarding the disposition and origins of such fears (see Ruel-Kellermann, 1984, for a review). Other studies (e.g., Lautch, 1971) focused less on dynamic approaches to fear in dentistry and attended to learned responses to the stimuli inherent in dental treatment situations (Kleinknecht, Klepac, \& Alexander, 1973). As the developing trend toward behavioral conceptualizations and treatment in psychology grew (Marks, 1969; Marks \& Gelder, 1966; Rachman, 1977), so did the understanding of the specific stimuli to which patients react with fear, as well as the particular ways in which they express such 
fears (Kleinknecht et al., 1973; Melzack, 1979). The increase in understanding of specific dental fear made assessment and treatment more accurate and effective. Thus, if patients were fearful of particular dental stimuli (e.g., sound of a drill or sight of a needle) or physiological responses associated with dental procedures (e.g., increased heart rate), then idiographic treatments could be implemented (Jerremalm et al., 1986; Klepac, 1975; Klepac et al., 1982).

\section{Contemporary View}

Fear of Pain. Recently, there has been greater specific research focusing on the fear of pain. As McNeil, Au et al., (2001) point out a vast majority of this work has been derived from studies with persons experiencing different types of chronic musculoskeletal pain (e.g., McCracken \& Gross, 1993; Vlaeyen \& Linton, 2000; Zvolensky, et al., 2001). The predominant theoretical approach to understanding fear of pain in these samples of patients is the fear-avoidance model (Lethem, Slade, Troup, \& Bentley, 1983; Vlaeyen, Kole-Snyders, Boeren, \& van Eek, 1995; Vlaeyen \& Linton, 2000; Waddell, Newton, Henderson, Somerville, \& Main, 1993). The fear-avoidance model is borrowed form Mowrer's two-factor theory (1939, 1960); fear is initially learned through classical conditioning and fear behavior is maintained through operant conditioning. More specifically, the maintenance of fear behavior is through the operant conditioning process of negative reinforcement (i.e., the avoidance, removal, or reduction of an aversive stimulus such as fear or pain). Within the fear-avoidance model, "confrontation" and "avoidance" are proposed to be responses to fear of pain, which lead to the reduction of fear over time or the maintenance/exacerbation of fear, respectively. While most fear of pain research has focused on chronic rather than acute pain, the proposed investigation has important implications for the latter state (e.g., responding to toothache pain). Although the fear-avoidance model has only recently been specifically applied in the dental literature (Sorrell \& McNeil, 2003), it certainly is compatible with fear of acute dental pain behavior. For example, a patient with clinically significant fear of dental pain can either "confront" such fears by attending regular dental appointments or "avoid" regular treatment until pain resulting from tooth decay or other oral disease exceeds that which would be expected in the dental chair (e.g., Dionne, 1992). Anaise and Mann (1982) revealed that fear of pain was negatively correlated with frequency of dental visits, and Newman and Gift (1992) found that individuals with a regular pattern of preventative dental care were more likely to have no fear of dental pain relative to those without regular preventative dental maintenance. Thus, fear of dental pain and patient responses to such fear seem to follow the fear- 
avoidance model of exaggerated pain perception (i.e., "confrontation" leads to a reduction in fear of dental pain).

The expectancy model of fear (Reiss \& McNally, 1985; Reiss, Peterson, Gursky, \& McNally, 1986 ) is a second conceptualization that has been used to understand fear of pain, and which may have important implications in fear of dental pain (Sorrell \& McNeil, 2003). The expectancy model suggests fear of anxiety to be a disposition toward the development of anxiety disorders, and it is this fear of anxiety that tends to be the clinically salient aspect of anxiety as is found among patients with panic and agoraphobia (Reiss et al., 1986). Accordingly, there are two components that drive this process: (a) anxiety expectancy and (b) anxiety sensitivity. Anxiety expectancy refers to the evoked arousal that characterizes anxiety (e.g., increased psychophysiology and racing thoughts) when stimuli are encountered, and anxiety sensitivity refers to the beliefs and perceptions that anxiety responses are threatening and harmful. It is the combination of expectancy and sensitivity that determines avoidance behavior, which is maintained by operant contingencies in that there is a reduction in aversive, anxietyrelated experiences. It has been hypothesized that anxiety sensitivity underlies fear of pain among chronic pain patients (Asmundson \& Norton, 1995; Asmundson, Norton, \& Norton, 1999; Norton \& Asmundson, 2003), patients with other pain-related problems (e.g., headaches; Asmundson, Norton, \& Veloso, 1999), as well as patients with broader psychopathology (e.g., PTSD; Asmundson, Coons, Taylor, \& Katz, 2002). Anxiety sensitivity is considered to be a major factor that influences avoidance behavior among pain patients. Anxiety sensitivity and fear of pain have been found to be significantly related (Zvolensky, Goodie, McNeil, Sperry, \& Sorrell, 2001), and anxiety sensitivity has been associated with negative pain experiences (Keogh \& Cochrane, 2002). A recent study by Greenburg and Burns (2003) found evidence that suggests fear of pain to be a manifestation of anxiety sensitivity. Chronic pain patients with high fear of pain were found to have general and pervasive tendencies to respond fearfully to a variety of potentially anxiety-provoking stimuli rather than just pain-related experiences. The authors argue that it is the similarity between responses that patients have to pain- and anxiety-related stimuli (e.g., increased physiological arousal and avoidance behavior) that accounts for their findings. Although anxiety sensitivity seems to be an important factor related to fear of pain with some pain patients (e.g., Asmundson \& Norton; Asmundson, Norton, \& Veloso), there is no investigation that has examined anxiety sensitivity among dental patients but the exploration of this avenue has been suggested (McNeil, Au et 
al., 2001). Determining the relations among anxiety sensitivity, fear of pain, and other relevant constructs during painful dental procedures could help elucidate the importance of the expectancy model of fear in dentistry.

A third fear of pain model derived is that proposed by Davey (1989a). This theoretical approach is based on Pavlovian models of clinical phobias and fears (e.g., Rescorla \& Wagner, 1972). The conditioning process may occur in a dental setting as follows: A patient is seated in the dental chair in a dental office (CS), pain is experienced during treatment when the dentist injects anesthetic into the upper palate (UCS), the patient then experiences fear (UCR) in response to the pain, and subsequent exposure to dental stimuli (e.g., dental office, dental chair) results in fear and later avoidance (CR). Therefore, once this process has occurred for a dental patient, events or situations associated with the UCR acquire aversive properties and are subsequently avoided. Mowrer's two-factor theory $(1939 ; 1960)$ is relevant to this model as well; fears acquired by classical conditioning are maintained by the fear-reducing effects of avoidance (e.g., decreased autonomic arousal). To account for some of the limitations of two factor theory, however, Lang (1971) described the triple response system of verbal report (e.g., interpretations, catastrophizing thoughts or statements, erroneous beliefs), behavior (e.g., avoidance), and physiology (e.g., autonomic arousal).

Considering the triple response systems, Davey (1989a) points out that there are at least two ways in which experience with a painful or traumatic dental-related event may not lead to the development of fear of dental pain. First, latent inhibition may moderate the conditioning process because a dental patient may have had several years of treatment in the absence of a painful/traumatic experience. That is, the association that has developed over the years of painless treatment is between attending the dentist and healthy oral hygiene. Second, even when a painful or traumatic experience does establish a CS-UCS (UCR) association, the strength of the resulting CR will depend on the patient's evaluation of the UCS (Davey, 1989a, 1989b; Davey \& Craigie, 1997). In other words, a patient may have a painful experience in the dental setting but fail to acquire a significant fear response because the aversiveness of pain is mediated by the knowledge that such an experience results in healthy teeth (Davey, 1989a).

Fear of dental pain now is considered a separate construct from general dental fear or anxiety (Johnson, Mayberry, \& McGlynn, 1990; Liddell \& Locker, 1997; McNeil \& Berryman, 1989; McNeil, Au et 
al., 2001). When asked about specific fears related to irregular dental treatment, most individuals rate fear of pain as their chief reason (Delfino, 1997; Smith, Thompson, \& Lee, 1993; Widstrom \& Martinsson, 1980). In some cases, fear of pain can adversely affect a dentist's ability to accurately diagnose oral disease states, which can ultimately result in more oral-related problems for the patient (Eli, 1993). These findings suggest that fear of dental pain may exacerbate dental avoidance and pain-related distress, as well as increase the risk of overlooked oral pathologies by dentists.

\section{Predictability and Information}

A major issue in the study of fear of dental pain is predictability (Sorrell \& McNeil, 2003). The terms "predictability" and "information" often are used interchangeably to imply knowing something about an event or experience (Miller, Combs, \& Stoddard, 1989). More precisely, predictability involves the relation between having the ability to identify events and/or stimuli (e.g., pain) associated with a situation and the actual experience of those events/stimuli. For example, having the knowledge and awareness that an unpleasant experience could occur during an immunization (i.e., the ability) and then actually identifying aspects of the procedure that lead to that unpleasantness (i.e., the experience) is predictability.

Theoretical basis of predictability. Painful dental experiences can be unpredictable with regard to the moment of occurrence, intensity, duration, and consequence (Arntz et al., 1990), and concentration on the potential negative consequences of inaccurate predictions may lead to increased fear and avoidance behavior. Predictability in the context of dental settings refers to the ability of a patient to accurately identify a stimulus that signals the onset, intensity, duration, and/or offset of an aversive event/stimulus (e.g., pain) during treatment (Arntz et al.; Kent, 1985; Zvolensky \& Eifert, 2001; Zvolensky, Lejuez, \& Eifert, 2000). When predicting the outcome of a painful episode, dental patients can underpredict, accurately predict, or over-predict the actual degree of pain experienced, based on events/stimuli that precede actual pain.

Predictability data. Several studies have examined the effects of fear of dental pain on patients' ability to identify stimuli associated with dental procedures. Van Buren and Kleinknecht (1979), for example, found a significant correlation between patients' pre-surgical fear level and over-prediction of dental pain regarding an oral surgery procedure. Higher levels of dental fear were related to overpredictions of actual pain experienced following surgery. McNeil and Berryman (1989) assessed the components of dental fear in adults. Results indicated that fear of dental pain was most predictive of 
overall dental fear for both males and females. Participants' fear of pain ratings were based on what they expected to experience in a dental setting and were related to a possibility (i.e., prediction) of pain, which were associated with higher levels of dental fear. Greater fear of dental pain is essentially a prediction of what would be experienced in a dental situation. In a study that supports this conclusion, Johnson et al. (1990) found that fear of painful dental events accounts for over $42 \%$ of the total variance when predicting dental fear; other theoretically-relevant factors (e.g., fear of negative evaluation by the dentist) only accounted for $10.3 \%$ of the total variance. More recent research with orofacial pain patients further supports these results (McNeil, et al., 2001).

In an experimental investigation on fear of dental pain and predictions of pain, Lindsay, Wege, and Yates (1984) obtained predictions of the fear and pain patients expected to experience during a tooth drilling procedure as well as the actual pain they experienced. Patients were more fearful and had higher predictions of pain prior to the procedure than they actually experienced during the drilling. Kent (1984) found similar results and also revealed that the accuracy of predictions by high and low dental-fearful patients was a function of type of dental procedure (i.e., drilling/extraction type or regular check-up). Whereas patients low in dental fear accurately predicted the amount of pain they would experience in either condition, patients high in dental fear over-predicted pain only in the drilling/extraction type condition. Therefore, the type of dental procedure and whether or not a patient has high fear of dental pain are important variables in accurately predicting experienced pain (Eli et al., 1997).

To address why highly fearful dental patients continue to over-predict pain in light of disconfirming experiences, Kent (1985) and Arntz and colleagues (1990) hypothesized that memory for acute dental pain is reconstructed over time by highly fearful patients. Results suggest that both high- and low-fear patients' recall of pain was significantly inflated relative to their actual experiences. The size of this change between experienced and remembered pain was larger for the high-fear patients than for low-fear patients. Arntz et al. also found that high dental fear patients required significantly more pain trials to accurately predict experienced pain relative to their low fear counterparts, supporting other work (e.g., Arntz \& Hout, 1988; McCracken, Gross, Sorg, \& Edmands, 1993; Rachman \& Lopatka, 1988). Examination of pain expectations among children also show that expectations and memory of pain are inflated relative to actually experienced pain during an acute medical procedure (Cohen, Blount, Cohen, Ball, McClellan, \& Bernard, 2001). More recently with adults, Gedney, Logan, and Baron (2003) found 
that the affective context in which pain was delivered (e.g., high vs. low dental fear) during root canal treatment significantly predicted the long-term memory of procedural sensory pain and pain unpleasantness. Specifically, baseline anxiety ratings predicted memory of pain at 18 months, suggesting that the further a patient is removed form the dental setting and the pain experienced there; the more the affective state during that experience influences their recall of the event.

Information. The use of information is among the most utilized methods of experimentally investigating the effects of predictability on pain and fear responding. Providing information to patients during health care procedures essentially gives them "signals" (i.e., predictability) about when an aversive event/stimulus will begin, change in intensity or duration, and/or stop. Research has shown that merely signaling the occurrence of an aversive event reduces the perceived noxiousness of that stimulus (Furedy \& Doob, 1972). Furthermore, several studies have shown that information about an aversive event (e.g., onset) is, in general, preferred over no information (e.g., Lejuez et al., 2000; Staub \& Kellett, 1972; Staub, Tursky, \& Schwartz, 1971), although individual preference will vary.

Indeed, information is a multidimensional concept with various dimensions contributing to its complexity. Information can occur on several continua regarding, for example, the amount, time, and type that it is given. Reading (1979) reviewed the dynamics of information and highlights several factors that contribute to the efficacy of information in preparing patients for a surgical procedure. The time it takes for a patient to learn about a procedure can vary from as little as 5 -minutes to as long as 30 -minutes (Reading, 1979); the amount of time required largely depends on the total amount of information given (Kent \& Blinkhorn, 1991). Furthermore, the patient can receive information before, during, and/or after the procedure and the type of information can either be procedural or sensory. Procedural information contains the sequences of events that will occur during the medical procedure, while sensory information contains the sorts of sensations that likely will be felt during the procedure (Ludwick-Rosenthal \& Neufeld, 1988). Thus, altering any of these aspects of information could affect patient responding during a medical procedure, and the results in this area of literature are mixed (Miller, Combs, \& Stoddard, 1989).

With regard to amount of information, differential effects on patient responding have been shown. Ludwick-Rosenthal and Neufeld (1988) review several studies that, for the most part, concur with the assertion that a moderate level of information about a medical procedure can facilitate patient responding during and after the procedure. More specifically, Herbertt and Innes (1979) varied the amount of 
procedural information provided to their dental patients and found a curvilinear relation between amount of information and patient anxiety. When too little or too much information was given, patients had greater anxiety levels relative to patients who were given moderate levels of information; although, considering coping style also is important when considering how much information to provide (Suls \& Fletcher, 1985). Regarding sensory information, providing participants with information about the type of pain or sensation to be expected can affect pain responding. Pain tolerance was increased, for example, when participants were given information concerning both the objective characteristics of an impending electric shock and the sensations they should expect to experience (Staub \& Kellett, 1972; Staub, Tursky, \& Schwartz, 1971). Egbert, Battit, and Welch (1964) investigated how providing medical patients with basic preparation plus additional information affected postoperative pain responding. The additional information included a description of postoperative pain, reassurance about pain, relaxation tips, and reassurance that pain medication was available if needed. The results indicate that patients with the additional information required only half as much morphine during the first 5 postoperative days and had 2.7 fewer days in the hospital. Unfortunately, the authors do not assess factors such as fear or anxiety prior to the procedure that might address why the additional information had pain-reducing effects (see Kent \& Blinkhorn, 1991 for a review). The amount of sensory information is of importance to consider as well. Giving too much sensory information about a medical procedure can actually make the experience of medical pain worse (Miller \& Mangan, 1983).

Some of what has been found regarding the effects of information on fear and pain has been derived from work in preparing children for medical procedures. Children consider information about pain before medical treatment to be an important component to their medical experience (Alex \& Richie, 1992; Palmero \& Lambert, 1997). Quinn-Crandall and Lammers (2002) found that children's specific need for preoperative pain-relevant information was related to the location and duration of pain that would be experienced from surgery. According to the self-regulation hypothesis (Leventhal \& Johnson, 1983), preparatory information decreases children's emotional response by decreasing the discrepancy between expectations and actual experiences. There have been beneficial effects for children when given preparatory information about dental procedures (Melamed, Weinstein, Hawes, \& Katin-Borland, 1975). To specifically test the self-regulation hypothesis, Spafford, von Baeyer, and Hicks (2002) provided preparatory procedural and sensory information to children undergoing ear piercing. Results supported 
the hypothesis that information helps children establish more realistic expectations about pain, and as a result, children experienced significantly less pain compared to children who did not have preparatory information. The time that information is given also may influence how patients respond during treatment (Reading, 1979). Data suggest that information given closer in time to a surgical procedure tends to be more beneficial in terms of postoperative recovery than information given a week prior to surgery (Mavrias, Peck, \& Coleman, 1990), although statistically significant effects were not observed. For the most part, however, information is given just prior to treatment in studies where there have been significant benefits of information for both children and adults (see Horne, Vatmanidis, \& Cereri, 1994 for a review).

Studies have emerged that address fear-avoidance beliefs among low back pain patients by providing information booklets designed to educate patients and prevent disability after injury. Information provided within the booklets used focus on reassurance and encouragement to resume activity as well as education about pain and how to cope most effectively. Despite effectively increasing patient knowledge (e.g., Daltroy et al., 1997), results from these studies have been somewhat mixed. Hazard and colleagues (2000), for example, found no significant impact of an educational pamphlet on pain severity, health care visits, or work absence among occupationally injured low back pain patients. Burton, Waddell, Tillotson, and Summerton (1999), however, used a pain booklet to provide information about pain to chronic low back pain patients and found meaningful results. Beliefs about back pain as well as functional outcome (e.g., return to work status) were examined and results suggest that carefully selected and presented information and advice about back pain can have a positive effect on patients' beliefs (e.g., despite no change in pain, patients experienced significant reductions in fear-avoidance beliefs) and clinical outcomes (e.g., decreased disability). Similarly, "Back Schools" (i.e., "educational programs developed by physical therapists for patients with back pain", Daltroy et al., 1997, pp.322) have been developed to educate back pain patients by providing information on pain and coping and shown to have positive immediate and long-term benefits (e.g., Glomsrod, Lonn, Soukup, Bo, \& Larsen, 2001). These studies are critical because they directly manipulates a treatment variable (i.e., fear beliefs about pain) targeted at an underlying factor that contributes to disability (i.e., avoidance).

In an effort to identify which patients respond most favorably to information, dispositional factors (Litt, 1996) such as patient locus of control (e.g., Arntz \& Schmidt, 1989; Baron \& Logan, 1993; Liddell \& 
Locker, 1997) and coping style (e.g., Kiyak, Vitaliano, \& Crinean, 1988; Miller, 1995) have received considerable attention. Patients have been identified as having either an internal or external locus of control (Ludwick-Rosenthal \& Neufeld, 1988), both of which affect how information impacts the patients' response to health care treatment. Those with an internal locus of control are characterized as people who believe they directly influence their lives whereas people with an external locus of control believe their lives are more controlled by factors in the outside world. Correlational studies examining locus of control suggest that the more patients experience a loss of control over negative symptoms (e.g., pain), the more fear and anxiety they experience during treatment (Arntz \& Schmidt, 1989). Other studies indicate that fear and pain during an aversive dental procedure depends on the patient's locus of control (e.g., Burger, 1989, 1992). If patients are given control of dental pain and do not desire it (i.e., external locus of control), distress ratings are higher relative to when control is absent. Similarly, if patients are not given control of dental pain but desire it (i.e., internal locus of control), they experience higher levels of distress (Arntz \& Schmidt; Baron \& Logan, 1993; Liddell \& Locker, 1997; Litt, Nye, \& Shafer, 1993; Logan et al, 1991).

The coping style literature focuses specifically on how patients deal with the information they are given about a medical procedure in terms of information monitoring (i.e., seeking) or blunting (i.e., avoidance) rather than an individual's locus of control, although these constructs likely are related. The monitoring patient is more vigilant and alert for and sensitized to the negative, potentially painful, or dangerous aspects of information and experience, whereas the blunting patient denies potential problems, minimizes such threats, and detracts themselves from such information (Kiyak, Vitaliano, \& Crinean, 1988; Miller, 1995). In a review on monitoring versus blunting styles of coping, Miller highlights the critical studies and findings in this area of investigation. Overall, monitors are more concerned and distressed with their medical condition, experience greater side effects, are more knowledgeable about their situation, and are less satisfied and more demanding about the psychosocial aspects of their care than blunting patients. The general conclusion is that patients experience medical procedures better when the information they receive matches their coping style: More information for those with a monitoring style and less for those with a blunting style (Miller, 1995; Muris, Jong, Zuuren, \& Horst, 1994). The explanation provided for this conclusion is that too much information for blunting patients disrupts 
their avoidance coping and too little information for monitoring patients deprives them of something to be procedurally meaningful and vigilant towards.

Therefore, it is important to assess patient's coping style to determine how much or how little information will be most helpful for them during treatment. It also has been suggested that the effects of information type on medical distress could be altered by monitoring and blunting style (Miller, Combs, \& Stoddard, 1989). Overall, the effects of information type on medical stress are very uneven and inconclusive. However, it appears that sensory information alone, and in combination with procedural information, appears to be the best for patients (Miller, et al., 1989).

Summary and critique. Fear of dental pain and dental fear have been shown to be reliably and significantly related (e.g., Van Buren \& Kleinknecht, 1979; Lindsay et al., 1984; McNeil \& Berryman, 1989; McNeil, Au et al., 2001). Furthermore, fear of dental pain uniquely and significantly predicts general dental fear (Eli et al., 1997; McNeil, Au et al.), suggesting that patients with high levels of dental fear anticipate high degrees of pain during dental treatment. The experimental literature confirms that there is differential accuracy in predicting dental-related pain as a function of fearfulness in dental patients (e.g., Arntz et al., 1990; Kent, 1984, 1985; and Lindsay et al.). That is, fear seems to disrupt a patient's ability to accurately identify aversive events/stimuli during dental procedures. Patients with high fear of dental pain generally over-predict the pain they will experience during treatment, and they remember the actual pain from the procedure to be greater compared to their non-fearful counterparts. A possible reason for this tendency is that experienced anxiety may interfere with the change processes of subjective schemas (Arntz et al.). Even if a highly fearful patient regularly attends the dentist, the 6-12 month interval between treatments (i.e., exposure) may be insufficient to disconfirm over-predictions of pain.

In the attempt to decrease fear of pain effects on pain and fear responding among dental patients, several studies have investigated the role of information as a form of predictability about medical procedures (see Ludwick-Rosenthal \& Neufeld, 1988 for a review). In general, the effects of information on pain and fear responding is positive (e.g., Herbertt \& Innes, 1979; Staub \& Kellett, 1972), however, there have been differential effects of information found as a function of dispositional variables (e.g., locus of control and coping style). Those with an external locus of control have more favorable responses (i.e., decreased fear and pain) when they have more information to help them identify aversive aspects of a dental procedure than when they have less information, and the opposite is true for patients with an 
internal locus of control (Arntz \& Schmidt, 1989; Baron \& Logan, 1993; Liddell \& Locker, 1997). Similarly, patients deal better with medical procedures when the amount of information matches their coping style (Kiyak, Vitaliano, \& Crinean, 1988). Miller (1995) further suggests that monitors may also require more emotional support to favorably cope with chronic disease. Although, as Suls and Fletcher (1985) point out, if monitors have enough information to adequately cope with an aversive medical procedure, then giving more or too much information can be distressing.

Indeed, a great deal has been learned from investigations regarding fear of dental pain and forms of predictability such as information; however, there continues to be a need to better understand these factors and how they affect patients during dental procedures. First, with regard to general predictability studies, many relied heavily on self-report measures as the primary assessment methodology. Therefore, method variance may have contributed to the obtained results. To address this concern, future studies should continue to employ other research methodologies, including experimental methods that can tap automatic aspects of psychological processes involved with fear of dental pain responding and prediction (e.g., psychophysiological reactivity). Second, although the results are consistent with the hypothesis that fear of dental pain leads to inaccurate predictions of pain, the direction of this relation cannot be determined with the cross-sectional designs and limited experimental studies employed. Therefore, more experimental and prospective tests should be conducted to determine the role(s) of fear of dental pain with patient predictions of pain.

\section{Statement of the Problem}

Considerable evidence suggests that fear of pain is significantly related to general dental fear and that information enhances predictability and reduces fear and pain responding among patients during dental procedures. Fear of pain, therefore, may be a crucial factor contributing to dental fear and pain as well as dental avoidance. Although dispositional variables have been investigated and provide support to how information affects fear of pain, patient characteristics such as locus of control and coping style do not address how or why information specifically functions the way that it does. Burton et al. (1999) provided promising evidence that directly addressing fear beliefs with fear-specific information can result in positive behavior change. These effects, however, have not been demonstrated with fear of dental pain or within a dental setting. Therefore, if fear of dental pain contributes to overall dental fear and is as important to consider as previous research suggests, then information directed at reducing such fear (by 
providing predictability of pain-related events during a procedure) should significantly ameliorate pain and fear responding above and beyond general procedural information. In that regard, the purpose of this study is to identify the important aspects of information that contribute to reducing dental pain and fear responding among patients during a dental procedure, endodontic therapy.

Given that both fear and pain are multidimensional states (Gross \& Collins, 1981; IASP, 1994), researchers and clinicians should attempt to take a multi-method approach when assessing fear of dental pain. Although it may not always be possible to assess each of these response modalities in clinical research, self-report, physiological measures and behavioral observations will give the best indication of patient problems with fear of dental pain. Therefore, self-report and physiological measurements were recorded in the present study; behavioral avoidance was not assessed due to several practical limitations conducting research in a clinical setting. First, most behavioral avoidance will have taken place much earlier in the course of patients' oral health problem (e.g., rescheduled endodontic treatment and/or noshow for appointment). Second, it was essential that the normal functioning of the dental clinic not be disrupted. Thus, asking the dental practitioners to perform more duties (e.g., recording behavioral responses) than is typical during endodontic treatment was not possible. Furthermore, limited space in treatment rooms prevented video recording instruments to be used in the clinics and/or additional personnel (e.g., research assistant) from observing procedures.

\section{Endodontic Treatment: Brief Description}

There are many areas of dentistry that serve as good clinical contexts to examine fear of dental pain (e.g., Eli et al., 1997). Endodontic treatment is an excellent clinical setting because it is an environment where both fear and pain frequently occur (e.g., Levitt, McGoldrick, \& Evans, 2000; Peretz \& Moshonov, 1998; Saxen \& Newton, 1999; Stabhoz \& Peretz, 1999). Endodontic (root canal) treatment generally involves the removal and replacement of a tooth's pulp. The pulp is soft tissue containing blood vessels, nerves, and connective tissue. To begin an endodontic procedure, the dentist starts by testing the vitality of the pulp which is non-responsive to electric and/or cold stimuli during the assessment (Bellizzi et al., 2001). Once the decision has been made to conduct the endodontic treatment, multiple injections of local anesthetic usually are given. Next, a rubber dam is put in place to isolate the affected tooth from saliva. The dentist then drills an opening through the crown of the tooth, and the pulp is removed. Lastly, the root of the tooth is cleaned and the crown is reduced and shaped. The dentist places 
a temporary filling in the crown opening to keep out saliva; a follow-up visit replaces the temporary with a permanent filling. Although local anesthetic is administered to minimize pain, patients often experience pain and consider this procedure to be fairly distressing (Baron, Logan, \& Hoppe, 1993; Wong, \& Lytle, 1991).

Hypotheses

Hypothesis 1. Verbal reports of fear and pain during an endodontic procedure will be significantly ameliorated by information designed to provide predictability about pain during root canal treatment relative to root canal procedure and dental hygiene information types.

Hypothesis 2. Cardiac responding during treatment will be significantly decreased by information designed to provide predictability about pain during root canal treatment relative to root canal procedure and dental hygiene information types.

Hypothesis 3. Verbal report ratings of fear and pain remembered will be elevated relative to experienced fear and pain during treatment in all groups; however, inflated ratings will be greater in patients from the root canal procedure and dental hygiene information groups relative to ratings made by patients in the pain information group.

Hypothesis 4. Findings from previous studies (McNeil \& Berryman, 1989; McNeil, Au et al., 2001) will be tested: Fear of pain will share a significant relation with dental fear, and it will predict dental fear above and beyond other theoretically-relevant variables.

Hypothesis 5. Fear of pain (as measured by the FPQ-III) will predict pre-information verbal reports of fear and pain prior to an endodontic procedure.

\section{Experiment 1}

Although videotaped information has been used effectively to increase understanding about medical procedures (Mahler \& Kulik, 2002), investigators often fail to determine if providing information actually increases knowledge. Thus, in response to recent impetus for evidence-based dentistry (e.g., Chiappelli \& Prolo, 2002; Goldstein, 2002), Experiment 1 was designed to evaluate the effects of providing information using educational videotapes on self-reported dental knowledge. The study involved the development of a 5-minute informational video designed to provide predictability about potentially painful aspects of endodontic treatment; it also included the development of the 15-item Dental Knowledge Inventory (DKI) designed to assess patient's understanding of oral hygiene, the procedure of 
endodontic treatment, and pain during endodontic treatment. In addition to providing empirical support for the use of videotaped dental information to increase knowledge, Experiment 1 includes data regarding the validity of the DKI and support for its use as a manipulation check in Experiment 2. The effects of information type on fear and pain responding among root canal patients will be the focus of Experiment 2 .

\section{Method}

\section{Participants}

A total of 268 undergraduate psychology students from West Virginia University participated in Experiment 1. A total of 153 females and 115 males participated (mean age $=19.9 ; S D=3.9$ ). Table 1 displays additional demographic information of participants. There were 3 groups; 77 participants viewed a dental hygiene video, 90 viewed a root canal procedure video, and 101 viewed a video about pain in root canal treatment.

Materials

Oral hygiene video. The oral hygiene video (American Dental Association, 1998a) was one of two videos used that was produced by the American Dental Association (ADA). The information presented was related to dentistry but unrelated to endodontic treatment. The 4 minute video described important oral hygiene information about proper brushing and flossing techniques. Specifically, the proper angle to hold a tooth brush in relation to your teeth, the amount of dental floss to use when flossing, and how long your gums may be sore after flossing is highlighted in the oral hygiene video. Each aspect of information is presented and repeated approximately 3 times. Appendix A presents the transcript and other details about this video.

Root canal procedure video. The root canal procedure video (American Dental Association, 1998b) was the other ADA video used. Information from this video describes important aspects of the procedure for root canal treatment but is unrelated to dental pain. Specific aspects of information presented in the video is why root canal therapy is performed, how pulp is removed from the pulp chambers, how many appointments are required for treatment, and the percentage of successful root canal procedures. Information is presented twice throughout the 4.5 minute video. Appendix B presents the detailed transcript and other aspects about this video.

Fear of dental pain video. The fear of dental pain video was developed to match the other two informational videos mentioned above. Content analyses were performed on the two ADA videos to 
determine the total running time, number of computer animations, and total time of animations (see Table 2). The fear of dental pain video then was professionally developed to closely parallel the style and presentation of the other videos, contrasting in the type of information provided. The function of the 5minute video was to provide information about pain (i.e., to enhance predictability about pain during root canal therapy) rather than specifically reduce fear of dental pain. The content of information about pain was based on dental pain research articles and reference books as well as from discussions with endodontic treatment providers. Furthermore, information about pain was presented in a way to indicate what patients could realistically expect during treatment. The five major points presented in the video include: (a) possible sensations experienced during administration of anesthesia (Melzack, 1979, 1987), (b) length of time for anesthesia to take effect (Cohen, 2001), (c) when the most discomfort typically is experience in root canal therapy (Miller, Dembo, Falace, \& Kaplan, 1995; Morse, Schacterle, Furst, \& Bose, 1981), (d) where numbness occurs following the administration of anesthesia (Cohen, 2001), and (e) other sensations you may experience during root canal therapy (L. Gochenour, personal communication, October 2001). See Appendix C for the transcript and other details about this video. Dental Knowledge Inventory. The Dental Knowledge Inventory (DKI) was developed to assess changes in dental knowledge resulting from educational videos. Further, the DKI functioned as a manipulation check in Experiment 2 (Experiment 2 is described below). It was designed to determine whether or not participants received, retained, and could demonstrate recall of information presented in an educational videotape. Following content analyses performed on the three videos used, several knowledge items were generated (i.e., 40 items) and then critiqued by several independent reviewers. Among the independent reviewers were approximately 25 individuals with education ranging from high school, college, and graduate school; there was a broad range of professions among reviewers, including some in office management, computer technical support, clinical psychology, and endodontics. Reviewers were sent the knowledge inventory items via electronic mail, answered the questions, made comments about wording, response options, and format and returned the inventory. Following 3 cycles of wording and response option changes, 15-items were retained and the DKI resulted (see Appendix D). This self-report questionnaire assesses dental knowledge across three domains: oral hygiene, root canal procedures, and pain during root canal treatment. There are 3 subscale scores obtained with 5 items per subscale. Participants completed the DKI before and after watching the information video. Change scores 
were used to determine whether or not participants actually received and retained the information presented in the video. It was hypothesized that scores should increase in a content specific fashion such that improvement is evident only on items related to information covered in the video viewed.

Demographic questionnaire. A brief demographic questionnaire also was given for participants to complete, which assessed information such as age, gender, and root canal history.

\section{Procedure}

Participants were approached at either the beginning or the end of class and informed about the study, asked to participate, and consented if they agreed to take part. There were a total of 7 classes that were included. Each class viewed the video in a group format. They first completed a brief demographic questionnaire and then the 15-item Dental Knowledge Inventory. Next, participants viewed one of the 3 videos and then completed the knowledge inventory for a second time. Participants were debriefed, given course extra credit, and thanked for their involvement.

\section{Results}

Mean pre-video to post-video subscale scores, specific to the video seen by each group, are as follows: Oral Hygiene Video Group (pre-score $=2.87$, post-score $=4.71$ ); Root Canal Procedure Video Group (pre-score $=2.89$, post-score $=4.17$ ), and Pain Information Video Group (pre-score $=3.23$, postscore $=4.53$ ). Table 3 includes mean pre-video and post-video scores for all subscales as well as standard deviations on the Dental Knowledge Inventory. The effects of videotape information on dental knowledge across time was assessed by conducting a 3 (Group) $\times 3$ (Scale) $\times 2$ (Time) repeated measures analysis of variance (ANOVA); Tukey's Honestly Significant Different (HSD) tests at the .05 level followed significant effects, as appropriate. A significant triple interaction was revealed among groups, subscales, and administration time, $F(4,263)=198.46, p<.001$, indicating that there was a content-specific change in knowledge as measured by the DKI (pre- to post-video) among groups. For example, scores on the fear of dental pain subscale of the DKI increased only for participants who viewed the fear of dental pain video. There also was a significant group by scale interaction, $F(4,263)=84.13, p$ $<.001$, indicating that there was a difference in knowledge between groups on the three subscales of the DKI. There was a main effect of time, $F(1,266)=7.38, p<.01$, indicating that participants' scores changed in a positive direction after watching a five minute informational video. Last, there was a main effect of group, $F(2,265)=8.51, p<.01$. Tukey's HSD analyses confirmed significant within-subject 
effects (i.e., scores on the subscale related to the content of the video watched significantly increased [p $<.05$ ] relative to the other subscales, which did not differ from one another). See Figure 1 for visual representation of significant within- and between-group effects on subscales of the DKI; Appendix $E$ displays the corresponding ANOVA table.

\section{Discussion}

The results of Experiment 1 indicate that all three of the videos were effective mediums to provide dental-related information and increase knowledge, at least in the short-term. Furthermore, the DKI was sensitive to changes in dental knowledge that occurred as a result of watching the videos. Scores on the DKI subscales increased in a content-specific fashion such that improvement was evident only on the subscale related to information covered in the video that participants viewed. Subscale scores did not change significantly on DKI items irrelevant to the video seen by participants. Thus, no practice effects or spurious changes in dental knowledge were evidenced.

It is possible, however, that participants were primed to seek specific information in the video by completing the DKI before watching it. In this way, participants may have been better prepared to answer the DKI items relevant to the video seen after watching the video. One way to control for this in future studies is to have participants view a specific video first and then complete the DKI (i.e., without a prevideo DKI administration). Subscale scores between groups would then be compared to observe differential knowledge based on the content of the video viewed. In the present study, it was imperative that pre-video knowledge be assessed within-groups to allow each group to be it own control and to ensure that there were no pre-existing differences in dental knowledge between groups. It also is possible that participants' lack of knowledge about root canal treatment influenced their ability to learn information related to this topic. The fact that scores did improve related to root canal treatment suggests that this was not the case, although it should be considered as a possibility.

Despite the limitations mentioned above, data from this experiment extend findings from previous research (e.g., Burton, Waddell, Tillotson, \& Summerton, 1999) to another mode of learning information, videotapes (cf., educational booklet) and to another medical population (cf., Mahler \& Kulik, 2002). Anecdotally, it already is assumed that videos are an efficient means of conveying information to patients; however, this study further supports their efficacy by providing empirical evidence. In sum, Experiment 1 
lends support to previous assumptions that merely providing dental information increases patient knowledge; accordingly, it appears that the DKI is a valid method of measuring knowledge change.

\section{Experiment 2}

This experiment examined the effects of information type on fear and pain responding among root canal patients. Specific hypotheses are highlighted above.

\section{Method}

\section{Participants}

Participants were 104 endodontic patients from a private dental practice in Clarksburg, West Virginia $(n=59)$ and the West Virginia University (WVU) School of Dentistry $(n=45)$. The mean age of all participants was 43.9 years. There were 3 groups consisting of 32 (20 female and 12 male) patients who received oral hygiene information, 35 (16 female and 19 male) who received root canal procedure information, and 37 (24 female and 13 male) who received information about pain during root canal treatment. Patients were randomly assigned to groups in a double blind fashion such that dental providers did not know which video the patient was presented; patients only saw one video and were not specifically aware of the content of the other two videos. Comparing patient demographics across clinics, there was a significant age by clinic interaction, $F(1,103)=6.35, p=.01$, indicating that the average age of patients from the private clinic were generally older $(M=47.1 ; S D=14.5)$ than patients from the WVU clinic $(M=39.4 ; S D=15.3)$. There were no other significant differences among variables between participants and clinics. Additional patient sociodemographic information is presented in Table 4. Materials

Informational videos. The same three informational videos were used as in Experiment 1: information about oral hygiene, root canal procedure, and pain during root canal treatment. The patients who were presented oral hygiene information were intended to serve as a control group by which to compare with patients who received procedural and pain-related types of information.

\section{Self-Report Measures}

Fear of Pain Questionnaire-III (FPQ-III). The FPQ-III (McNeil \& Rainwater, 1998) is a 30-item selfreport inventory designed to assess a trait-like fear response across a variety of different pain stimuli. Whereas other self-report measures for fear of pain assess the emotional state of fear and/or anxiety associated with chronic pain (e.g., Pain Anxiety Symptoms Scale; McCracken, Zayfert, \& Gross, 1992), 
the FPQ-III is designed to assess fears that are related to specific situations. A total score (range: $30-150)$ and three subscale scores (i.e., fear of Severe Pain, Minor Pain, and Medical/Dental Pain) are derived, with higher scores indicating greater fear of pain. On a five point Likert-type scale $(1=$ not at all to $5=$ extreme), respondents indicate the degree to which they experience fear regarding pain-relevant stimuli. Good test-retest correlations (i.e., range from .69-.76), internal consistency (i.e., alpha coefficients range from .87-.92), and predictive validity have been reported (Hursey \& Jacks, 1992; McNeil \& Rainwater; Sperry-Clark, McNeil, \& Ciano-Federoff, 1999). The factor structure of the FPQ-III recently was tested and found to be consistent with the original structure at its inception (Osman, Breitenstein, Barrios, Gutierrez, \& Kopper, 2002). Within the arena of dentistry, the FPQ-III has been shown to uniquely predict dental fear in both females and males (McNeil \& Berryman, 1989) compared with other theoretically relevant measures. Further, orofacial pain patients report significantly greater fear of severe pain relative to clinical, routine prophylaxis patients (McNeil et al., 2001).

Dental Fear Survey (DFS). The DFS (Kleinknecht, Klepac, \& Alexander, 1973) is a 20-item selfreport measure designed to assess various responses to the dental experience. Specifically, the DFS elicits dental-relevant ratings of avoidance and fear (e.g., "Has fear of dental work ever caused you to put off making an appointment?"), autonomic arousal (e.g., "When having dental work done, my muscles become tense"), and fear of dental stimuli (e.g., "Rate how much fear, anxiety, or unpleasantness seeing the anesthetic needle causes you"). A total score (range: 20-100) as well as the three subscale scores mentioned previously are derived. On a five-point Likert-type scale $(1=$ never or a little to $5=$ often or a lot), respondents indicate the degree to which they experience fear regarding dental-relevant stimuli with higher scores indicative of greater dental fear. Previous research has demonstrated that the DFS yields a reliable factor structure (e.g., $15.5 \%-24.5 \%$ of total variance accounted for by the 3 factors; Kleinknecht, Thorndike, McGlynn, \& Harkavy, 1984; McGlynn, McNeil, Gallagher, \& Vrana, 1987), significant predictive validity (Bernstein, Kleinknecht, \& Alexander, 1979), as well as stability and internal consistency (i.e., alpha coefficients between .52-.95 and correlations between .51-.88; McGlynn et al., 1987).

Anxiety Sensitivity Index (ASI). The ASI (Reiss, Peterson, Gursky, \& McNally, 1986) is a 16-item self-report questionnaire designed to assess fear of anxiety symptoms (e.g., heart beating rapidly, upset stomach, feeling shaky) which arises from the belief that these symptoms will result in harmful consequences. On a five-point Likert-type scale $(0=$ very little to $4=$ very much), respondents indicate 
their sensitivity to anxiety symptoms. Higher scores indicate greater anxiety sensitivity. The ASI has high levels of internal consistency (alpha coefficient of .88; Peterson \& Reiss, 1992) and good test-retest reliability ( $r=.75$; Reiss, Peterson, Gursky, \& McNally, 1986). Research indicates that the factor structure of the ASI is comprised of three lower-order factors (i.e., Physical, Psychological, and Social Concerns), which all load on a single higher-order factor (Global Anxiety Sensitivity; Stein, Jang, \& Livesley, 1999). The total and subscale ASI scores are distinct from trait anxiety and are commonly used as indices of anxiety sensitivity (Schmidt, 1999).

Miller Behavioral Style Scale (MBSS). The MBSS (Miller, 1987) is a 32-item self-report measure designed to assess coping style (i.e., information seeking or information distracting) in regard to naturalistic physical and psychological stress. It divides respondents into high and low monitors and high and low blunters based on their self-reported preference for information or distraction (Miller, 1987). The scale presents four distressing scenes, followed by eight response options, and asks respondents to indicate how s/he would respond to that situation. Each of the eight response options following the four scenes is of information-seeking or information-avoiding variety (e.g., "I would carefully read the information provided ..." or "I would watch the in-flight film . ..", respectively). Adequate test/retest reliability (.70-.80) has been found to be highly stable over a 4-month interval (Miller, 1987), and scores generally are not related to demographic (e.g., socioeconomic status) or trait variables such as depression and anxiety (Miller, 1995). The MBSS also has been shown to accurately predict how individuals actually attend or avoid information during physical and cognitive challenges (Miller, 1987).

Dental Knowledge Inventory (DKI). The DKI is a 15-item self-report measure of dental knowledge across three domains: oral hygiene, root canal procedure, and pain during root canal treatment. The DKI was used as manipulation check based on its demonstrated sensitivity to dental knowledge change, as evidenced by the results of Experiment 1.

\section{Additional Measures}

Numeric Rating Scale (NRS). Appendix F presents the NRS that patients used to rate their fear and pain during treatment. Each scale ranges from 0 (e.g., No pain) to 100 (e.g., Worst possible pain) and patients indicate which number on that scale best corresponded with their rating at that time. NRSs have demonstrated good validity and strong correlations with other intensity measures (Jensen, Karoly, \& Braver, 1986). Fear and pain ratings were taken at 7 different times during the procedure (see Appendix 
$\mathrm{G}$ for specific times ratings were taken). For the analyses used in the present study, only 4 of the 7 rating times were used. Specifically, ratings used included those obtained before the pre-baseline (i.e., as soon as patients entered the clinic), after the video was viewed, after shaping the root canals during treatment, and immediately after treatment was over. The other 3 rating times did not meaningfully contribute to understanding the data as they did not significantly differ from the rating that immediately preceded it (all p-values $>.25)$.

Polar heart rate monitor. The Polar S610i (Polar Electro Inc) Heart Rate monitor was used to measure cardiac responding. This monitor registers and records cardiac responding using a sensor and transmitter that is worn under the patients' clothing and across the chest with an adjustable, elastic band. The monitor first obtains a cardiac electrical impulse every 5 seconds and then transmits an infra red signal to a receiver inside of a wristwatch that records the interbeat interval between each signal (the wristwatch used was out of patient's sight). The interbeat intervals are converted into heart rate readings and stored on the receiver until it is downloaded onto an IBM-compatible computer. The Polar computer interface unit and Polar S610i HR Analysis Software were used to download heart rate data. The Polar monitor has been used in previous studies (e.g., Bar Or et al., 1996) and shown to provide a valid measure of heart rate compared to traditional measures of heart rate (ECG) during stationary laboratory tasks (Goodie, Larkin, \& Schauss, 2000).

\section{Procedure}

A total of 143 patients were approached in the clinics prior to root canal treatment to determine their willingness to participate. Of the patients who agreed to participate, there were 83 scheduled patients and 21 emergency patients (14 patients from the Clarksburg clinic and 25 from the WVU clinic declined participation). Patients were told that their involvement would not affect their treatment, they would learn about clinical research from their participation, and would receive $\$ 10.00$ for their time in the study. Generally, patients who use the WVU clinic include members of a community that is in close proximity to a state university. Therefore, many patients from the WVU clinic may attend college, may be university employees or professors, and are younger compared to those patients from the private clinic.

After patients agreed to hear more about the investigation, the purposes of the study were explained more fully and informed consent was completed. Verbal reports of fear and pain were taken throughout the procedure; see Appendix $G$ for specific times when ratings were taken. The patients first 
completed a pre-procedure heart rate baseline and completed the Dental Knowledge Inventory. They next viewed the informational video and completed the DKI again. Following the video and the second administration of the DKI, the patient received treatment. When treatment was concluded, patients completed a series of self-report measures (described above) and a post-procedure heart rate baseline was recorded. Patients were telephoned approximately three weeks later to obtain verbal reports of current fear and pain as well as remembered fear and pain during the root canal procedure using the NRS described above and presented in Appendix F.

\section{Data Analytic Approach}

This experiment used a mixed factorial design with one between-group variable (i.e., information type) and one within-group variable (i.e., time of measurement during treatment). Repeated measures analyses of variance (ANOVAs) and regression procedures were used to address the hypotheses listed above. The first set of analyses examined between group difference among dependent measures (i.e., verbal reports of fear and pain and cardiac response). Second, regression analyses incorporated theoretically-relevant factors (e.g., fear of pain and anxiety sensitivity) as predictor variables of dental fear and verbal reports of fear and pain upon arrival for treatment.

\section{Power Analysis}

The statistical software program G-Power (Faul \& Erdfelder, 1992) was used to determine adequate power for the present study. The power analysis, using 3 groups with 30 participants per group, revealed sufficient power $(>.80)$ to detect medium-sized effects $\left(f^{2}=.25 ; p<.05\right)$. Therefore, a total of 104 participants exceeded the necessary 90 required to confidently reject that non-significant differences are due to small sample size.

\section{Results}

\section{Manipulation Check}

A manipulation check was employed using the Dental Knowledge Inventory developed in Experiment 1 to assess the initial impact of information presentation. Mean pre-video to post-video subscale scores, specific to the video seen by each group, are as follows: Oral Hygiene Video Group (pre-score $=1.94$, post-score $=4.22) ;$ Root Canal Procedure Video Group $($ pre-score $=2.66$, post-score $=$ 4.49; and Pain Information Video Group (pre-score $=2.19$, post-score $=4.68$ ). Table 5 includes mean pre-video and post-video scores for all subscales as well as standard deviations on the Dental Knowledge 
Inventory for all 104 patients. The effects of videotaped information on dental knowledge across time was assessed conducting 3 (Group) X 3 (Scale) X 2 (Time) repeated measures ANOVAs; Tukey's HSD tests at the .05 level followed significant effects, as appropriate. A significant triple interaction was revealed among groups, subscales, and administration time, $F(4,100)=90.6, p<.001$. This finding indicates that there was a significant content specific change in knowledge as measured by the DKI (pre- to post-video) between groups, which replicates results found in Experiment 1 and extends findings to a clinical sample of root canal patients. There was neither a significant subscale by time interaction, $F(2,102)=.98, p=$ .37 , nor a group by time interaction, $F(2,102)=1.57, p=.21$. There was, however, a significant scale by group interaction, $F(4,100)=27.61, p<.001$. The interaction indicates that there was a significant difference in knowledge between groups on the three subscales of the DKI. There also were main effects of scale, $F(2,102)=11.28, p<.001$, and time, $F(1,103)=166.96, p<.001$, indicating that patients had significant differences on subscale scores, and significant changes on scores after watching the informational video, respectively. There was no main effect of group, $F(2,102)=.79, p>.45$. Tukey's HSD analyses confirmed the effects of the triple interaction that suggested scores significantly improved on the subscales related to the content of the video watched by groups relative to the other subscales, which did not significantly differ. Figure 4 displays a visual representation of significant within and between group effects on the DKI subscales. Appendix $\mathrm{H}$ displays corresponding ANOVA table.

\section{Analyses by Hypotheses}

Hypothesis 1. Verbal reports of fear and pain will be significantly ameliorated by information designed to provide predictability about pain during root canal treatment relative to root canal procedure and dental hygiene information types. The effects of videotaped information on fear and pain ratings across treatment were assessed conducting 3 (Group) X 4 (Time) repeated measures ANOVAs; Tukey's HSD tests at the .05 level followed significant effects, as appropriate. Means and standard deviations for fear and pain ratings across the procedure are displayed in Tables 6 and 7, respectively. For fear ratings, there was no significant interaction between groups, $F(6,98)=1.25, p=.28$. There was, however, a significant main effect of time, $F(3,101)=43.33, p<.01$. There was no significant main effect of group, $F$ $(2,102)=.72, p=.49$. Tukey's HSD tests at the .05 level indicate that there was a significant decrease in fear ratings such that ratings after treatment were lower from ratings at other times during treatment, which did not differ from one another. 
For pain ratings across the procedure, there was no significant interaction between groups, $F(6$, $98)=.76, p=.59$. There was, however, a significant main effect of time, $F(3,101)=10.74, p<.01$. There was no significant main effect of group, $F(2,102)=1.87, p=.16$. Tukey's HSD tests at the .05 level indicate that there was a significant decrease in pain ratings after treatment relative to pain ratings at other times during treatment, which did not differ from one another. Overall, hypothesis 1 was not confirmed for either verbal reports of fear or pain. Figures 3 and 4 show a visual representation of the above stated main effects. Appendices I and J display corresponding ANOVA tables.

Hypothesis 2. Cardiac responding during treatment will be significantly decreased by information designed to provide predictability about pain during root canal treatment relative to root canal procedure and dental hygiene information types. To test this hypothesis, heart rate data first were converted to change scores in which the pre-procedure baseline heart rate was subtracted from the heart rate value at the time of measurement (i.e., heart rate during injection, drilling, and cleaning and shaping of canals). Negative values indicate decreases in heart rate from baseline. Due to equipment malfunction, there is heart rate data from 97 participants available for analysis ( 29 from the oral hygiene group, 33 from the procedure group, and 35 from the pain group). Table 8 displays means and standard deviations for heart rate change values at the three times of heart rate measurement. Next, the effects of videotaped information on heart rate across time were assessed using 3 (Group) $\times 3$ (Time) repeated measures ANOVAs. Results indicate that there was no significant interaction among groups, $F(4,93)=1.47, p=$ .24. There was, however, a significant main effect of time, with heart rate changing across the procedure, $F(2,95)=6.81, p<.001$. There was no main effect of group, $F(2,95)=1.23, p=.30$. Tukey's HSD tests at the .05 level indicate that heart rate during injection was significantly decreased from baseline relative to heart rate during drilling and cleaning/shaping canals, which did not differ from one another. These findings suggest that either defensive or orienting cardiac responses may be evidenced (Graham \& Clifton, 1966). Hypothesis 2, therefore, was not supported. See Figure 5 for visual representation of the time main effect. Appendix $\mathrm{K}$ displays the corresponding ANOVA table.

Hypothesis 3. Verbal report ratings of fear and pain remembered will be elevated compared to experienced fear and pain during treatment in all groups; however, inflated ratings will be greater in patients from the root canal procedure and dental hygiene information groups relative to ratings made by patients in the pain information group. Due to the unavailability of some participants after treatment, there 
were a total of 90 patients who were able to be contacted for follow-up (30 from the oral hygiene group, 31 from the procedure group, and 29 from the dental pain group). The average follow-up contact time was 22 days. Table 9 display means and standard deviations for experienced fear and worst remembered fear ratings among groups. The fear rating used was fear rating \# 4 from the procedural flow (Appendix $G$ ). Specifically, the fear rating was recorded after patients experienced injections, drilling, and shaping of the root canals. The effects of videotaped information on remembered fear from treatment to follow-up was assessed conducting a 3 (Group) X 2 (Time) repeated measures ANOVA. Results indicate that there was no interaction for fear ratings among groups across time, $F(2,88)=.59, p=.56$. There was a significant main effect of fear ratings across time, $F(1,89)=14.23, p<.001$, indicating that memory for experienced fear was inflated over time. There was no main effect of group, $F(2,88)=1.3, p=.28$. Tukey's HSD tests at the .05 level indicate that remembered fear at follow-up was significantly elevated relative to fear during treatment. Figure 6 shows the main effect. Appendix L displays the corresponding ANOVA table.

Table 10 displays means and standard deviations for experienced pain and worst remembered pain ratings among groups. The pain rating used was pain rating \# 4 from the procedural flow (Appendix G). Specifically, the pain rating was recorded after patients experienced injections, drilling, and shaping of the root canals. The effects of videotaped information on remembered pain from treatment to follow-up was assessed conducting a 3 (Group) X 2 (Time) repeated measures ANOVA. Results indicate that there was no interaction among groups, $F(2,88)=0.07, p=.93$. There was a main effect, however, for pain ratings across time, $F(1,89)=60.16, p<.001$. There was no main effect of group, $F(2,88)=0.23, p=$ .80. Tukey's HSD tests at the .05 level indicate that pain at follow-up was significantly elevated relative to pain during treatment. This main effect supports previous findings that suggest memory for pain is often inflated (e.g., Arntz, van Eck, \& Heijmans, 1990), and inaccurate memory of pain may maintain fearfulness. See Figure 7 for a visual display of this main effect. Appendix $M$ displays the corresponding ANOVA table.

Overall, hypothesis 3 was only supported in part. Both fear and pain memory were inflated significantly at follow-up compared to during treatment across groups. There were no differential effects among groups as predicted.

Hypothesis 4. Findings from previous studies (McNeil \& Berryman, 1989; McNeil et al., 2001) were tested: Fear of pain (as measured by the FPQ-III) will share a significant relation with dental fear, 
and fear of pain will predict dental fear above and beyond other theoretically-relevant variables. See Table 11 for means and standard deviations on all self-report measures. Mean scores obtained in the present study fall within one standard deviation of scores obtained from other studies using these same measures (McNeil, Au et al., 2001; Miller, 1987; Zvolensky et al., 2001). There were no significant differences on any measure between clinics or among groups; all $p$ values are between .15 and .87 .

To evaluate relations among self-report measures, zero-order correlations were conducted between the FPQ-III (total and subscale scores), DFS (total and subscale scores), ASI (total score), and MBSS (Monitoring and Blunting scale scores), as well as with demographic variables. For the purpose of this analysis, gender was coded as a numerical variable such that male $=1$ and female $=2$. The results, presented in Table 12, show that the FPQ-III shares a significant relation with all of its subscales, the ASI, the DFS total scale, and several of the DFS subscales. The FPQ-III Severe subscale was related with gender. The DFS was highly related with each of its subscales, the ASI, and each of the FPQ-III scales. Further, the DFS total score had a significant negative relation with age, indicating that younger patients had higher dental fear compared to their counterparts; gender also was related with the DFS Physiological subscale. Age also was significantly related with root canal history such that older patients were more likely to have past root canal experience. The MBSS Monitoring scale score was significantly related with the ASI.

Based on the zero-order correlational analysis, and consistent with previous research (McNeil, $\mathrm{Au}$ et al., 2001; McNally \& Eke, 1996), a hierarchical multiple linear regression analysis was performed to determine the relative amount of variance accounted for by the FPQ-III in predicting dental fear. In this regression model, the DFS total score was the dependent measure; as criterion variables, demographics were entered into step one, MBSS (Monitoring score) and the ASI were entered into step two, and the FPQ-III (total score) was entered into step three. The criterion variables were significant predictors of dental fear, $F(5,99)=8.61, p<.01 ; R^{2}=.31\left(\right.$ adjusted $\left.R^{2}=.27\right)$. In this regression model, age, $\beta=-.18$ $(N=104, p<.05)$, anxiety sensitivity, $\beta=.37(N=104, p<.05)$ and fear of pain, $\beta=.23(N=104, p<$ .05) account for a significant amount of the variance in predicting dental fear. These results demonstrate that fear of pain continued to account for a significant amount of variance in dental fear above and beyond other theoretically important factors. Table 13 displays a summary of this regression model. Hypothesis four was supported, confirming previous research and extending results in an important way 
to root canal patients by demonstrating that fear of pain is a significant factor in predicting general dental fear relative to other theoretically-relevant variables.

Hypothesis 5. Fear of pain (as measured by the FPQ-III) will predict pre-information fear and pain ratings prior to an endodontic procedure. First, to evaluate how the FPQ-III and other standardized anxiety-related measures relate to pre-information fear and pain ratings, zero-order correlations were conducted (see Table 12). According to the results of the correlation, factors that significantly correlate with fear ratings before treatment (from highest correlations to lowest) include the DFS total score, DFS Physiological subscale, and DFS Avoidance subscale, DFS Specific Stimuli subscale, FPQ-III Severe subscale, gender, and FPQ-III total score. Factors that significantly correlate with pain ratings before treatment (from highest correlations to lowest) include the DFS Physiological subscale, age (correlated negatively), DFS total score, and verbal reports of fear.

Next, two separate hierarchical multiple linear regression analyses were conducted to determine the relative amount of variance accounted for by factors that correlated significantly with verbal reports of fear and pain before treatment. In these models, fear and pain ratings were used as dependent variables and DFS total score (and its three subscales), FPQ-III total score, FPQ-III Severe subscale, age, and gender were criterion variables. For verbal reports of fear, the criterion variables were significant predictors, $F(8,96)=9.92, p<.00 ; \mathrm{R}^{2}=.46$ (adjusted $\left.\mathrm{R}^{2}=.41\right)$. In this regression model, DFS total score, $\beta=4.42(N=104, p<.05)$, DFS Specific Stimuli subscale, $\beta=-2.09(N=104, p<.05)$, FPQ-III total score, $\beta=0.56(N=104, p<.05)$, FPQ-III Severe subscale, $\beta=-0.50(N=104, p<.05)$, and gender, $\beta=.26(N=104, p<.05)$, account for a significant amount of the variance in predicting level of fear before treatment. Table 14 displays summary of this regression model with verbal reports of fear as the dependent factor. Although several factors account for a significant amount of variance regarding fear before treatment, the FPQ-III total and Severe subscale scores continue to account for significant variance above and beyond other relevant factors. For verbal reports of pain, the criterion variables were not significant predictors of verbal reports of pain before treatment, $F(8,96)=1.53, p>.10 ; \mathrm{R}^{2}=.11$ (adjusted $\mathrm{R}^{2}=.04$ ), suggesting that relevant psychological factors and gender were not important variables accounting for pain prior to root canal therapy. Table 15 displays summary of this regression model with verbal reports of pain as the dependent factor. Overall, hypothesis five was not fully supported. It was, however, supported in part. Fear of pain predicted verbal reports of fear prior to 
treatment above and beyond other theoretically relevant factors although fear of pain did not predict verbal reports of pain before treatment.

\section{Discussion}

Increased dental knowledge following videotape information was replicated in Experiment 2, indicating that all three of the videos were effective mediums to provide dental-related information with a clinical sample of root canal patients. As was found in Experiment 1, the Dental Knowledge Inventory (DKI) was sensitive to changes in dental knowledge that occurred as a result of watching the videos. Subscale scores increased in a content specific fashion such that improvement was evident only on the subscale related to information covered in the video that patients viewed. Subscale scores did not change significantly on DKI items irrelevant to the video seen by patients. Thus, as with Experiment 1, there was no evidence of practice effects or random changes in dental knowledge.

There were no differential effects of information type on fear and pain responding found in Experiment 2 despite increased knowledge, which is consistent with some previous research (e.g., Daltroy et al., 1997; Hazard et al., 2000). Verbal reports of fear and pain both were somewhat low among groups, particularly with regard to fear ratings. Thus, floor effects could, at least in part, be contributing to the observed results. Nonetheless, although the absence of differential effects contradicts some previous research demonstrating the benefits of procedural and pain sensory information on fear and pain during medical procedures (see Ludwick-Rosenthal \& Neufeld, 1988 for a review), it is consistent with other research (e.g., see Miller, Combs, \& Stoddard, 1989 for a review). There may be other important factors controlling behavior during root canal treatment that is unaccounted for by predictability about procedural or sensory components of pain. For example, the therapeutic alliance between the patient and care provider could attenuate fear and pain responding (although this factor was not measured). Furthermore, it has been proposed that coping style (i.e., monitoring and blunting) affects patient's response to information during dental treatment; however, the evidence found in Experiment 2 suggests that coping style was not a relevant factor in the present study. Coping style, as measured by the Miller Behavioral Style Scale (Miller 1987), was neither significantly related to dental fear nor fear of pain, and it did not predict fear responding. Nevertheless, if patients were selected for groups based on high and low monitoring and blunting scores, different results may be found. This question is an empirical one, however, that awaits more thorough examination. 
Previous research has indicated that memory of pain generally is inflated compared to actually experienced pain during health care treatments such as those in dentistry (e.g., Arntz \& Hout, 1988), which may have significant implications for the maintenance of dental fear and avoidance. Importantly, the results of the present study replicate and extend previous research by finding that both fear and pain memory are inflated over time compared to that which is experienced during treatment. Patients in all groups demonstrated the tendency to have elevated reports of fear and pain ratings at a 3-week follow-up compared to ratings during treatment. Given that patients are unable to accurately recall their level of fear during treatment, coupled with data that indicates affective state during pain predicts memory of pain at 18 months (Gedney, Logan, \& Baron, 2003), fear of pain may be the mechanism that affects pain memory (cf., fear of fear). If fear of pain maintains inaccurate memory of pain, as data from this study suggests, then treatment options could include exposure to both dental-related pain and feared dental stimuli related to pain (e.g., drill, sound of drill, and needles). Further, treatments that target erroneous beliefs about pain for fearful patients, which have been found to be successful intervention for chronic musculoskeletal pain patients (e.g., Crombez, Vervaet, Lysens, Baeyens, \& Eelen, 1998; Vlaeyen, Jong, Geilen, Heuts, \& Breukelen, 2001; Vowles \& Gross, 2003), also could be helpful for root canal patients. Data from Experiment 2 also suggests that fear of pain, as measured by the FPQ-III, is significantly related to and predictive of general dental fear, confirming previous work (McNeil \& Berryman, 1989; McNeil, Au et al., 2001). Importantly, results extend previous work by showing that fear of pain accounted for a significant and unique amount of variance in predicting patients' verbal report of fear prior to root canal treatment. This finding is important because it shows that fear of pain predicts verbal behavior prior to root canal treatment (i.e., verbal fear report) as opposed to general dental fear as measured by the Dental Fear Survey. Shared method variance also is reduced by using verbal behavior as the criterion variable in predicting fear before treatment. Taken together, findings from Experiment 2 improve our understanding of dental fear. Specifically, significant positive relations between fear of pain and dental fear extends to verbal behavior, which strengthens the theoretical underpinnings that suggest fear of pain to be a critical factor involved in dental fear (e.g., van Wijk \& Hoogstraten, 2003). Future investigations will benefit from expanding these findings to additional behavioral responses such as treatment avoidance and/or physiological responding. 


\section{General Discussion}

The main goals of Experiment 1 were to (a) develop a five-minute informational video designed to enhance predictability about painful aspects of root canal treatment using information, (b) construct a 15item measure of dental-related knowledge, and (c) test the validity of using the dental knowledge assessment as a manipulation check for Experiment 2. The primary goals of Experiment 2 were to (a) assess the effects of information type on fear and pain responding among root canal patients, (b) test findings from previous research that suggest fear of pain as an important predictive factor in general dental fear, and (c) extend previous research by examining the ability of theoretically relevant factors to predict verbal reports of fear and pain when patients arrive for root canal treatment. To achieve the stated goals of Experiment 1, two informational videos available from the American Dental Association were used as models by which to professionally construct an informative video about pain during root canal treatment. Next, content analyses of the videos guided the construction of the 15-item Dental Knowledge Inventory; the videos and the DKI were used with 268 undergraduate psychology students to determine the effects of videotaped information on knowledge. Results suggested that there was a significant content specific change in dental knowledge, as measured by the DKI, after participants viewed an informational video related to dentistry. These findings support the use of videotapes as a medium to provide information and increase dental knowledge, and data from both Experiment 1 and Experiment 2 support the use of the DKI as an effective method of measuring knowledge change.

To attain the goals for Experiment 2, dental-relevant information was manipulated with 104 endodontic patients. There were five main findings. First, results from Experiment 1 were replicated with a clinical sample of root canal patients. Second, there were significant main effects for verbal reports of fear and pain and cardiac response across the duration of treatment. Verbal reports of fear and pain decreased across the course of treatment and cardiac response was significantly decreased from baseline during injections relative to drilling and cleaning/shaping of canals, which did not differ from one another. Third, fear and pain memories at a 3-week follow-up were significantly elevated compared to patients' reported fear and pain during treatment, confirming and extending previous research. Fourth, previous research was supported that has found fear of pain to be significantly related to and predictive of general dental fear. Fifth, previous research was extended by finding fear of pain to be significantly related to and predictive of verbal reports of fear as root canal patients entered the clinic for treatment 
above and beyond other theoretically-relevant factors. Overall, the results from the two experiments provide unique contributions to the literature on fear of pain in general and fear of dental pain in particular. These contributions are highlighted and detailed below.

\section{Major Findings and Confirmed Hypotheses}

Replication of previous research. The importance of pain education and preparation for health care-related procedures for patients is well established (e.g., Quinn-Crandall \& Lammers, 2002). Different modalities have been effective at providing patients with information about treatment, including booklets (Burton et al., 1999), leaflets (Rees, Ford, \& Sheard, 2003), and videos (McGregor, 2003). Results from Experiment 1 are consistent with previous research by showing that dental knowledge was increased among undergraduate students after watching a 5-minute videotape about oral hygiene or different aspects of root canal treatment; Experiment 2 replicated this finding with root canal patients. Thus, videos are an effective method of providing patients with information, which is important given evidence that suggests information in video format leads to more memory retention than information presented in audio or print format, especially for older adults (Frieske \& Park, 1999). Although there were improvements in knowledge, there were no changes in behavior during treatment (e.g., fear and pain responding), suggesting additional factors that influence responding. Total dental knowledge before treatment and the total amount of knowledge changed compared to pre-treatment could be important factors contributing to results from the present study. On average, dental knowledge improved in a content specific fashion after watching a video; however, some patients in the oral hygiene and root canal procedure video groups may already have been knowledgeable about pain during a root canal procedure. These patients certainly will respond differently regarding fear and pain during treatment, relative to patients in the same groups who have very little or no knowledge about pain during root canal therapy. In a related way, patients in the pain information group, who had relatively large pain knowledge changes, may benefit differently compared to patients in the same group who either already had high levels of pain knowledge prior to viewing the video, or patients who did not improve at all in knowledge. An interesting way to test this possibility would be to categorize patients into groups based on their knowledge level before treatment as well as their improved knowledge after viewing videotaped information.

Another important factor that may offset the benefits of dental knowledge is memory for aversive experiences. Pain and fear memory were inflated at follow-up compared to that which was experienced 
during treatment, extending and supporting previous research (Arntz et al., 1990; Arntz \& Hout, 1988; Kent, 1985). This effect has been linked to the affective context in which pain is experienced during root canal treatment (Gedney, Logan, \& Baron, 2003). Specifically, baseline anxiety ratings predict memory of pain as long as 1.5 years after treatment, suggesting that the further patients are removed form the dental setting and the pain experienced there, the more the affective state during that experience influences recall of the event. Patients who come into the dental clinic with higher levels of fear and experience pain during treatment are likely to later remember the pain as much worse, compared to patients who have lower levels of fear. In the context of the present study, patients' fears before treatment likely influenced the way that they later recalled their actual experience of pain during treatment. The lack of differences in fear and pain memory among groups is not particularly surprising given that there were no differences on reported fear or pain before treatment. Results from other studies examining methods to reduce fear of pain-related movements (e.g., McCracken, Gross, Sorg, \& Edmands, 1993; Rachman \& Lopatka, 1988) suggest that it is reasonable to assert that fearful dental patients also may need several exposures to (dental) pain before they can accurately recall what they experienced in past appointments or predict what they will experience in future dental situations. Without the experience of mild to moderate pain in a safe, anxiety reduced context, patients' fear of pain likely will be maintained by avoidance into later adulthood when dental fears and fear of pain generally decrease (Liddell \& Locker, 1993; 1997).

A second result from the current study that is well documented in the literature is that fear of pain is an important factor in dental fear (McNeil \& Berryman, 1989; McNeil, Au et al., 2001). The fact that fear of pain predicted dental fear in the current study further asserts that fear of pain is a likely main contributor to the maintenance of dental fear. Although the use of the fear-avoidance model to better understand dental fear has only been recent (Sorrell \& McNeil, 2003), data from this study fit nicely with Lethem and colleagues' conceptualization (1983). Patients' fear of pain and tendency to avoid regular dental appointments creates a cycle of fear and avoidance behavior that feeds off of the other, which can prevent patients from receiving preventive dental visits (Kegeles, 1963). It is not until patients confront their fears and pain during treatment (disconfirming unrealistic expectations), that they gain the necessary experience to develop realistic conceptualizations of dental treatment, and break the fear-avoidance cycle. If patients wait until they need treatment, however, pain may be worse than if they received preventive care, and greater pain likely will maintain their fears. Soh (1992), for example, found that of 
306 dental patients screened for dental fear, there were over twice as many high fear patients than nonfearful patients who received restorations and extractions; the opposite was true for patients who received check-ups and prophylaxis. Fearful patients may have put off treatment to the point that restoration and/or extraction was the only treatment option, and the pain experienced during these procedures would likely exacerbate their existing fear and preserve the fear-avoidance cycle.

Extension of previous research. An important finding from the current study and extension of previous research was the establishment of a significant relation between anxiety sensitivity and dental fear. Although empirical data have not demonstrated this relation prior to Experiment 2, the theoretical basis of the expectancy model (Reiss \& McNally, 1985; Reiss, Peterson, Gursky, \& McNally, 1986) would suggest that expectancy and anxiety sensitivity encompasses dental fear. As noted above, anxiety expectancy refers to the responses when anxiety evoking stimuli are encountered (e.g., increased psychophysiological response), and anxiety sensitivity refers to the belief that these responses are threatening, dangerous, and harmful. Thus, dental patients with a general fear of anxiety, that is higher levels of anxiety sensitivity as measured by the Anxiety Sensitivity Index, are more likely to develop dental fear when they become anxious, fearful, and/or experience pain in the dental setting. Secondary to the patient's belief that sensations of anxiety or fear are harmful, heart palpitations and racing thoughts that may occur in the dental chair become specific internal stimuli that are associated with the aversive situation and ultimately evoke the same fear response when experienced at future appointments.

Although this anxiety scenario needs to be empirically investigated in dentistry, recent data suggest that anxiety sensitivity is not only closely related to negative pain experiences but also may predispose otherwise healthy persons toward more negative responses to painful events (Keogh \& Birkby, 1999; Keogh \& Mansoor, 2001). Comparing a clinical sample of panic patients with a nonclinical control group, Schmidt and Cook (1999) found that anxiety sensitivity predicted pain responding during a cold pressor task, suggesting that anxiety sensitivity mediates panic responding and pain. In an attempt to identify a potential cognitive mechanism by which anxiety sensitivity influences the experience of pain, Keogh and Cochrane (2002) found that healthy persons with high anxiety sensitivity demonstrated greater interpretive bias and more negative pain experiences relative to persons with low anxiety sensitivity, and interpretive biases were related to worse affective pain experiences. Keogh and Cochrane also found that the tendency to negatively interpret ambiguous bodily sensations related to panic (e.g., 
pounding heart) mediates anxiety sensitivity and emotional responses to pain. Taken together, the studies reviewed above suggest that the tendency to respond fearfully to sensation of anxiety also greatly influence pain responding. It is believed that anxiety sensitivity contributes to pain vis a vis its relation to fear of pain. That is, the similarities in responding that characterize anxiety and pain are what influence increased pain responding among persons with high anxiety sensitivity (Greenberg \& Burns, 2003).

Another important extension of previous research found in this study is that fear of pain predicted patients' verbal report of fear prior to treatment. These are the first data to show that fear of pain, as measured by the FPQ-III, predicts verbal behavior associated with dental fear among dental patients (cf., self-report measures) above and beyond other theoretically relevant factors. As pointed out above, more will be learned about the importance of fear of dental pain by applying the FPQ-III in predicting additional overt-behaviors that characterize dental fear.

Major Findings and Unsupported Hypotheses

Fear, pain, and information type. Verbal reports of fear and pain were decreased at the end of treatment relative to other times before and during root canal therapy, regardless of information given to patients. Also, cardiac response during treatment did not differ as a function of information type, although there was a significant decrease in heart rate from baseline during injections compared to the decrease in heart rate during drilling and cleaning/shaping root canals. The finding that verbal reports of fear and pain decreased after treatment is not a surprise. The lack of interaction between types of information, however, contradicts research that suggests differential effects of information type on fear and pain responding (e.g., Ludwick-Rosenthal \& Neufeld, 1988; Soh, 1992). With regard to physiological responding, results suggest that there may have been more of a defensive response prior to treatment (i.e., increased heart rate responding) that switched to an orienting response (i.e., cardiac deceleration) only after treatment commenced and not after watching a 5-minute video (see Graham, 1979 for a review). It is quite possible that although patients were given information, anxiety may have interfered with their ability to adequately understand it, disconfirm their current beliefs, reduce fear, and decrease physiological arousal. This hypothesis is consistent with the Yerkes-Dodson law (1908), which states that an inverted U-shaped relation exists between one's state of stress (e.g., anxiety) and the ability to effectively perform a cognitive task. Too little arousal may not motivate an individual to perform at maximal ability and too high arousal may interfere with that individual's ability to maximize performance. 
Rather, an optimal level of stress or anxiety (i.e., the peak of the inverted $U$ ) is needed for a skill or task to be executed at its highest level. Questions about the Yerkes-Dodson law have been made which have resulted in modifications of the law (e.g., Naatanen, 1973, Neiss, 1988). Specifically, the amount of decline in performance following the optimal level of arousal seems to be a function of performance on an alternate behavior rather than disruption on an initial task from anxiety or stress. In this case, attention is diverted to performing another task or responding to other stimuli and performance subsequently decreases. Due to questions raised about the explanatory utility of the Yerkes-Dodson law, some have disregarded its use altogether (e.g., Christianson, 1992).

In response to explanatory limitations of the Yerkes-Dodson law, cognitive models of anxiety suggest that stress and anxiety cause attention shifts from one stimulus to another and serve an adaptive role by assisting persons to search for and evaluate sources of threat (see Mendl, 1999 for a review). Catastrophizing, for example, is a cognitive tendency to ruminate, magnify, or feel helpless about pain (Keefe, Brown, Wallston, \& Caldwell, 1989; Rosenstiel \& Keefe, 1983), and has been implicated in why pain beliefs negatively impact behavior (Buer \& Linton, 2002; Sullivan et al., 2002). High levels of catastrophizing have been found to be reliably related to increased reports of pain intensity (Buer \& Linton) and painful dental procedures (e.g., Sullivan \& Neish, 1998). It is thought that catastrophizing increases pain by focusing one's attention toward pain and/or by increasing emotional reactivity to pain. Although catastrophizing was not measured in the current study, it could have been a limiting factor related to patients' understanding procedural- and pain-relevant information during root canal therapy.

Furthermore, even if anxiety or fear did not affect patients' understanding of information given to them, having information may not necessarily lead to behavior change. The fact that information did not appear to differentially influence responding suggests that other variables may have maintained behavior. Environmental factors such as stimulus intensity and aversiveness (Ariely, 1998; Sorrell et al., 2001; Vowles et al., 2003), for example, may affect how patients respond to dental-related stimuli, regardless of information. A more salient or intense stimulus may take precedence over controlling behavior relative to a weaker, less intense stimulus. In the current study, having information about pain during treatment may not take priority over more salient situational factors present in the endodontic chair (e.g., fear, sound of drill, sight of needle), and thus information did not differentially influence behavior. Recent evidence suggests that the degree of stimulus aversiveness will impact behavior. Vowles and colleagues (2003) 
found that behavior was dependent on the perceived aversiveness of a stimulus during fear and pain induction. Specifically, they found that fear overrides pain when fear is perceived to be the worst stimulus in an environment and the reverse is true when pain is perceived to be the worst (e.g., Bolles \& Faneslow, 1980, Eccleston \& Crombez, 1999). Aversiveness was not examined in the present study; however, if patients perceived the aversiveness of the root canal procedure to be greater than the potential benefits of information on treatment, the beneficial effects of information may have been negated. That is, information may have been discounted if patients believed that it would not make the aversiveness of treatment much less.

An important component to the effects of information when considering the aversiveness of stimuli is that patients did not have a specific experience to attach to the information provided. For example, patients may have had difficulty identifying with or understanding what a "pinching or pressing" sensation would be like when an injection was administered. Although many patients from experiment 2 had root canal treatment experience (i.e., $56 \%$ ), it is well established that pain memory is inflated following treatment (Arntz \& Schmidt, 1989); this result also was replicated in the study. If patients were to receive information, engage in a pain experience (e.g., cold pressor, algometer, electric pulp stimulation), and then have treatment, the information paired with the experience may help disconfirm irrational or inflated pain beliefs and make the information about treatment more salient and beneficial. Without a pain experience, however, information may lose some of its potency to provide predictability. Along these lines, providing pain information several days before treatment may allow patients the time necessary to consider it and integrate it into their concept of what they believe will likely occur during treatment. Evidence suggests, for example, that it is important to consider the time in which an intervention is made when preparing patients for a medical procedure (Melamed, Meyer, Gee, \& Soule, 1976). The fact that there were no differences among groups for pain memory suggests that patients may need more time to listen to treatment-related information for it to meaningfully impact their expectations about treatment and subsequent recall of those experiences. In a related way, the medium by which information is conveyed to patients can impact responding. Hazard et al. (2000) suggest that personal interaction with a health care provider may be more advantageous compared to pamphlets, or videos in the case of the present study. 
Another explanation for why there were no differential effects of information type is that the oral hygiene video may have functioned as a distraction for patients prior to treatment. Although the effects of the oral hygiene video on fear and pain were not significantly different from the effects of the other two videos, the general trend was in the direction that favors the use of this video to moderate fear and pain responding during treatment (e.g., see Fernandez \& Turk, 1989 for a review). Due to the lack of a control group that did not receive any information other than what is normally given prior to treatment, the possibility of distraction as a mechanism of action for the oral hygiene video cannot be confirmed nor disconfirmed at this time. An additional plausible effect of the oral hygiene video is that it presented a sense of control to patients over dental-relevant behaviors (i.e., brushing and flossing), which in turn affected fear and pain responding for patients who received this information. Whereas perceived control often has been investigated with regard to anxiety-related events such as pain (e.g., Feldner \& Hekmat, 2001), the concept of control and its importance in mental and physical health is vast (see Shapiro, Schwartz, \& Astin, 1996 for a review). Although the control that the oral hygiene video may have provided patients is not control over negative emotions such as fear, it is a type of control that could impact some aspect of their life. It is possible that the sense of control obtained from learning this skill could translate into a sense of control over their current environment (to an extent), including their emotional and pain response during treatment. More empirical work investigating the parameters of control needs to be conducted before it can be dismissed that the oral hygiene video did not impact responding in this way.

Regarding the fear of dental pain video, there may have been subtle iatrogenic effects by sensitizing patients for upcoming procedure pain. Although the information about pain was designed to reduce irrational expectations about pain during root canal treatment, it has been established that the amount of sensory information is important to consider when giving sensory information about a medical procedure: too much sensory information can make the experience of pain worse (Miller \& Mangan, 1983). In this regard, the knowledge about how much pain coupled with the fact that pain was likely to occur during the procedure may have been interpreted as threatening. Crombez and colleagues (1998) assert that the threat of pain not only disrupts attention but also is consistent with the development of a hypervigilance in which persons scan their body for threat (Watson \& Pennebaker, 1989). As a result of hypervigilance, patients may have expected pain during specific parts of treatment and thus were more aware of their pain experiences. 
Related to hypervigilance, pain expectancy is an estimate of what persons anticipate they will experience during an aversive situation such as a painful dental procedure. Arntz and Lousberg (1990) investigated the effects of underestimated electric shock pain on subsequent estimates of shock. Results suggested that (a) several corrective experiences are needed to gain more accurate estimates, (b) reduction in fear of painful stimuli was delayed, and (c) confidence about accuracy of estimates increases with practice. Therefore, if patients from Experiment 2 had underestimated dental-pain experiences during past treatments, the information presented in the pain video may not have been enough to reduce their fear of pain. Also, accounting for inaccurate pain memory, several accurate estimates of pain would be needed before patients' fear would be reduced. To further the pain expectancy line of research, Pfingsten and colleagues (2001) investigated the relations among pain expectancy, fear-avoidance beliefs, and behavioral avoidance. They found that pain expectancy led to increased avoidance during a leg-flexion task among chronic low back pain patients. Furthermore, there was a significant positive relation between avoidance behavior and fear-avoidance beliefs, indicating that erroneous beliefs about pain influenced behavior. Taken together, results from the Arntz and Lousberg (1990) and Pfingsten et al. (2001) studies suggest that although a brief informational video may enhance predictability about pain during root canal treatment, it may not be enough to influence estimates and beliefs about pain, which can subsequently affect fear and pain behavior.

\section{Limitations}

Although results of these experiments significantly contribute to the literature on fear of pain in dentistry, there are caveats that should be addressed. First, and perhaps what most restricts interpretation of findings from Experiment 2, is the lack of a true "treatment as normal" control group. It cannot be determined from the results what the effects would be if patients viewed no informational video prior to treatment. It is quite possible that no video would demonstrate similar effects as those exhibited by the three used in the present study, although unlikely given results of previous research. Nonetheless, it is a limitation that needs to be acknowledged. In a related way, the oral hygiene video could have functioned as a distraction for patients; without a control group that does not receive information, the distraction hypothesis cannot be determined from the present study.

A second limitation regarding the prediction of dental fear is that measurement of these constructs was reliant on self-report as the primary assessment methodology. Therefore, shared method 
variance may have contributed to the obtained results. This issue in not a novel one and has been raised in previous research (e.g., Greenberg \& Burns, 2003; McNeil, Au et al., 2001; Zvolensky et al., 2001). To address this concern, future studies should employ other research methodologies, including experimental methods that can tap other aspects of psychological processes involved with fear and pain responding (e.g., psychophysiological reactivity and/or avoidance behavior). A prime example of using fear of pain to predict dental fear without shared method variance as a factor would involve having patients complete the FPQ-III and self-report measures of similar constructs (e.g., Anxiety Sensitivity Index and Dental Fear Survey) and then determining which patients cancel, no show, reschedule, or otherwise delay follow-up treatment (i.e., avoidance). Patients' avoidance of follow-up treatment would be a behavioral measure of dental fear, and determining which self-report measure predicts avoidance would provide important information in understanding dental fear.

A third limitation is that the gender of provider, research personnel, and patients were not directly considered together in the analyses conducted. Research has consistently documented gender differences with regard to reports of fear and pain (e.g., Fillingim \& Maixner, 1995; Riley, Robinson, Wise, Myers, \& Fillingim, 1998), with females typically reporting more negative responses relative to males. Results from Experiment 2 support previous research by showing that there was a positive and significant relation between fear ratings before treatment and gender. To understand why this difference between gender exists, evidence suggests that males respond more favorably to sensory-focused coping during experimental pain challenges (i.e., pain reduction) compared to women who do not benefit from the same form of coping (Keogh \& Herdenfeldt, 2002). Data also suggest a meaningful interaction between the gender of persons reporting fear and pain and persons hearing these reports (e.g., Carter et al., 2002; Vowles et al., 2003). Specifically, participant and experimenter gender was found to significantly influence pain such that males had higher pain tolerance relative to females during an experimental pain challenge, and males had longer pain tolerance when female experimenters were present during pain stimulation. In a related way, treatment responding among root canal patients in the current study could have been affected by the gender of the provider as well as the research personnel collecting data. Although information that could be gained by considering these factors in the present study would be compromised by a lack of power to detect significant effects, gender of provider and research personnel is an important component to consider because it introduces a social dimension to fear and pain responding. The 
multidimensionality of fear and pain certainly incorporates social factors (Sanders, 2002; Turk \& Monarch, 2002), and including gender as a variable in future research may lead to important findings.

\section{Future Directions}

Research. Although the results from this study help clarify understanding about fear of dental pain, there continues to be issues that warrant further research attention. The first area of research that should be expanded is in regard to knowledge enhancement. Which mediums are best to provide dental information (e.g., pamphlet, video, or oral instruction from a provider) and which result in the greatest improvement in knowledge and behavior change (e.g., reduced fear, pain, and avoidance)? Secondary to knowledge enhancement is understanding patients' desire for information. As was discussed above, there are types of patients with coping styles who desire information and others who do not (i.e., monitors and blunters, respectively). Desire for information likely falls on a continuum, influenced by coping style, in which some patients have different needs (or levels) for "less" information and other patients have different needs for "more" information. Stated differently, are there differences among monitors, as well with among blunters, in terms of how much information they desire to satisfy their coping needs? Suls and Fletcher (1985) suggest that there will be differences. An interesting way to examine this research question more precisely would be to identify monitors and blunters, present scenarios about different medical procedures, and ask them to provide a rating that captures a range of desired types and amounts of information to help them cope during the procedure. Then, patients could be asked the same questions prior to treatment and provided with the type and amount of information that matches their reported desires/needs.

Another important research venture would be to use a treatment control group to elucidate the effects of information type on fear and pain responding during root canal treatment. Having a control group would clarify whether or not the oral hygiene video was a distraction from fear and pain. A no information control group also would help clarify if the oral hygiene video helped patients feel a sense of control over their environment by learning a skill that they could implement. Also, coping style was not related to dental fear or fear of pain, but it could mediate how information affects patients' responding during dental treatments, especially considering the positive results found in past research (e.g., see Miller, Combs, \& Stoddard, 1989 for a review). The question becomes: how does information and coping 
style influence fear and pain? To address this question, patients could be screened and selected for information groups based on high and low monitoring and blunting scores.

Future investigations will benefit from expanding results found in this study from the FPQ-III and the ASI. Additional behavioral responses such as treatment avoidance and/or physiological responding should be used as criterion variables with fear of pain and fear of anxiety as predictors. In a related way, the relations among catastrophizing, aversiveness, and fear and pain responding could be explored as potential mediators of fear of pain.

Results from other studies examining methods to reduce fear of pain-related movements (e.g., Arntz \& Lousberg, 1990; McCracken, Gross, Sorg, \& Edmands, 1993) suggest that fearful dental patients also may need several exposures to (dental) pain before they can then later accurately recall what they experienced in past appointments or accurately predict what they will experience in future dental situations. Using similar methods to what has been found effective with chronic pain patients (e.g., Vlaeyen, Jong, Geilen et al., 2001; Vlaeyen, Jong, Sieben, \& Crombez, 2002) may provide useful clinical implications for treating fear of dental pain. Thus, using graded exposure may reduce patients' fear of pain and increase their accuracy of pain expectancy.

As a final research direction, gender of patient, provider, and research technician should be considered a priori by generating groups with equivalent female and male combinations. In this way, the effects of gender, as a social dimension affecting pain, can be examined more precisely during dental treatment.

Clinical. Future clinical directions should be guided, at least in part, by what is understood within fear of dental pain research, and vice versa. Given findings from previous research, dispositional factors such as coping style, desire for control, and fear of pain should be considered when giving dental patients information (Litt, 1996). Also, giving too much sensory information about pain could have adverse effects on fear and pain. So, first and foremost, dentists should give as much information as a patient needs to be fully informed about a dental procedure. Next, factors such as dental fear, fear of pain, and anxiety sensitivity should be considered to gain a sense of how patients will respond during potentially painful treatments and how their responses during treatment could influence their attendance at future appointments. Based on future research examining the factors listed above, different types of information may be important for different patients depending on their reactions to fear and pain during treatment. 


\section{Conclusions}

An informational video and knowledge inventory were developed and the effects of information type were examined among root canal patients. Taken together, results from Experiments 1 and 2 suggest that videotape information can increase dental knowledge and therefore can increase predictability about dental treatments. Although there were no differential effects of information type on fear and pain responding, there were important replications and extensions of previous research. In particular, findings support the use of videotapes as a medium to provide information and increase dental knowledge, pain memory at a 3-week follow-up was significantly elevated compared to patients' actual pain during treatment, fear of pain was significantly related to and predictive of general dental fear, fear of pain was found to be significantly related to and predictive of verbal reports of fear as root canal patients enter the clinic, and anxiety sensitivity was significantly related to dental fear. The current study answered important questions and helped expose additional problems worth investigating. In this regard, several unexplored directions remain for future research, as outlined above. Until these avenues are more closely targeted and explored, fear and pain likely will continue to be integral components of the dental experience in general and in the maintenance of dental fear in particular. 


\section{References}

Abram, S. E. (1993). Advances in chronic pain management since gate control. Regional Anesthesia, 18, 66-81.

Al Absi, M. A., \& Rokke, P. D. (1991). Can anxiety help us tolerate pain? Pain, 46, 43-51.

Albino, J. E. N., (2000). Factors influencing adolescent cooperation in orthodontic treatment. Seminars in Orthodontics, 6, 214-223.

Alex, M., \& Richie, J. (1992). School-aged children's interpretation of their experience with acute surgical pain. Journal of Pediatric Nursing, 7, 171-180.

American Dental Association (Producer). (1998a). Taking care of your teeth and gums. (Available from the American Dental Association, 211 E. Chicago AVE, Chicago, IL 60611).

American Dental Association (Producer). (1998b). Root canal. (Available from the American Dental Association, 211 E. Chicago AVE, Chicago, IL 60611).

Anaise, J. Z., \& Mann, J. (1982). Prevalence of dental caries and demands for services among Israeli kibbutz youth. Community Dentistry and Oral Epidemiology, 10, 161-162.

Ariely, D. (1998). Combining experiences over time: The effects of duration, intensity changes and on-line measurements on retrospective pain evaluations. Journal of Behavioral Decision Making, 11, $19-45$.

Arntz, A., \& De Jong, P. (1993). Anxiety, attention, and pain. Journal of Psychosomatic Research, 37, 423-432.

Arntz, A., Dreessen, L., \& De Jong, P. (1994). The influence of anxiety on pain: Attentional and attributional mediators. Pain, 56, 307-314.

Arntz, A., Dreessen, L., \& Merckelbach, H. (1991). Attention, not anxiety, influences pain. Behaviour Research and Therapy, 29, 41-50.

Arntz, A., \& Hout, M. van den (1988). Generalizability of the match/mismatch model of fear. Behaviour Research and Therapy, 26, 207-223.

Arntz, A., \& Lousberg, R. (1990). The effects of underestimated pain and their relationship to habituation. Behaviour Research and Therapy, 28, 15-28.

Arntz, A., \& Schmidt, A. J. M. (1989). Perceived control and the experience of pain. In A. Steptoe \& A. Appels (Eds.), Stress, Personal Control and Health (pp. 131-162). London: John Wiley \& Sons. 
Arntz, A., Van Eck, M., \& Heijmans, M. (1990). Predictions of dental pain: The fear of any expected evil, is worse than the evil itself. Behaviour Research and Therapy, 28, 29-41.

Asmundson, G. J. G., Coons, M. J., Taylor, S., \& Katz, J. (2002). PTSD and the experience of pain: Research and clinical implications of shared vulnerability and mutual maintenance models. Canadian Journal of Psychiatry, 47, 930-937.

Asmundson, G. J. G., \& Norton, G. R. (1995). Anxiety sensitivity in patients with physically unexplained chronic back pain: A preliminary report. Behaviour Research and Therapy, 33, 771-777.

Asmundson, G. J. G., Norton, P. J., \& Norton, G. R. (1999). Beyond pain: The role of fear and avoidance in chronicity. Clinical Psychology Review, 19, 97-119.

Asmundson, G. J. G., Norton, P. J., \& Veloso, F. (1999). Anxiety sensitivity and fear of pain in patients with recurring headaches. Behaviour Research and Therapy, 37, 703-713.

Barlow, D. H. (1991). Disorders of emotion. Psychological Inquiry, 2, 58-71.

Barlow, D. H. (2002). Anxiety and its disorders: The nature and treatment of anxiety and panic ( $2^{\text {nd }}$ ed.). New York: Guilford Press.

Baron, R. S., \& Logan, H. (1993). Desired control, felt control, and dental pain: Recent findings and remaining issues. Motivation and Emotion, 17, 181-204.

Baron, R. S., Logan, H., \& Hoppe, S. (1993). Emotional and sensory focus as mediators of dental pain among patients differing in desired and felt control. Health Psychology, 12, 381-389.

Bar Or, T., Bar Or, O., Waters, H., Hirji, A., \& Russell, S. (1996). Validity and social acceptability of the Polar Vantage XL for measuring heart rate in preschoolers. Pediatric Exercise Science, 8, 115121.

Bellizzi, R., Hartwell, G. R., Ingle, J. I., Goerig, A. C., Neaverth, E. J., Marshall, F. J., Krasny, R. M., Frank, A. L., \& Gaum, C. (2001). Diagnostic procedures. In J. I. Ingle \& L. K. Bakland (Eds.), Endodontics. Baltimore: Williams \& Wilkins.

Bernstein, D. A., Kleinknecht, R. A., \& Alexander, L. D. (1979). Antecedents of dental fear. Journal of Public Health and Dentistry, 39, 113-124.

Bolles, R. C., \& Faneslow, M. S. (1980). A perceptual-defensive-recuperative model of fear and pain. The Behavioral and Brain Sciences, 3, 291-323. 
Buer, N., \& Linton, S. J. (2002). Fear-avoidance beliefs and catastrophizing: Occurrence and risk factor in back pain and ADL in the general population. Pain, 99, 485-491.

Burger, J. M. (1989). Negative reactions to increases in perceived personal control. Journal of Personality and Social Psychology, 56, 246-256.

Burger, J. M. (1992). Desire for control. New York: Plenum.

Burton, A. K., Waddell, G., Tillotson, K. M., Summerton, N. (1999). Information and advice to patients with back pain can have a positive effect. A randomized controlled trial of a novel educational booklet in primary care. Spine, $24,2484-2491$.

Byers, M. R., \& Burgess, J. A. (2001). Pain of dental and intraoral origin. In J. D. Loeser (Ed.), Bonica's Management of Pain ( $3^{\text {rd }}$ ed., pp. 909-924). PA: Lippincott, Williams, \& Wilkins.

Carter, L. E., McNeil, D. W., Vowles, K. E., Sorrell, J. T., Turk, C., Ries, B., \& Hopko, D. R. (2002). Effects of emotion on pain reports, tolerance and physiology. Pain Research and Management, 7, 21-30.

Chadwick, B. L. (2002). Assessing the anxious patient. Dental Update, 29, 448-454.

Chiappelli, F., \& Prolo, P. (2002). Evidence-based dentistry for the $21^{\text {st }}$ century. General Dentistry, 50, 270-273.

Christianson, S. -A. (1992). Emotional stress and eyewitness memory: A critical review. Psychological Bulletin, 112, 284-309.

Cioffi, D., \& Holloway, J. (1993). Delayed costs of suppressed pain. Journal of Personality and Social Psychology, 64, 274-282.

Cleeland, C. S., (1986). How to treat a construct. Journal of Pain and Symptom Management, 1, 161-162.

Cohen, L. L. (2002). Reducing infant immunization distress through distraction. Health Psychology, 21, 207-211.

Cohen, L. L., Blount, R. L., Cohen, R. J., Ball, C. M., McClellan, C. B., \& Bernard, R. S. (2001). Children's expectations and memories of acute distress: Short- and long-term efficacy of pain management interventions. Journal of Pediatric Psychology, 26, 367-374.

Cohen, L. L., Blount, R. L., Cohen, R. J., Schaen, E. R., \& Zaff, J. F. (1999). Comparative study of distraction versus topical anesthesia for pediatric pain management during immunizations. Health Psychology, 18, 591-598. 
Cohen, L. L., Blount, R. L., \& Panopoulos, G. (1997). Nurse coaching and cartoon distraction: An effective and practical intervention to reduce child, parent, and nurse distress during immunizations. Journal of Pediatric Psychology, 22, 355-370.

Cohen, S. (2001). Diagnostic procedures. In S. Cohen \& R. C. Burns (Eds.), Pathways of the pulp ( $8^{\text {th }}$ ed, pp. 1-30). St. Louis: Mosby.

Corah, N. L. (1988). Dental anxiety. Assessment, reduction and increasing patient satisfaction. Dental Clinics of North America, 32, 779-790.

Craske, M. G. (1999). Anxiety disorders: Psychological approaches to theory and treatment. Boulder: Westview Press.

Crombez, G., Eccleston, C., Baeyens, F., \& Eelen, P. (1998). Attentional disruption is enhanced by the threat of pain. Behaviour Research and Therapy, 36, 195-204.

Crombez, G., Vervaet, L., Lysens, R., Baeyens, F., \& Eelen, P. (1998). Avoidance and confrontation of painful, back-straining movements in chronic back pain patients. Behavior Modification, 22, $62-$ 77.

Crombez, G., Vlaeyen, J. W. S., Heuts, P. H. T. G., \& Lysens, R. (1999). Pain-related fear is more disabling than pain itself: Evidence on the role of pain-related fear in chronic back pain disability. Pain, 80, 329-339.

Daltroy, L. H., Iversen, M. D., Larson, M. G., Lew, R., Wright, E., Ryan, J., Zwerling, C., Fossel, A. H., \& Liang, M. H. (1997). A controlled trial of an educational program to prevent low back injury. The New England Journal of Medicine, 337, 322-328.

Davey, G. (1989a). Dental phobias and anxieties: Evidence for conditioning processes in the acquisition and modulation of a learned fear. Behaviour Research and Therapy, 27, 51-58.

Davey, G. (1989b). UCS revaluation and conditioning models of acquired fears. Behaviour Research and Therapy, 27, 521-528.

Davey, G., \& Craigie, P. (1997). Manipulation of dangerousness judgements to fear-relevant stimuli: Effects on a priori UCS expectancy and a posteriori covariation assessment. Behaviour Research and Therapy, 35, 607-617.

Delfino, J. (1997). Public attitudes toward oral surgery: Results of a gallup poll. Journal of Oral Maxillofacial Surgery, 55, 564-567. 
Deshpande, R. G., Khan, M., \& Genco, C. A. (1999). Invasion strategies of the oral pathogen porphyromonas gingivalis: Implications for cardiovascular disease. Invasion Metastasis, 18, 5769.

Dionne, R. A. (1992). New approaches to preventing and treating postoperative pain. Journal of the American Dental Association, 123, 27-34.

Eccleston, C. (1994). Chronic pain and attention: A cognitive approach. British Journal of Clinical Psychology, 33, 535-547.

Eccleston, C., \& Crombez, G. (1999). Pain demands attention: A cognitive-affective model of the interruptive function of pain. Psychology Bulletin, 125, 356-366.

Egbert, L. D., Battit, E. W., \& Welch, C. E., (1964). Reduction of post-operative pain by encouragement and instruction of patients. New England Journal of Medicine, 270, 825-827.

Eifert, G. H., Lejuez, C. W., \& Bouman, T. K. (1998). Somatoform disorders. In A. Bellack, M. Hersen, \& P. Salkovskis (Eds.), Comprehensive clinical psychology (pp. 543-565). New York, NY: Elsevier Science.

Eli, I. (1993). Dental anxiety: A cause for possible misdiagnosis of tooth vitality. International Endodontic Journal, 26, 251-253.

Eli, I., Bar-Tal, Y., Fuss, Z., \& Silberg, A. (1997). Effects of intended treatment on anxiety and on reaction to electric pulp stimulation in dental patients. Journal of Endodontics, 23, 694-697.

Faul, F. \& Erdfelder, E. (1992). GPOWER: A priori, post hoc, and compromise power analysis for MSDOS (Computer program). Bonn, FRG: Bonn University, Department of Psychology.

Feinmann, C., \& Madland, G. (1999). Special problems in dentistry. In C. Feinmann (Ed.), The Mouth, the Face, and the Mind (pp. 23-36). NY: Oxford University Press.

Feldner, M. T., \& Hekmat, H. (2001). Perceived control over anxiety-related events as a predictor of pain behavior in a cold pressor task. Journal of Behavior Therapy and Experimental Psychiatry, 32, 191-202.

Fernandez, E., \& Turk, D. C. (1989). The utility of cognitive coping strategies for altering pain perception: A meta-analysis. Pain, 38, 123-135.

Fillingim, R. B., \& Maixner, W. (1995). Gender differences in the response to noxious stimuli. Pain Forum, 4, 209-221. 
Frieske, D. A., \& Park, D. C. (1999). Memory for news in young and old adults. Psychology and Aging, 14, 90-98.

Fine, P. G. (1985). The pathways and mechanisms of pain and analgesia: A review and clinical perspective. Hospital Formulary, 20, 972-985.

Frere, C., Crout, R., Yorty, J., \& McNeil, D. (2001). Effects of audiovisual distraction during dental prophylaxis. Journal of the American Dental Association, 132, 1031-1038.

Furedy, J. J., \& Doob, A. N. (1972). Signaling unmodifiable shocks: Limits on human informational cognitive control. Journal of Personality and Social Psychology, 21, 111-115.

Glomsrod, B., Lonn, J. H., Soukup, M. G., Bo, K., \& Larsen, S. (2001). “Active Back School”, prophylactic management for low back pain: Three-year follow-up of a randomized, controlled trial. Journal of Rehabilitation Medicine, 33, 26-30.

Goldstein, G. R. (2002). What is evidence-based dentistry? Dental Clinics of North America, 46, 1-9.

Goodie, J. L., Larkin, K. T., \& Schauss, S. (2000). Validation of the Polar Heart Rate Monitor for assessing heart rate during physical and mental stress. Journal of Psychophysiology, 14, 159164.

Graham, F. K. (1979). Distinguishing among orienting, defensive, and startle reflexes. In H. D. Kimmel, E. H. van Olst, \& J. F. Orlebeke (Eds.), The orienting reflex in humans (pp. 137-167). Hillsdale, NJ: Erlbaum.

Graham, F. K., \& Clifton, R. K. (1966). Heart-rate change as a component of the orienting response. Psychological Bulletin, 65, 305-320.

Graves, D. T., Jiang, Y., \& Genco, C. (2000). Periodontal disease: Bacterial virulence factors, host response and impact on systemic health. Current Opinion in Infectious Diseases, 13, 227-232.

Gross, R. T., \& Collins, F. L. (1981). On the relationship between anxiety and pain: A methodological confounding. Clinical Psychology Review, 1, 375-386.

Hadjistavropoulos, H. D., \& Craig, K. D. (1994). Acute and chronic low back pain: Cognitive, affective, and behavioural dimensions. Journal of Consulting and Clinical Psychology, 62, 341-349.

Hazard, R. G., Reid, S., Haugh, L. D., \& McFarlane, G. (2000). A controlled trial of an educational pamphlet to prevent disability after occupational low back injury. Spine, 25, 1419-14-23. 
Herbertt, R. M., \& Innes, J. M. (1979). Familiarization and preparatory information in the reduction of anxiety in child dental patients. Journal of Dentistry for Children, 46, 319-323.

Horne, D. J. de L., Vatmanidis, P., \& Cereri, A. (1994). Preparing patients for invasive medical and surgical procedures: Adding behavioral and cognitive interventions. Behavioral Medicine, 20, 510.

Horst, G., \& Wit, C. A. (1993). Review of behavioural research in dentistry 1987-1992: Dental anxiety, dentist-patient relationship, compliance, and dental attendance. International Dental Journal, 43, 265-278.

Hursey, K. G., \& Jacks, S. D. (1992). Fear of pain in recurrent headache suffers. Headache, 32, 283-286. International Association for the Study of Pain Task Force on Taxonomy. (1994). Classification of chronic pain: Descriptions of chronic pain syndromes and definitions of pain terms (2nd ed.; pp. 209-214). Seattle, WA: IASP Press.

Jensen, M. P., Karoly, P., \& Braver, S. (1986). The measurement of clinical pain intensity: A comparison of six methods. Pain, 27, 117-126.

Jerremalm, A., Jansson, L., \& Ost, L. G. (1986). Individual response patterns and the effects of different behavioral methods in the treatment of dental phobia. Behaviour Research and Therapy, 34, 587596.

Johnson, M. H., Breakwell, G., Douglas, W., \& Humphries, S. (1998). The effects of imagery and sensory detection distractors on different measures of pain: How does distraction work? British Journal of Clinical Psychology, 37, 141-154.

Johnson, B., Mayberry, W. E., \& McGlynn, F. D. (1990). Exploratory factor analysis of a sixty-item questionnaire concerned with fear of dental treatment. Journal of Behavior Therapy and Experimental Psychiatry, 21, 199-203.

Johnson, M. H., \& Petrie, S. M. (1997). The effects of distraction on exercise and cold pressor tolerance for chronic low back pain sufferers. Pain, 69, 43-48.

Keefe, F. J., Brown, G. K., Wallston, K. A., \& Caldwell, D. S. (1989). Coping with rheumatoid arthritis pain: Catastrophizing as a maladaptive strategy. Pain, 37, 51-56. 
Keefe, F. J., Beaupre, P. M., Gil, K. M., Rumble, M. E., \& Aspnes, A. K. (2002). Group therapy for patients with chronic pain. In D. Turk \& D. Gatchel (Eds.), Psychological approaches to pain management: A practitioner handbook ( $2^{\text {nd }}$ ed., pp. 234-255). NY: Guilford Press.

Kent, G. (1983). Psychology in the dental curriculum. British Dental Journal, 154, 106-109.

Kent, G. (1984). Anxiety, pain and type of dental procedure. Behaviour Research and Therapy, 22, 465469.

Kent, G. (1985). Memory of dental pain. Pain, 21, 187-194.

Kent, G., \& Blinkhorn, A. S. (1991). The Psychology of Dental Care (2 ${ }^{\text {nd }}$ ed.). New York: Wright.

Keogh, E., \& Birkby, J. (1999). The effect of anxiety sensitivity and gender on the experience of pain. Cognition and Emotion, 13, 813-829.

Keogh, E., \& Cochrane, M. (2002). Anxiety sensitivity, cognitive biases, and the experience of pain. The Journal of Pain, 3, 320-329.

Keogh, E. \& Herdenfeldt, M. (2002). Gender, coping, and the perception of pain. Pain, 97, 195-201.

Keogh, E., \& Mansoor, L. (2001). Investigating the effects of anxiety sensitivity and coping strategies on the perception of cold pressor pain in healthy women. European Journal of Pain, 5, 11-25.

Kight, M, Gatchel, R. J., \& Wesley, L. (1999). Temporomandibular disorder: Evidence for significant overlap with psychopathology. Health Psychology, 18, 177-182.

Kiyak, H. A., Vitaliano, P. P., \& Crinean, J. (1988). Patients' expectations as predictors of orthognathic surgery outcomes. Health Psychology, 7, 251-268.

Kleiber, C., \& Harper, D. C. (1999). Effects of distraction on children's pain and distress during medical procedures: A meta-analysis. Nursing Research, 48, 44-49.

Kleinknecht, R. A., Klepac, R. K., \& Alexander, L. D. (1973). Origins and characteristics of fear of dentistry. Journal of the American Dental Association, 86, 842-848.

Kleinknecht, R. A., Thorndike, R. M., McGlynn, F. D., Harkavy, J. (1984). Factor analysis of the dental fear survey with cross-validation. Journal of the American Dental Association, 108, 59-61.

Klepac, R. K. (1975). Successful treatment of avoidance of dentistry by desensitization or by increasing pain tolerance. Journal of Behavior Therapy and Experimental Psychiatry, 6, 307-310. 
Klepac, R. K., Dowling, J., \& Hauge, G. (1982). Characteristics of clients seeking therapy for the reduction of dental avoidance: Reactions to pain. Journal of Behavior Therapy and Experimental Psychiatry, 13, 293-300.

Klepac, R. K., Dowling, J., Hauge, G., \& McDonald, M. (1980). Reports of pain after dental treatment, electrical tooth pulp stimulation, and cutaneous shock. Journal of the American Dental Association, 100, 692-695.

Klepac, R. K., McDonald, M., Hauge, G., \& Dowling, J. (1980). Reactions to pain among subjects high and low in dental fear. Journal of Behavioral Medicine, 3, 373-384.

Kloffon, C. E. (1988). Anxiety, infection, and death. International Journal of Psychosomatics, 35, 61-62.

Kunzelmann, K. H. \& Dunninger, P. (1990). Dental fear and pain: Effects on patient's perception of the dentist. Community Dentistry and Oral Epidemiology, 18, 264-266.

Lacroix, R., \& Barbaree, H. E. (1992). Pain-elicited responses and their role in predicting future pain duration and severity. Behaviour Research and Therapy, 30, 471-478.

Lang, P. J. (1968). Fear reduction and fear behavior: Problems in treating a construct. In J. M. Schlien (Ed.), Research in psychotherapy (Vol. III). Washington, DC: APA.

Lang, P. J. (1971). The application of psychophysiological methods to the study of psychotherapy and behavior modification. In A. E. Bergin \& S. L. Garfield (Eds.), Handbook of psychotherapy and behavior change: An empirical analysis (pp. 75-125). New York: John Wiley.

Lautch, H. (1971). Dental phobia. British Journal of Psychiatry, 119, 151-160.

Lejuez, C. W., Eifert, G. H., Zvolensky, M. J., \& Richards, J. B. (2000). Preference between onset predictable and unpredictable administrations of $20 \%$ carbon-dioxide-enriched air: implications for better understanding the etiology and treatment of panic disorder. Journal of Experimental Psychology Applied, 6, 349-358.

Lethem, J., Slade, P. D., Troup, J. D. G., \& Bentley, G. (1983). Outline of a fear-avoidance model of exaggerated pain perception-I. Behaviour Research and Therapy, 21, 401-408.

Leventhal, H., \& Johnson, J. E. (1983). Laboratory and field experimentation: Development of a theory of self-regulation. In P. J. Wooldridge, M. H. Schmitt, J. K. Skipper, \& R. C. Leonard (Eds.). Behavioral science and nursing theory (pp. 189-262). St. Louis: C. V. Mosby. 
Levitt, J., McGoldrick, P., \& Evans, D. (2000). The management of severe dental phobia in an adolescent boy: A case report. International Journal of Pediatric Dentistry, 10, 348-353.

Liddell, A., \& Locker, D. (1993). Dental anxiety in the elderly. Psychology and Health, 8, 175-183.

Liddell, A., \& Locker, D. (1997). Gender and age differences in attitudes to dental pain and dental control. Community Dentistry and Oral Epidemiology, 25, 314-318.

Litt, M. D. (1996). A model of pain and anxiety associated with acute stressors: Distress in dental procedures. Behaviour Research and Therapy, 34, 459-476.

Lindsay, S. J. E., Wege, P., \& Yates, J. (1984). Expectations of sensations, discomfort and fear in dental treatment. Behaviour Research and Therapy, 22, 99-108.

Ludwick-Rosenthal, R., \& Neufeld, R. J. (1988). Stress management during medical procedures: An evaluative review of outcome studies. Psychological Bulletin, 104, 326-342.

Mahler, H. I. M., \& Kulik, J. A. (2002). Effects of a videotape information intervention for spouses on spouse distress and patient recovery from surgery. Health Psychology, 21, 427-437.

Marks, I. M. (1969). Fears and phobias. New York: Academic Press.

Marks, I. M., \& Gelder, M. G. (1966). Different ages of onset in varieties of phobia. American Journal of Psychiatry, 123, 218-221.

Mavrias, R., Peck, C., \& Coleman, G. (1990). The timing of pre-operative preparatory information. Psychology and Health, 5, 39-45.

McCracken, L. M., \& Gross, R. T. (1993). Does anxiety affect coping with chronic pain? The Clinical Journal of Pain, 9, 253-259.

McCracken, L. M., \& Gross, R. T. (1998). The role of pain-related anxiety reduction in the outcome of multidisciplinary treatment for chronic low back pain: Preliminary results. Journal of Occupational Rehabilitation, 8, 179-189.

McCracken, L. M., Gross, R. T., Sorg, P. J., \& Edmands, T. A. (1993). Prediction of pain in patients with chronic low back pain: Effects of inaccurate prediction and pain-related anxiety. Behaviour Research and Therapy, 31, 647-652.

McCracken, L. M., Zayfert, C., Gross, R. T. (1992). The Pain Anxiety Symptoms Scale: Development and validation of a scale to measure fear of pain. Pain, 50, 67-73. 
McGlynn, F. D., McNeil, D. W., Gallagher, S. L., \& Vrana, S. (1987). Factor structure, stability, and internal consistency of the Dental Fear Survey. Behavioral Assessment, 9, 57-66.

McGregor, S. (2003). Information on video format can help patients with localized prostate cancer to be partners in decision making. Patient Education and Counseling, 49, 279-283.

McNally, R. J., \& Eke, M. (1996). Anxiety sensitivity, suffocation fear, and breath-holding duration as predictors of response to carbon dioxide challenge. Journal of Abnormal Psychology, 105, 146149.

McNeil, D. W., Au, A. R., Zvolensky, M. J., McKee, D. R., Klineberg, I. J., \& Ho, C. C. K. (2001). Fear of pain in orofacial pain patients. Pain, $89,245-252$.

McNeil, D. W., \& Berryman, M. L. (1989). Components of dental fear in adults? Behaviour Research and Therapy, 27, 233-236.

McNeil, D. W., Lejuez, C. W., Sorrell, J. T. (2001). Behavioral theories of social phobia: Contributions of basic behavioral principles. In S. G. Hofmann \& P. M. DiBartolo (Eds.), Social phobia and social anxiety: An integration. Needham Heights: Allyn \& Bacon.

McNeil, D. W., \& Rainwater, A. J. (1998). Development of the Fear of Pain Questionnaire-III. Journal of Behavioral Medicine, 21, 389-410.

McNeil, D. W., Turk, C. L., \& Ries, B. J. (1994). Anxiety and fear. Encyclopedia of Human Behavior, 1, 151-163.

McNeil, D. W., Vrana, S. R., Melamed, B. G., Cuthbert, B. N., \& Lang, P. J. (1993). Emotional imagery in simple and social phobia: Fear versus anxiety. Journal of Abnormal Psychology, 102, 212-225.

Melamed, B. G., Weinstein, D. G., Hawes, R., \& Katin-Borland, M. (1975). Reduction of fear-related dental management problems with use of filmed modeling. Journal of the American Dental Association, 29, 265-278.

Melzack, R. (1979). The language of pain. Dental Dimensions, 3, 2-5.

Melzack, R. (1987). The short-form of the McGill Pain Questionnaire. Pain, 30, 191-197.

Melzack, R., \& Wall, P. D. (1965). Pain mechanisms: A new theory. Science, 50, 971-979.

Mendl, M. (1999). Performing under pressure: Stress and cognitive function. Applied Animal Behaviour Science, 65, 221-244. 
Miller, S. M. (1987). Monitoring and blunting: Validation of a questionnaire to assess different styles for coping with stress. Journal of Personality and Social Psychology, 52, 345-353.

Miller, S. M. (1995). Monitoring versus blunting styles of coping with cancer influence the information patients want and need about their disease. Cancer, 17, 167-177.

Miller, S. M., Combs, C., \& Stoddard, E. (1989). Information, coping and control in patients undergoing surgery and stressful medical procedures. In A. Steptoe \& A. Appels (Eds.), Stress, personal control, and health. New York: Wiley \& Sons.

Miller, C. S., Dembo, J. B., Falace, D. A., \& Kaplan, A. L. (1995). Salivary cortisol response to dental treatment of varying stress. Oral Surgery, Oral Medicine, Oral Pathology, 79, 436-441.

Miller, S. M., \& Mangan, C. E. (1983). Interacting effects of information and coping style in adapting to gynecological stress: Should the doctor tell all? Journal of Personality and Social Psychology, 45, 223-236.

Mojon, P. (2002). Oral health and respiratory infection. Journal of the Canadian Dental Association, 68, 340-345.

Morse, D. R., Schacterle, G. R., Furst, L., \& Bose, K. (1981). Stress, relaxation, and saliva: A pilot study involving endodontic patients. Oral Surgery, Oral Medicine, Oral Pathology, 52, 308-313.

Mowrer, O. H. (1939). Stimulus response theory of anxiety. Psychological Review, 46, 553-565.

Mowrer, O. H. (1960). Learning theory and behavior. New York: John Wiley.

Muris, P., Jong, P. de., Zuuren, F. van, Horst, G. ter (1994). Coping style, anxiety, cognitions, and cognitive control in dental phobia. Personality and Individual Differences, 17, 549-566.

Naatanen, R. (1973). The inverted-U relationship between activation and performance: A critical review. In S. Kornblum (Ed.), Attention and performance (Vol. 4, pp. 155-174). San Diego, CA: Academic Press.

Neiss, R. (1988). Reconceptualizing arousal: Psychological states in motor performance. Psychological Bulletin, 103, 345-366.

Newman, J. F., \& Gift, H. C. (1992). Regular pattern of preventive dental service - A measure of access. Social Science and Medicine, 35, 997-1001.

Norton, P. J., \& Asmundson, G. J. G. (2003). Amending the fear-avoidance model of chronic pain: What is the role of physiological arousal? Behavior Therapy, 34, 17-30. 
Osman, A., Breitenstein, J. L., Barrios, F. X., Gutierrez, P. M., \& Kopper, B. A. (2002). The Fear of Pain Questionnaire-III: Further reliability and validity with nonclinical samples. Journal of Behavioral Medicine, 25, 155-173.

Palmero, T., \& Lambert, S. (1997). A descriptive study of children's beliefs concerning the use of analgesics in treating postoperative pain. Children's Health Care, 26, 47-59.

Peretz, B., \& Moshonov, J. (1998). Dental anxiety among patients undergoing endodontic treatment. Journal of Endodontics, 24, 435-437.

Peterson, R. A., \& Reiss, S. (1992). Anxiety Sensitivity Index Manual (2nd ed.). Worthington, OH: International Diagnostic Systems.

Quinn-Crandall, M., \& Lammers, C. R. (2002). Pre-operative pain education: Children and parents' perspectives [Abstract]. Pain Medicine, 3, 184-185.

Rachman, S. (1977). The conditioning theory of fear acquisition: A critical examination. Behaviour Research and Therapy, 15, 375-387.

Rachman, S. (1991). Neoconditioning and the classical theory of fear acquisition. Clinical Psychology Review, 11, 155-173.

Rachman, S., \& Lopatka, C. (1988). Accurate and inaccurate predictions of pain. Behaviour Research and Therapy, 26, 291-296.

Reading, A. E. (1979). The short term effects of psychological preparation for surgery. Social Science and Medicine, 13, 641-654.

Rees, C. E., Ford, J. E., \& Sheard, C. E. (2003). Patient information leaflets for prostate cancer: Which leaflets should healthcare professionals recommend? Patient Education and Counseling, 49, 263272.

Reiss, S., \& McNally, R. J. (1985). The expectancy model of fear. In S. Reiss, \& R. R. Bootzin (Eds.), Theoretical issues in behavior therapy (pp.107-122). New York: Academic Press.

Reiss, S., Peterson, R. A., Gursky, M., \& McNally, R. J. (1986). Anxiety, sensitivity, anxiety frequency, and the prediction of fearfulness. Behaviour Research and Therapy, 24, 1-8.

Reissland, N. (1983). Cognitive maturity and the experience of fear and pain in hospital. Social Science and Medicine, 17, 1389-1395 
Rescorla, R. A., \& Wagner, A. R. (1972). A theory of Pavlovian conditioning: Variations in the effectiveness of reinforcement and nonreinforcement. In A. H. Black \& W. F. Prokasy (Eds.), Classical conditioning II: Current research and theory (pp. 64-69). New York: Appleton-CenturyCrofts.

Rhudy, J. L., \& Meagher, M. W. (2000). Fear and anxiety: Divergent effects on human pain thresholds. Pain, 84, 65-75.

Rhudy, J. L., \& Meagher, M. W. (2001). Noise stress and human pain thresholds: Divergent effects in men and women. The Journal of Pain, 2, 57-64.

Riley, J. L., Robinson, M. E., Wise, E. A., Myers, C. D., \& Fillingim, R. B. (1998). Sex differences in the prediction of noxious experimental stimuli: A meta-analysis. Pain, 74, 181-187.

Rosenstiel, A. K., \& Keefe, F. J. (1983). The use of coping strategies in chronic low back pain patients: Relationship to patient characteristics and current adjustment. Pain, 17, 33-44.

Ruel-Kellermann, M. (1984). What are the psychological factors involved in motivating individuals to retain their teeth? Dreams and facts. International Dental Journal, 34, 105-109.

Sanders, S. H. (2002). Operant conditioning with chronic pain: Back to basics. In D. Turk \& D. Gatchel (Eds.), Psychological approaches to pain management: A practitioner's handbook ( $2^{\text {nd }} \mathrm{ed} ., \mathrm{pp}$. 128-137). NY: Guilford Press.

Saxen, M. A., \& Newton, C. W. (1999). Managing the endodontic patient with disabling anxiety or phobia. Journal of the Indiana Dental Association, 78, 21-23.

Shapiro, D. H., Schwartz, C. E., \& Astin, J. A. (1996). Controlling ourselves, controlling our world: Psychologys role in understanding positive and negative consequences of seeking and gaining control. American Psychologist, 51, 1213-1230.

Schmidt, N. B. (1999). Examination of differential anxiety sensitivities in panic disorder: A test of anxiety sensitivity subdomains in predicting fearful responding to a $35 \% \mathrm{CO}_{2}$ challenge. Cognitive Therapy and Research, 23, 3-19.

Schmidt, N. B., \& Cook, J. (1999). Effects of anxiety sensitivity on anxiety and pain during a cold pressor challenge in patients with panic disorder. Behaviour Research and Therapy, 37, 313-323. 
Schuurs, A. H. B., Duivenvoorden, H. J., Thoden van Velzen, S. K., \& Verhage, F. (1980). Three factors predicting irregular versus regular dental attendance: A model fitting to empirical data. Community Dentistry and Oral Epidemiology, 8, 413-419.

Seligman, M. E. P. (1971). Phobias and preparedness. Behavior Therapy, 2, 307-320.

Seyrek, S. K., Corah, N. L., \& Pace, L. F. (1984). Comparison of three distraction techniques in reducing stress in dental patients. Journal of the American Dental Association, 108, 327-329.

Smith, T. A., Thompson, J. A., \& Lee, W. E. (1993). Assessing patient pain during dental laser treatment. Journal of the American Dental Association, 124, 90-95.

Soh, G. (1992). Effects of explanation of treatment procedures on dental fear. Clinical Preventive Dentistry, 14, 10-13.

Sorrell, J. T., \& McNeil, D. W. (2003). Fear of pain in dentistry: A critical review. Manuscript in preparation.

Sorrell, J. T., McNeil, D. W., Vowles, K. E., Broadman, L. M., Hursey, K. G., Huber, S. J., Vaglienti, R. M., \& Kennedy, S. G. (2001, March). Effects of Pain and Fear Stimulus Intensity on Pain Responding in Chronic Pain Patients. Poster presented at the Society for Behavioral Medicine Conference, Seattle, WA.

Spafford, P. A., von Baeyer, C. L., \& Hicks, C. L. (2002). Expected and reported pain in children undergoing ear piercing: A randomized trial of preparation by parents. Behaviour Research and Therapy, 40, 253-266.

Sperry-Clark, J. A., McNeil, D. W., \& Ciano-Federoff, L. (1999). Assessing chronic pain patients: The Fear of Pain Questionnaire - III (pp. 293-305). In L. Vandercreek and T. L. Jackson (Eds.), Innovations in Clinical Practice: A Source Book. Sarasota, FL. Professional Resources Press.

Stabholz, A., \& Peretz, B. (1999). Dental anxiety among patients prior to different dental treatments. International Dental Journal, 49, 90-94.

Staub, E., \& Kellett, D. S. (1972). Increasing pain tolerance by information about aversive stimuli. Journal of Personality and Social Psychology, 21, 198-203.

Staub, E., Tursky, B., \& Schwartz, G. E. (1971). Self-control and predictability: Their effects on reactions to aversive stimulation. Journal of Personality and Social Psychology, 18, 157-162.

Stein, M. B., Jang, K. L., \& Livesley, W. J. (1999). Heritability of anxiety sensitivity: A twin study. American Journal of Psychiatry, 156, 246-251. 
Sullivan, M. J. L., \& Neish, N. R. (1998). Catastrophizing, anxiety and pain during dental hygiene treatment. Community Dentistry and Oral Epidemiology, 26, 344-349.

Sullivan, M. J. L., Rodgers, W. M., Wilson, P. M., Bell, G. J., Murray, T. C., \& Fraser, S. N. (2002). An experimental investigation of the relation between catastrophizing and activity intolerance. Pain, $100,47-53$

Suls, J., \& Fletcher, B. (1985). The relative efficacy of avoidant and nonavoidant coping strategies: A meta-analysis. Health Psychology, 4, 249-288.

Surgical Update (1987). Guidelines for the management and treatment of dental pain. American Association of Oral and Maxillofacial Surgeons Surgical Update, 3, 2-4.

Turk, D. C., \& Monarch, E. S. (2002). Biopsychosocial perspective on chronic pain. In D. Turk \& D. Gatchel (Eds.), Psychological approaches to pain management: A practitioner's handbook $\left(2^{\text {nd }}\right.$ ed., pp. 128-137). NY: Guilford Press.

Turk, D. C., \& Rudy, T. E. (1987). Toward a comprehensive assessment of chronic pain patients. Behaviour Research and Therapy, 25, 237-245.

van Buren, J., \& Kleinknecht, R. A. (1979). An evaluation of the McGill Pain Questionnaire for use in dental pain assessment. Pain, 6, 23-33.

van Wijk, A. J., \& Hoogstraten, J. (2003). The Fear of Dental Pain Questionnaire: Construction and validity. European Journal of Oral Science, 111, 12-18.

Vassend, O. (1993). Anxiety, pain and discomfort associated with dental treatment. Behaviour Research and Therapy, 31, 659-666.

Vlaeyen, J. W. S., Jong, J. de, Geilen, M., Heuts, P. H. T. G., \& Breukelen, G. van (2001). Graded exposure in vivo in the treatment of pain-related fear: A replicated single-case experimental design in four patients with chronic low back pain. Behaviour Research and Therapy, 39, 151166.

Vlaeyen, J. W. S., Jong, J. de., Sieben, J., \& Crombez, G. (2002). Graded exposure in vivo for painrelated fear. In D. Turk \& D. Gatchel (Eds.), Psychological approaches to pain management: A practitioner handbook ( $2^{\text {nd }}$ ed., pp. 210-233). NY: Guilford Press. 
Vlaeyen, J. W. S., Kole-Snijders, A. M. J., Boeren, R. G. B., \& Eek, H. V. (1995). Fear of movement/(re)injury in chronic low back pain and its relation to behavioral performance. Pain, 62, 363-372.

Vlaeyen, J. W. S., \& Linton, S. J. (2000). Fear-avoidance and its consequences in chronic musculoskeletal pain: A state of the art. Pain, 85, 317-332.

Vowles, K. E., \& Gross, R. T. (2003). Work-related beliefs about injury and physical activity capability for work in individuals with chronic pain. Pain, 101, 291-298.

Vowles, K. E., McNeil, D. W., Sorrell, J. T., \& Lawrence, S. M. (2003). Fear and pain: Which one is worse? Manuscript submitted to Journal of Abnormal Psychology.

Vowles, K. E., McNeil, D. W., Sorrell, J. T., McKee, D. R., Zvolensky, M. J., Graves, R. W., Weaver, B. D., Riel, J. R., \& Lawrence, S. M. (2001, March). Relation among fear, anxiety, and appointment adherence in oral surgery patients. Poster presented at the Society for Behavioral Medicine Conference, Seattle, WA.

Waddell, G., Newton, M., Henderson, I., Somerville, D., \& Main, C. (1993). A fear-avoidance beliefs questionnaire (FABQ) and of fear-avoidance beliefs in chronic low back pain and disability. Pain, $52,157-168$.

Wall, P. D., \& Melzack, R. (Eds.). (1994). Textbook of pain. ( $3^{\text {rd }}$ ed.) Edinburgh: Churchill Livingstone. Watson, D., \& Pennebaker, J. W. (1989). Health complaints, stress, and distress: Exploring the central role of negative affectivity. Psychological Review, 96, 234-254.

Widstrom, E., \& Martinsson, T. (1980). Social background and dental care habits and attitudes of Finnish immigrants in Sweden. Community Dentistry and Oral Epidemiology, 8, 407-412.

Williams, D. (1996). Acute pain management. In D. Gatchel \& D. Turk (Eds.), Psychological approaches to pain management: A practitioner's handbook (pp. 55-77). NY: Guilford Press.

Weinstein, P. (1990). Breaking the worldwide cycle of pain, fear, and avoidance: Uncovering risk factors and promoting prevention for children. Annals of Behavioral Medicine, 12, 141-147.

Wong, M, \& Jacobsen, P. (1992). Reasons for local anesthesia failures. Journal of the American Dental Association, 123, 69-73.

Wong, M., \& Lytle, W. (1991). A comparison of anxiety levels associated with root canal therapy and oral surgery treatment. Journal of Endodontics, 17, 461-465. 
Yerkes, R. M., \& Dodson, J. D. (1908). The relation of strength of stimulus to rapidity of habit formation. Journal of Comparative Neurological Psychology, 18, 459-482.

Zinbarg, R. E., (1998). Concordance and synchrony in measures of anxiety and panic reconsidered: A hierarchical model of anxiety and panic. Behaviour Research and Therapy, 29, 301-323.

Zvolensky, M. J., \& Eifert, G. H. (2001). A review of psychological factors/processes affecting anxious responding during voluntary hyperventilation and inhalations of carbon dioxide-enriched air. Clinical Psychology Review, 21, 375-400.

Zvolensky, M. J., Goodie, J. L., McNeil, D. W., Sperry, J. S., \& Sorrell, J. T. (2001). Anxiety sensitivity in the prediction of pain-related fear and anxiety in a heterogeneous chronic pain population. Behaviour Research and Therapy, 39, 683-696.

Zvolensky, M. J., Lejuez, C. W., \& Eifert, G. H. (2000). Prediction and control: Operational definitions for the experimental analysis of anxiety. Behaviour Research and Therapy, 38, 653-663. 


\author{
Appendix A \\ Oral Hygiene Video \\ "Taking Care of your Teeth and Gums" \\ Total running time: 248 seconds $=4$ mins $\& 8 \mathrm{sec}$ \\ Total \# of animation scenes: 5 \\ Total animation time: $66 \mathrm{sec}$ \\ Total \# of words: 625
}

1. "The way to care for your teeth and gums is with brushing twice a day and flossing every day.

2. An ideal way to brush is to hold the toothbrush at an angle to your teeth. The correct angle is about 45 degrees.

3. Use short strokes and move the brush back and forth with gentle motions.

4. Brush the inside of the top and bottom of the tooth surfaces of the parts that are closest to your tongue. Brush the top of your teeth along the chewing surface. Then brush the outside of your teeth, both top and bottom.

5. The final step in good brushing technique is to brush your tongue. After 3 to 4 months replace your toothbrush with a new one, and look for a brush with soft bristles.

6. There's another important part of caring for your teeth and gums. Each day use floss or an interdental cleaner to remove plaque and food particles from between your teeth.

7. Break off about 18 inches of floss and wind most of it around your middle finger. Wind what's left of the floss around the middle finger of your other hand so you can take up the floss as you use it.

8. Hold the floss firmly between your thumb and forefinger with about an inch of floss between them so there is no slack. Use a gentle motion to guide the floss between your teeth.

9. Move it back and forth with a rubbing motion. Be careful not to injure your mouth by jerking or snapping the floss into your gums.

10. Right there where the floss contacts your gum line, curve it against one tooth. Slide the floss gently into the space between your gum and tooth until you feel resistance. Hold the floss against your tooth and gently rub the side of the tooth so you are moving the floss away from the gum.

11. Be sure to floss the back of the last tooth where plaque can collect.

12. When you $1^{\text {st }}$ start flossing everyday, you may have sore gums for the $1^{\text {st }} 5$ days or so. That should disappear after flossing breaks up the plaque and gets rid of the bacteria build up on your teeth.

13. Remember that flossing is an important part of caring for your teeth and gums.

14. The key to a program of good oral hygiene is to set up a brushing and flossing routine that you can stick with. Brush at least twice a day with a flouride toothpaste. Use one that has the seal of acceptance from the American Dental Association. 


\section{Appendix A (con't)}

15. Hold the toothbrush at a 45 degree angle to your teeth. Move the brush back and forth in short gentle strokes. Brush the inner tooth surfaces. Brush the chewing surfaces. And brush the inside of your front teeth. Finish by brushing your tongue.

16. Once a day, remove food particles by using floss or inter-dental cleaner to clean where your toothbrush can't reach.

17. Wind about 18 inches of floss around your middle finger. Guide the floss between your teeth. When the floss reaches your gum line, rub the sides of the teeth.

18. Don't forget to floss the back of your last tooth to remove plaque.

19. Eat a balanced diet and limit snacks between meals. Get regular check-ups by your dentist. And have your teeth cleaned periodically by a dental professional. If your gums bleed in spite of daily flossing, see your dentist.

20. With brushing, flossing, and the other components of good oral hygiene, you can keep your smile for a lifetime."

Note: Copyright by American Dental Association, 1998. 


\author{
Appendix B \\ Endodontic Procedure Video \\ "Root Canal Procedure" \\ Total running time: 273 seconds $=4$ mins $\& 33 \mathrm{sec}$ \\ Total \# of animation scenes: 3
}

Total amount of animation time: $100 \mathrm{sec}$

Total \# of words: 765

1. "A pleasant smile is one of the most important elements of anyone's appearance.

2. Healthy teeth are the key to that smile.

3. Root canal treatment is an important part of dental healthcare for many people.

4. You probably have a number of questions about the procedure. Why has your dentist recommended it, what does it involve, how long will it take? How will root canal treatment affect the long-term health of your teeth and your smile.

5. Root canal treatment can safely and comfortable save a tooth that otherwise would have to be removed. In fact, the procedure is successful about $90 \%$ of the time. Keep in mind that a healthy restored tooth is always better than an artificial one.

6. If you have more questions about the procedure, your dentist will be happy to answer them. Root canal treatment can preserve your teeth and save an important asset, your own unique smile.

7. Each year 100 s of 1000 s of people under go root canal treatment to preserve their teeth.

8. The procedure is design to help you keep the tooth that otherwise is virtually certain to be lost to oral disease. Root canal treatment can save the tooth and preserve your smile. You may wonder, when a tooth is in trouble, why not just remove it?

9. Your teeth, both up and lower, are like members of a team. Each is unique and important with its own job to do. Unless you replace that lost tooth, the teeth near it will begin to move out of alignment. You could loss other teeth too. Replacing your own tooth with a bridge or an implant is much more complex than preserving that tooth with root canal treatment.

10. You're probably wondering why has your dentist has recommended root canal treatment. Because there is an inflamed tissue or in infection inside your tooth. An infection that is destroying the tooth from the inside.

11. Deep in the tooth is what's called the dental pulp, it contains blood vessels, nerves, and lymphatic vessels that nourish the tooth and keep it strong. Sometimes, though, the tooth is injured or becomes decayed. When this happens, the pulp invariably becomes inflamed. If bacteria gets inside and infection occurs, unless the infected pulp is removed, that infection will spread and destroy the bone tissue around the tooth.

12. Without Root canal treatment, sooner or later the tooth will have to be removed.

13. What's involved in removing the pulp and stopping the inflammation or infection? That's where root canal treatment comes in. The procedure involves several steps. First, the dentist administers local anesthesia and places a sheet of rubber around your tooth to protect it and isolate it from the rest of your mouth. 
Appendix B (con't)

14. Then the dentist enters the tooth through the crown and carefully removes the inflamed or infected pulp from both the pulp chamber and root canals. The dentist cleans, enlarges, and shapes the root canals. The dentist may apply medication between the root canals to prevent infections between appointments and allow the tooth to heal. When that's done, the dentist puts in a temporary filling to protect the crown of the tooth. During the next appointment, the dentist removes the temporary filling and re-enters the tooth. The pulp chambers and the root canals are cleaned once again. And this time they are filled and sealed permanently with a material that will prevent bacteria from re-entering the canals. At a later appointment, the dentist applies a protective crown over the tooth.

15. If the tooth that has been treated is a back tooth, the crown is made up of material specially chosen for strength. For a front tooth, the crown is designed to match your natural tooth color and preserve your appearance.

16. Is root canal painful? Thanks to today's anesthetic techniques it should be no more uncomfortable than any other dental procedure.

17. If you experience any post-operative discomfort in the 2 to 4 days after root canal treatment, contact your dentist immediately.

18. How long does it take to complete root canal treatment? Usually it can be finished up in 1 to 3 appointments.

19. Remember that, even though the treatment is complex, it is simpler and easier than if a tooth was extracted and replaced with an artificial tooth. Each of your own teeth, like your own smile, is precious. "

Note: Copyright by American Dental Association, 1998. 


\author{
Appendix C \\ Fear of Dental Pain Video \\ "Reducing Fear about Pain in Root Canal Therapy" \\ Total running time: $300 \mathrm{sec}=5$ mins \\ Total \# of animations: 3 \\ Total animation time: $96 \mathrm{sec}$ \\ Total \# of words: 662
}

1. "Strong, healthy teeth are an important part of overall health, and serve vital functions in eating, talking, and smiling.

2. It is essential to care for your teeth to preserve their natural strength, your overall oral health, and your smile.

3. Sometimes, however, a tooth may become damaged or diseased, and will need root canal therapy in order to keep it.

4. Although root canal treatment can be an important part of dental health care, many individuals are afraid of it because they expect pain and other discomfort during the procedure.

5. One of the main reasons people expect pain during root canal treatment has to do with misconceptions about it portrayed in television, radio, and newspapers. Many people mistakenly believe that pain and root canal therapy go hand in hand. In reality, root canal therapy is similar to many other dental procedures. With today's technologies, distress during this dental treatment is minimized and even prevented. There are a few important points about the treatment that can help you know realistically what to expect.

6. The most discomfort typically experienced during root canal treatment occurs BEFORE the procedure even begins.

7. As your dentist administers an anesthetic one or more times, you may experience a "pinch" or some "pressure," but those sensations will go away within a few seconds. Then, usually within five minutes, the anesthesia will numb the affected tooth and the tissue around it. Treatment will begin only after numbness occurs. You may feel vibrations for a period of time during root canal therapy.

8. Some patients do not experience any distress at all during root canal treatment. Others experience slight discomfort, however, those sensations are normal and the anesthesia minimizes any significant pain. Remember, the treatment you receive will greatly reduce the possibility of future problems with the affected tooth.

9. Some important points for you to remember about root canal therapy include the following: First, the most uncomfortable part of root canal therapy is BEFORE the treatment even begins. Second, you may feel a "pinch" or "pressure" sensation as the anesthetic is slowly administered. Third, it is usually within 5 minutes that the anesthetic will take effect, and only then will the procedure begin. Fourth, the anesthetic will thoroughly numb the affected tooth and the tissue around it. Fifth, during root canal therapy, it is normal to experience sensations of vibration. Nevertheless, the anesthetic should help to prevent pain or distress.

10. Any discomfort you MAY experience during root canal therapy is temporary. Usually, after the anesthetic has been administered, uncomfortable sensations go away. 


\section{Appendix C (con't)}

11. You can and should tell your dentist if you experience any significant distress or uncomfortable sensations during root canal therapy. After the initial anesthesia, other techniques are available, if necessary, to provide you the greatest comfort.

12. Remember, the anesthesia used for root canal treatment is very effective! Dentists receive special training about the best ways to administer anesthesia.

13. Slight soreness after the procedure is not unexpected, but it should go away in a day or two. If you have any significant discomfort, pain, or swelling two to four days after root canal therapy, however, contact your dentist immediately.

14. Keep these five important points in mind while going through this procedure: First, the most uncomfortable part of root canal therapy is BEFORE treatment. Second, temporary "pinch" or "pressure" sensations MAY be felt when the anesthetic is being given. Third, the anesthetic typically takes effect within five minutes. Fourth, the anesthetic will numb the affected tooth and tissue around it. Fifth, while you may experience sensations of vibration during the procedure, the anesthetic will help to prevent pain. Remembering these five points will help make your overall experience more comfortable and enjoyable; your teeth and smile will both be healthier for it.

15. You should feel proud knowing that you have chosen to receive root canal therapy, a restorative dental treatment that can help you maintain your strong, natural, healthy teeth."

Note: Copyright by West Virginia University School of Dentistry, 2002. 


\section{Appendix D}

Dental Knowledge Inventory
1. What is an ideal angle to hold your toothbrush when brushing your teeth?
a) About a 90 degree angle
b) About a 45 degree angle
c) About a 25 degree angle
d) About a 65 degree angle

2. Root canal treatment is successful about what percent of the time?
a) $85 \%$
b) $90 \%$
c) $95 \%$
d) $98 \%$

3. What is one reason that dentists refer patients for root canal treatment?

a) The root of a tooth has become diseased and needs to be replaced with an implant.

b) The root of the tooth has become decayed and needs to be removed and replaced with a filling.

c) There is inflamed tissue and/or an infection inside a tooth that needs treatment.

d) A cavity inside a tooth needs to be treated.

4. What sensations are most people likely to experience when anesthetic is administered during root canal treatment?
a) Sharp or stabbing
b) Pinching or pressing
c) Flashing or throbbing
d) Penetrating or piercing

5. How long does it usually take for the anesthesia used in root canal therapy to begin working?
a) Immediately
b) Within 10 minutes
c) Within 5 minutes
d) Within 15 minutes

6. What is the final step in good tooth brushing technique?
a) Brush your tongue
b) Brush the inside portions of your cheeks
c) Brush your gums
d) Brush your teeth again with fresh toothpaste

7. How long does it take to complete root canal treatment?
a) 2-4 appointments
b) 1-3 appointments
c) 3-5 appointments
d) Only 1 appointment

8. When you first start flossing every day, how long should you expect your gums to be sore?
a) For the first 5 days
b) For the first 10 days
c) For the first 2 days
d) For the first 7 days

9. When is the most discomfort typically experienced during root canal treatment?
a) Before treatment even begins
b) When the infected pulp is removed
c) During the administration of anesthesia
d) During drilling the infected tooth

10. What total length of dental floss should you first pull out when flossing?
a) About 24 inches
b) About 10 inches
c) About 14 inches
d) About 18 inches

11. What is the material called deep inside teeth that contains blood vessels, nerves, and lymphatic vessels?
a) Enamel
b) Dentin
c) Gingiva
d) Pulp

12. Where is numbness present once the anesthesia used for root canal therapy has been administered?

a) Immediately surrounding the infected tooth

b) Within the pulp of the infected tooth

c) In the tissue surrounding the infected tooth

d) In the tissue and teeth surrounding the infected tooth

13. What sensations might you experience during root canal treatment?
a) Scraping
b) Pulling
c) Probing
d) Vibration

14. How often should you replace your toothbrush?

a) Every month

b) Every 2 months

c) Every 3-4 months

d) Every 5-6 months

15. What should you do if you experience post-operative discomfort in the 2 to 4 days after root canal treatment?

a) Call your dentist after the $5^{\text {th }}$ day

b) Call your dentist after the $4^{\text {th }}$ day

c) Call your dentist immediately

d) Call your dentist after the $7^{\text {th }}$ day

Note: Bolded/italicized answers indicate the correct response to each question. 


\section{Appendix E}

ANOVA Table for Pre- and Post-Video Scores on the DKI in Experiment 1

\begin{tabular}{|c|c|c|c|}
\hline Effects & $\underline{\mathrm{df}}$ & $\underline{F}$ & $\underline{p}$ \\
\hline$S \times T \times G$ & 4 & 198.46 & .001 \\
\hline$S \times G$ & 4 & 84.14 & .001 \\
\hline$S \times T$ & 2 & 2.10 & .12 \\
\hline $\mathrm{T} \times \mathrm{G}$ & 2 & 1.08 & .34 \\
\hline$S$ & 2 & .68 & .51 \\
\hline $\mathrm{T}$ & 1 & 7.39 & .001 \\
\hline$G$ & 2 & 8.51 & .001 \\
\hline
\end{tabular}

Note. $N=268 . S=$ Subscale; $T=$ Time of assessment; $\mathrm{G}=$ Group 


\section{Appendix F}

Numeric Rating Scale

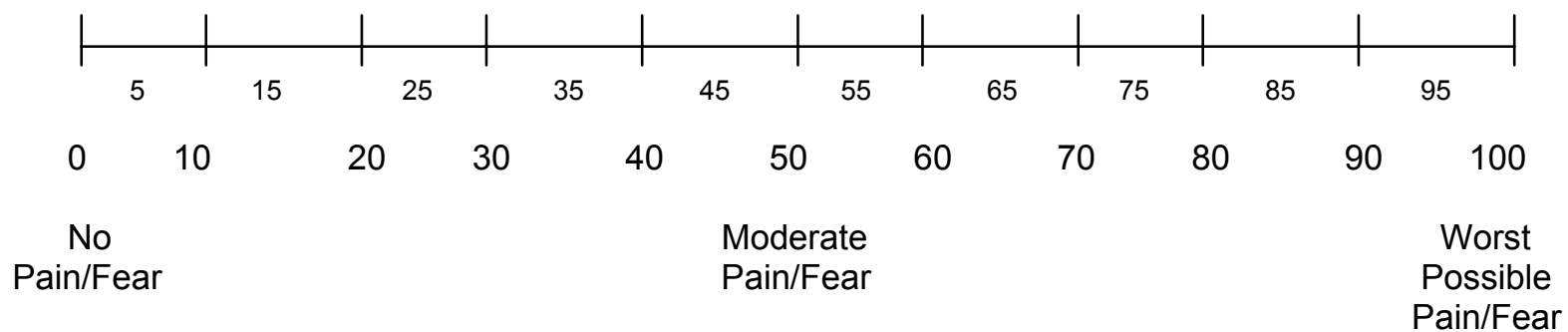




\section{Appendix G \\ Procedural Flow}

1. Patient recruitment: Approached in the waiting room prior to treatment.

2. Patient to the clinic: Study described and informed consent obtained.

3. Fear \& Pain Rating 1: Current fear and pain ratings recorded.

4. Heart rate pre-baseline: 5-mins of pre-procedural baseline.

5. $\quad$ Fear \& Pain Rating 2: Current fear and pain ratings recorded.

6. Knowledge test \#1: Pre-information test using Dental Knowledge Inventory.

7. Information: 5-minute informational video shown.

8. Knowledge test \#2: Post-information test using Dental Knowledge Inventory.

9. $\quad$ Fear \& Pain Rating 3: Current fear and pain ratings recorded.

10. Root canal procedure: Patients receive treatment "as usual" while heart rate is monitored.

11. Fear \& Pain Ratings 4: Current fear and pain ratings obtained after injections, drilling, and shaping and cleaning of canals.

12. Fear \& Pain Ratings 5: Current fear and pain ratings recorded after dentist declares procedure is over.

13. Patient transfer: Patient transferred to another room to complete trait questionnaires.

14. Fear \& Pain Ratings 6: Current fear and pain ratings recorded.

15. Questionnaires completed: FPQ-III, DFS, ASI, and MBSS.

16. Heart rate post-baseline: 5-mins of post-study baseline.

17. Fear \& Pain Ratings 7: Current fear and pain ratings recorded.

18. Debriefing: Purpose of the study explained and participation payment.

19. Telephone Follow-up: Patients telephoned; Current fear and pain ratings recorded; Remembered fear and pain ratings recorded. 


\section{Appendix $\mathrm{H}$}

ANOVA Table for Pre- and Post-Video Scores on the DKI in Experiment 2

\begin{tabular}{|c|c|c|c|}
\hline Effects & $\underline{\mathrm{df}}$ & $\underline{F}$ & $\underline{p}$ \\
\hline$S \times T \times G$ & 4 & 90.6 & .001 \\
\hline$S \times G$ & 4 & 27.61 & .001 \\
\hline$S \times T$ & 2 & .98 & .38 \\
\hline$T \times G$ & 2 & 1.57 & .21 \\
\hline$S$ & 2 & 11.28 & .001 \\
\hline $\mathrm{T}$ & 1 & 166.98 & .001 \\
\hline G & 2 & .79 & .46 \\
\hline
\end{tabular}

Note. $N=104 . S=$ Subscale; $T=$ Time of assessment; $G=$ Group 


\section{Appendix I}

ANOVA Table for Verbal Reports of Fear

\begin{tabular}{cccc}
\hline$\underline{\text { Effects }}$ & $\underline{\mathrm{df}}$ & $\underline{\mathrm{F}}$ & $\underline{\mathrm{p}}$ \\
\hline $\mathrm{T} \times \mathrm{G}$ & 6 & 1.25 & .28 \\
$\mathrm{~T}$ & 3 & & \\
$\mathrm{G}$ & & 43.33 & .001 \\
& 2 & .72 & .49 \\
\hline
\end{tabular}

Note: $N=104 . \mathrm{T}=$ Time; $\mathrm{G}=$ Group. 
Appendix $\mathrm{J}$

ANOVA Table for Verbal Reports of Pain

\begin{tabular}{cccc}
$\underline{\text { Effects }}$ & $\underline{\mathrm{df}}$ & $\underline{\mathrm{F}}$ & $\underline{\mathrm{p}}$ \\
\hline $\mathrm{T} \times \mathrm{G}$ & 6 & .76 & .59 \\
$\mathrm{~T}$ & 3 & 10.74 & .001 \\
$\mathrm{G}$ & 2 & & \\
& & 1.87 & .16 \\
\hline
\end{tabular}

Note: $N=104 . \mathrm{T}=$ Time; $\mathrm{G}=$ Group. 


\section{Appendix K}

ANOVA Table for Heart Rate Change Scores

\begin{tabular}{cccc}
\hline$\underline{\text { Effects }}$ & $\underline{\mathrm{df}}$ & $\underline{\mathrm{F}}$ & $\underline{\mathrm{p}}$ \\
\hline $\mathrm{T} \times \mathrm{G}$ & 4 & 1.38 & .24 \\
$\mathrm{~T}$ & 2 & & \\
$\mathrm{G}$ & & 6.66 & .001 \\
\hline
\end{tabular}

Note: $N=97 . \mathrm{T}=$ Time; $\mathrm{G}=$ Group . 
Appendix L

ANOVA Table for Fear Memory

\begin{tabular}{cccc}
\hline$\underline{\text { Effects }}$ & $\underline{\mathrm{df}}$ & $\underline{\mathrm{F}}$ & $\underline{\mathrm{p}}$ \\
\hline $\mathrm{T} \times \mathrm{G}$ & 2 & .59 & .56 \\
$\mathrm{~T}$ & 1 & & \\
$\mathrm{G}$ & 2 & 14.23 & .001 \\
& & 1.31 & .28 \\
\hline
\end{tabular}

Note: $N=90$. T $=$ Time; $\mathrm{G}=$ Group . 
Appendix M

ANOVA Table for Pain Memory

\begin{tabular}{cccc}
\hline$\underline{\text { Effects }}$ & $\underline{\mathrm{df}}$ & $\underline{\mathrm{F}}$ & $\underline{\mathrm{p}}$ \\
\hline $\mathrm{T} \times \mathrm{G}$ & 2 & 0.07 & .93 \\
$\mathrm{~T}$ & 1 & & \\
$\mathrm{G}$ & & 60.16 & .001 \\
\hline
\end{tabular}

Note: $N=90$. T $=$ Time; $\mathrm{G}=$ Group . 
Table 1.

Demographic summary for participants in Experiment 1.

Variable

Gender

Female

Male

Age

Asian-American

Hispanic-American

Other

Positive
(19.9)

246

6

5

Total N (Mean)

153

115

2

9

23
Root Canal Hx
$\%(\mathrm{SD})$

$57 \%$

$43 \%$

$92 \%$

$2 \%$

$2 \%$

$1 \%$

$3 \%$

$9 \%$

Note: $N=268$. 


\section{Table 2.}

Video content analysis.

\begin{tabular}{|c|c|c|c|}
\hline Video & $\begin{array}{l}\text { Total } \\
\text { Running Time }\end{array}$ & $\begin{array}{l}\text { Total \# of } \\
\text { Animation } \\
\text { Scenes (total time) }\end{array}$ & $\begin{array}{l}\text { Total \# of } \\
\text { Words }\end{array}$ \\
\hline Dental Hygiene & $4 \mathrm{~m} \mathrm{08s}$ & $5(1 \mathrm{~m} \mathrm{6s})$ & 625 \\
\hline Major Points: & \multicolumn{3}{|c|}{$\begin{array}{l}\text { 1. Proper angle to hold toothbrush. } \\
\text { 2. Final step when brushing. } \\
\text { 3. How long gums will be sore once flossing begins. } \\
\text { 4. Length of dental floss that should be used. } \\
\text { 5. Frequency of replacing toothbrush. }\end{array}$} \\
\hline
\end{tabular}

Root Canal Procedure

Major Points:
$4 m 33 s$

3 (1m 40s)

765

1. Rate of success for RC therapy.

2. Reasons for RC therapy.

3. Total length of RC treatment.

4. Description of pulp.

5. Follow-up adherence.
Fear of Dental Pain

Major Points:
$5 \mathrm{~m} \mathrm{00s}$

$$
3(1 \mathrm{~m} 36 \mathrm{~s})
$$

1. Sensations during injections.

2. Latency of anesthesia effects.

3. When discomfort typically is experienced.

4. Where numbness occurs after injections.

5. Sensations during pulp removal. 
Table 3.

Means and standard deviations for pre- and post-video DKI subscale scores in Experiment 1.

\begin{tabular}{|c|c|c|c|}
\hline \multirow[t]{2}{*}{ Group } & \multirow[t]{2}{*}{ Subscale } & \multicolumn{2}{|c|}{ Mean (SD) } \\
\hline & & Pre & Post \\
\hline \multirow[t]{3}{*}{ A } & Oral hygiene & $2.87(.98)^{a}$ & $4.71(.56)^{b}$ \\
\hline & Procedure & $3.00(1.04)^{a}$ & $2.09(1.23)^{\mathrm{a}}$ \\
\hline & Fear of dental pain & $3.27(1.08)^{a}$ & $2.26(1.15)^{a}$ \\
\hline \multirow[t]{3}{*}{ B } & Oral hygiene & $2.98(1.02)^{a}$ & $2.07(1.12)^{a}$ \\
\hline & Procedure & $2.89(1.17)^{a}$ & $4.17(.95)^{b}$ \\
\hline & Fear of dental pain & $2.81(1.17)^{a}$ & $1.96(.91)^{a}$ \\
\hline \multirow[t]{3}{*}{ C } & Oral hygiene & $3.16(1.06)^{a}$ & $2.21(1.10)^{a}$ \\
\hline & Procedure & $3.16(1.01)^{a}$ & $2.29(.93)^{a}$ \\
\hline & Fear of dental pain & $3.23(1.12)^{a}$ & $4.53(.69)^{b}$ \\
\hline
\end{tabular}

Note: $N=268 . \mathrm{A}=$ Oral hygiene video group; $\mathrm{B}=$ Root canal procedure video group; $\mathrm{C}=$ Fear of dental pain video group. Different superscripts indicate significant differences; $p<.05$. Range of possible scores for each subscale is 0 (none correct) to 5 (all five items correct). 
Table 4.

Demographic summary for participants in Experiment 2.

Variable

Gender

(\% Female)

(\% Male)

Age
(Mean [SD])
Ethnicity
(\% Caucasian)
(\% African-American)
(\% Asian-American)
(\% Other)

Root Canal Hx

(\% Positive)
WVU Clinic

$23 \%(n=24)$

$20 \%(n=21)$

39.7 [15.3]

$$
\begin{gathered}
40 \%(n=41) \\
1 \%(n=1) \\
1 \%(n=1) \\
2 \%(n=2)
\end{gathered}
$$

$27 \%(n=28)$
Private Clinic

$38 \%(n=39)$

$19 \%(n=20)$

47.1 [14.5]

$57 \%(n=59)$

- $\quad(n=0)$

- $\quad(n=0)$

- $\quad(n=0)$

$30 \%(n=31)$
Total

$60 \%(N=63)$

$40 \%(N=41)$
43.9 [15.3]

$97 \%(N=100)$

$1 \%(N=1)$

$1 \%(N=1)$

$1 \%(N=2)$

Note: $N=104$. 
Table 5.

Means and standard deviations for pre- and post-video DKI subscale scores in Experiment 2.

\begin{tabular}{|c|c|c|c|}
\hline \multirow[t]{2}{*}{ Group } & \multirow[t]{2}{*}{$\underline{\text { Subscale }}$} & \multicolumn{2}{|c|}{ Mean (SD) } \\
\hline & & $\underline{\text { Pre }}$ & Post \\
\hline \multirow[t]{3}{*}{ A } & Oral hygiene & $1.94(1.01)^{a}$ & $4.22(.94)^{b}$ \\
\hline & Procedure & $2.06(1.16)^{a}$ & $2.03(1.07)^{a}$ \\
\hline & Fear of dental pain & $2.11(1.10)^{a}$ & $2.00(1.08)^{a}$ \\
\hline \multirow[t]{3}{*}{ B } & Oral hygiene & $2.41(1.04)^{a}$ & $2.56(1.11)^{a}$ \\
\hline & Procedure & $2.66(1.06)^{a}$ & $4.49(.61)^{b}$ \\
\hline & Fear of dental pain & $2.89(.99)^{a}$ & $2.65(1.03)^{a}$ \\
\hline \multirow[t]{3}{*}{ C } & Oral hygiene & $2.22(1.01)^{a}$ & $2.16(1.08)^{a}$ \\
\hline & Procedure & $2.37(1.06)^{a}$ & $2.26(1.04)^{a}$ \\
\hline & Fear of dental pain & $2.19(1.08)^{a}$ & $4.68(.63)^{b}$ \\
\hline
\end{tabular}

Note: $N=104 . \mathrm{A}=$ Oral hygiene video group; $\mathrm{B}=$ Root canal procedure video group; $\mathrm{C}=$ Fear of dental pain video group. Different superscripts indicate significant differences; $p<.05$. Range of possible scores for each subscale is 0 (none correct) to 5 (all five items correct). 
Table 6

Means and standard deviations for verbal reports of fear in Experiment 2.

\begin{tabular}{|c|c|c|c|}
\hline Group & Fear Rating & Mean & (Standard Deviation) \\
\hline \multirow[t]{4}{*}{ A } & 1 & $30.31^{\mathrm{a}}$ & $(28.40)$ \\
\hline & 3 & $22.97^{a}$ & $(25.20)$ \\
\hline & 4 & $21.38^{a}$ & $(26.66)$ \\
\hline & 5 & $.63^{\mathrm{b}}$ & $(2.46)$ \\
\hline \multirow[t]{4}{*}{ B } & 1 & $32.63^{a}$ & $(30.74)$ \\
\hline & 3 & $29.14^{a}$ & $(30.26)$ \\
\hline & 4 & $27.60^{a}$ & $(31.16)$ \\
\hline & 5 & $4.74^{b}$ & (14.35) \\
\hline \multirow[t]{4}{*}{ C } & 1 & $29.32^{a}$ & $(30.19)$ \\
\hline & 3 & $26.76^{a}$ & $(30.60)$ \\
\hline & 4 & $32.49^{a}$ & (32.68) \\
\hline & 5 & $11.76^{b}$ & (23.22) \\
\hline \multirow[t]{4}{*}{ Total } & 1 & $30.74^{a}$ & (29.58) \\
\hline & 3 & $26.39^{a}$ & $(28.76)$ \\
\hline & 4 & $27.42^{a}$ & $(30.47)$ \\
\hline & 5 & $5.97^{b}$ & (16.72) \\
\hline
\end{tabular}

Note: $N=104 . \mathrm{A}=$ Oral hygiene video group; $\mathrm{B}=$ Root canal procedure video group; $\mathrm{C}=$ Fear of dental pain video group. Different superscripts indicate significant differences; $p<.05$. 


\section{Table 7}

Means and standard deviations verbal reports of pain in Experiment 2.

\begin{tabular}{|c|c|c|c|}
\hline Group & Pain Rating & Mean & (Standard Deviation) \\
\hline \multirow[t]{4}{*}{ A } & 1 & $14.16^{\mathrm{a}}$ & (20.98) \\
\hline & 3 & $12.44^{\mathrm{a}}$ & $(20.89)$ \\
\hline & 4 & $14.44^{a}$ & $(21.20)$ \\
\hline & 5 & $1.34^{b}$ & $(6.22)$ \\
\hline \multirow[t]{4}{*}{ B } & 1 & $10.06^{a}$ & (20.53) \\
\hline & 3 & $9.60^{a}$ & $(19.72)$ \\
\hline & 4 & $13.06^{a}$ & $(20.14)$ \\
\hline & 5 & $6.31^{b}$ & (19.96) \\
\hline \multirow[t]{4}{*}{ C } & 1 & $20.19^{a}$ & $(25.82)$ \\
\hline & 3 & $17.76^{a}$ & (23.99) \\
\hline & 4 & $20.84^{a}$ & $(28.44)$ \\
\hline & 5 & $7.57^{b}$ & (15.39) \\
\hline \multirow[t]{4}{*}{ Total } & 1 & $14.92^{\mathrm{a}}$ & (22.87) \\
\hline & 3 & $13.38^{a}$ & (21.74) \\
\hline & 4 & $16.25^{\mathrm{a}}$ & $(23.75)$ \\
\hline & 5 & $5.23^{b}$ & $(15.27)$ \\
\hline
\end{tabular}

Note: $N=104 . \mathrm{A}=$ Oral hygiene video group; $\mathrm{B}=$ Root canal procedure video group; $\mathrm{C}=$ Fear of dental pain video group. Different superscripts indicate significant differences; $p<.05$. 


\section{Table 8}

Means and standard deviations for heart rate change values.

\begin{tabular}{|c|c|c|c|}
\hline Group & $\underline{\text { Rating }}$ & Mean & (Standard Deviation) \\
\hline \multirow[t]{3}{*}{ A } & 1 & $-4.9^{b}$ & (6.5) \\
\hline & 2 & $-1.6^{a}$ & (11.0) \\
\hline & 3 & $-1.3^{a}$ & $(10.7)$ \\
\hline \multirow[t]{3}{*}{ B } & 1 & $-2.4^{b}$ & $(10.7)$ \\
\hline & 2 & $-0.9^{a}$ & $(8.2)$ \\
\hline & 3 & $-2.7^{b}$ & $(7.2)$ \\
\hline \multirow[t]{3}{*}{ C } & 1 & $-1.1^{b}$ & (6.6) \\
\hline & 2 & $1.5^{\mathrm{a}}$ & $(7.4)$ \\
\hline & 3 & $0.1^{\mathrm{a}}$ & (7.5) \\
\hline \multirow[t]{3}{*}{ Total } & 1 & $-2.7^{b}$ & $(8.0)$ \\
\hline & 2 & $-0.2^{a}$ & (8.9) \\
\hline & 3 & $-1.3^{a}$ & (8.5) \\
\hline
\end{tabular}

Note: $n=97 . \mathrm{A}=$ Oral hygiene video group; $\mathrm{B}=$ Root canal procedure video group; $\mathrm{C}=$ Fear of dental pain video group. 1 = Injection heart rate; 2 = Drilling heart rate; $3=$ Cleaning and shaping canal heart rate. Different superscripts indicate significant differences; $p<.05$. 
Table 9

Means and standard deviations for experienced fear during treatment and remembered fear at follow-up.

Group Mean (SD)

During Tx Follow-up

A

$17.72(23.79)^{a} \quad 32.48(30.65)^{b}$

B

$24.97(27.23)^{a}$

$31.94(29.88)^{b}$

C

$29.67(30.65)^{a}$

$41.53(31.77)^{b}$

Total

$24.20(27.54)^{a}$

$35.31(30.74)^{b}$

Note: $n=90 . \mathrm{A}=$ Oral hygiene video group; $\mathrm{B}=$ Root canal procedure video group; $\mathrm{C}=$ Fear of dental pain video group. Different superscripts indicate significant differences; $p<.05$. 


\section{Table 10}

Means and standard deviations for experienced pain during treatment and remembered pain at follow-up.

Group $\underline{\text { Mean (SD) }}$

$$
\text { During Tx }
$$

Follow-up

A

$$
15.24(21.93)^{a}
$$

$38.79(28.56)^{b}$

B

$14.10(21.13)^{a}$

$36.29(28.31)^{b}$

C

$18.17(28.28)^{a}$

$39.70(32.76)^{b}$

Total

$16.02(23.80)^{a}$

$38.23(29.64)^{b}$

Note: $n=90 . \mathrm{A}=$ Oral hygiene video group; $\mathrm{B}=$ Root canal procedure video group; $\mathrm{C}=$ Fear of dental pain video group. Different superscripts indicate significant differences; $p<.05$. 
Table 11

Means and Standard Deviations (SD) for the four self-report measures used in Experiment 2.

$\begin{array}{llll}\text { Measure } & \underline{\text { Scale }} & \underline{\text { Present Study }} & \text { Other Studie } \\ \text { FPQ-III } & & \underline{\text { Mean (SD) }} & \\ & \text { Severe } & 29.98(10.7) & 35.6(9.3)^{1} \\ & \text { Minor } & 18.10(6.3) & 21.3(7.6)^{1} \\ & \text { Medical/Dental } & 22.44(7.9) & 28.8(9.0)^{1} \\ & \text { Total } & 70.52(21.8) & 85.1(21.3)^{1}\end{array}$

DFS

$\begin{array}{lcc}\text { Avoidance } & 13.45(5.9) & 14.7(8.1)^{1} \\ \text { Physiological } & 10.5(3.9) & 10.5(4.6)^{1} \\ \text { Specific } & 13.73(6.1) & 17.7(6.9)^{1} \\ \text { Total } & 39.75(15.0) & 45.3(18.4)^{1}\end{array}$

ASI

Total $\quad 15.05(9.8) \quad 20.3(14.5)^{2}$

MBSS

$\begin{array}{lll}\text { Monitoring } & 9.83(3.1) & 9.7(2.6)^{3} \\ \text { Blunting } & 3.66(2.3) & 5.6(2.86)^{3}\end{array}$

Note: $N=104$. FPQ-III = Fear of Pain Questionnaire-III; DFS = Dental Fear Survey; ASI = Anxiety

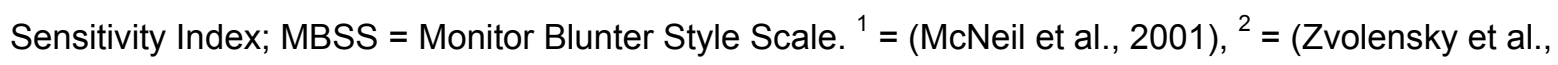
2001), ${ }^{3}=($ Miller, 1987). 
Table 12

Correlations among demographic, self-report measures, and fear and pain ratings before treatment.

\begin{tabular}{|c|c|c|c|c|c|c|c|c|c|c|c|c|c|c|c|c|}
\hline & 1 & 2 & 3 & 4 & 5 & 6 & 7 & 8 & 9 & 10 & 11 & 12 & 13 & 14 & 15 & 16 \\
\hline 1. Age & -- & -.17 & $.21^{*}$ & -.10 & -.12 & -.07 & -.11 & .02 & -.13 & -.14 & $-.24^{*}$ & -.19 & $-.22^{*}$ & $-.24^{*}$ & -.17 & $-.23^{*}$ \\
\hline 2. Gender & & -- & .19 & .11 & .16 & .10 & .18 & -.02 & .15 & $.25^{\star \star}$ & .19 & .11 & .18 & $.24^{*}$ & $.32^{* *}$ & .07 \\
\hline 3. $\mathrm{RC} \mathrm{Hx}$ & & & -- & -.05 & .11 & -.08 & .02 & -.04 & -.07 & .13 & -.06 & -.02 & -.13 & .02 & -.12 & -.05 \\
\hline 4. MB_M & & & & -- & .19 & $.22^{*}$ & .17 & .13 & .16 & .15 & .07 & .03 & .10 & .05 & .13 & -.04 \\
\hline 5. MB_B & & & & & -- & .10 & -.02 & -.08 & .01 & .01 & .11 & .10 & .07 & .10 & -.05 & -.10 \\
\hline 6. ASI & & & & & & -- & $.32^{* *}$ & $.35^{\star *}$ & $.31^{* *}$ & $.21^{*}$ & $.45^{\star \star}$ & $.31^{\star *}$ & $.45^{\star \star}$ & $.44^{\star *}$ & .05 & .04 \\
\hline 7. FPQ_T & & & & & & & -- & $.82^{* *}$ & $.88^{* *}$ & $.89^{* *}$ & $.37^{* *}$ & .19 & $.51^{\star \star}$ & $.27^{*}$ & $.22^{*}$ & -.07 \\
\hline 8. FPQ_M & & & & & & & & -- & $.68^{* *}$ & $.56^{\star \star}$ & $.24^{*}$ & .07 & $.39^{* *}$ & .16 & .10 & -.12 \\
\hline 9. FPQ_MD & & & & & & & & & -- & $.65^{\star *}$ & $.50^{* *}$ & $.29^{* *}$ & $.65^{* *}$ & $.33^{* *}$ & .12 & -.07 \\
\hline 10. FPQ_S & & & & & & & & & & -- & $.24^{*}$ & .12 & $.31^{*}$ & $.21^{*}$ & $.36^{* *}$ & .00 \\
\hline 11. DFS_T & & & & & & & & & & & -- & $.91^{* *}$ & $.90^{* *}$ & $.84^{* *}$ & $.57^{\star *}$ & $.20^{*}$ \\
\hline 12. DFS_A & & & & & & & & & & & & -- & $.69^{\star *}$ & $.69^{* *}$ & $.54^{\star *}$ & .17 \\
\hline 13. DFS_S & & & & & & & & & & & & & -- & $.65^{\star *}$ & $.45^{* *}$ & .13 \\
\hline 14. DFS_P & & & & & & & & & & & & & & -- & $.54^{* *}$ & $.25^{\star}$ \\
\hline 15. Fear & & & & & & & & & & & & & & & -- & $.19^{*}$ \\
\hline 16. Pain & & & & & & & & & & & & & & & & -- \\
\hline
\end{tabular}

Note. $N=$ 104. $\mathrm{RC} \mathrm{Hx}=$ Positive Root canal history; MB_M = Monitor Blunter Style Scale: Monitoring Scale; MB_M $=$ Monitor Blunter Style Scale: Blunting Scale; $A S I=$ Anxiety Sensitivity Index; FPQ_T = Fear of Pain Questionnaire - III: Total Score; FPQ_M = Fear of Pain Questionnaire - III: Minor Score; FPQ_MD = Fear of Pain Questionnaire III: Medical/Dental Score; FPQ_S = Fear of Pain Questionnaire - III: Severe Score; DFS_T = Dental Fear Survey: Total Score; DFS_A = Dental Fear Survey: Avoidance Score; DFS_S = Dental Fear Survey: Specific Dental Stimuli Score; DFS_P = Dental Fear Survey: Physiological Score; Fear $=\bar{V}$ erbal Report of Fear before Treatment; Pain = Verbal Report of Pain before Treatment. Males were coded as 1 and females were coded as 2.

* $p<.05$

** $p<.01$ 


\section{Table 13}

Summary of hierarchical regression analysis for variables predicting dental fear $(N=104)$.

\begin{tabular}{llll}
\hline Variable & B & SE B & $\beta$ \\
& & \\
\hline
\end{tabular}

Step 1

$\begin{array}{llll}\text { Age } & -.21 & .10 & -.22 \text { * } \\ \text { Gender } & 4.70 & 2.95 & .15\end{array}$

Step 2

$\begin{array}{lccc}\text { Age } & -.19 & .09 & -.19 \text { * } \\ \text { Gender } & 3.73 & 2.70 & .12 \\ \text { ASI Total } & .66 & .14 & .43 \text { * } \\ \text { MBSS_Mon } & -.26 & .43 & -.05\end{array}$

Step 3

\begin{tabular}{lccl} 
Age & -.18 & .09 & $-.18^{*}$ \\
Gender & 2.82 & 2.65 & .09 \\
ASI Total & .56 & .14 & $.37^{*}$ \\
MBSS_Mon & -.36 & .42 & -.08 \\
FPQ-III Total & .16 & .06 & .23 * \\
\hline
\end{tabular}

Note. ASI Total $=$ Anxiety Sensitivity Index Total Score; MBSS_Mon $=$ Miller Behavioral Style Scale Monitoring Subscale; FPQ-III Total = Fear of Pain Questionnaire-III Total Score. ${ }^{*} p<.05$. 
Table 14

Summary of hierarchical regression analysis for variables predicting verbal reports of fear before treatment $\underline{(N=104) .}$

\begin{tabular}{llll}
\hline Variable & B & SE B & $\beta$ \\
& & \\
\hline
\end{tabular}

Step 1

$\begin{array}{llll}\text { Age } & -.23 & .18 & -.12 \\ \text { Gender } & 18.11 & 5.72 & .30 \text { * }\end{array}$

Step 2

$\begin{array}{lccc}\text { Age } & -.02 & .16 & .01 \\ \text { Gender } & 12.48 & 4.91 & .21 \text { * } \\ \text { DFS Avoid } & -7.87 & 4.97 & -1.57 \\ \text { DFS Fear } & -9.30 & 4.85 & -1.93 \\ \text { DFS Physio } & -7.49 & 4.84 & -.98 \\ \text { DFS Total } & 8.91 & 4.58 & 4.52\end{array}$

Step 3

$\begin{array}{llll}\text { Age } & -.02 & .16 & -.01 \\ \text { Gender } & 15.48 & 4.97 & .26^{*} \\ \text { DFS Avoid } & -7.32 & 4.87 & -1.46 \\ \text { DFS Fear } & -10.08 & 4.74 & -2.09 * \\ \text { DFS Physio } & -7.13 & 4.73 & -.93 \\ \text { DFS Total } & 8.72 & 4.47 & 4.42 \\ \text { FPQ-III Severe } & -1.39 & .54 & -.50 * \\ \text { FPQ-III Total } & .76 & .29 & .56 * \\ \end{array}$

Note. DFS Avoid = Dental Fear Survey Avoidance Subscale; DFS Fear = Dental Fear Survey Fear of Specific Dental Stimuli Subscale; DFS Physio = Dental Fear Survey Physiological Subscale; FPQ-III Severe $=$ Fear of Pain Questionnaire-III Severe Subscale; FPQ-III Total = Fear of Pain Questionnaire-III Total Score. ${ }^{*} p<.05$. 
Table 15

Summary of hierarchical regression analysis for variables predicting verbal reports of pain before treatment $\underline{(N=104) .}$

\begin{tabular}{llll}
\hline Variable & B & SE B & $\beta$ \\
& & \\
\hline
\end{tabular}

Step 1

$\begin{array}{llll}\text { Age } & -.33 & .15 & -.22 \text { * } \\ \text { Gender } & 1.45 & 4.58 & .03\end{array}$

Step 2

$\begin{array}{llll}\text { Age } & -.28 & .15 & -.18 \\ \text { Gender } & -.12 & 4.73 & -.01 \\ \text { DFS Avoid } & 1.48 & 4.78 & .38 \\ \text { DFS Fear } & .96 & 4.66 & .26 \\ \text { DFS Physio } & 2.66 & 4.65 & .45 \\ \text { DFS Total } & -1.23 & 4.40 & -.80\end{array}$

Step 3

$\begin{array}{llll}\text { Age } & -.28 & .15 & -.18 \\ \text { Gender } & .59 & 4.90 & .01 \\ \text { DFS Avoid } & .93 & 4.80 & .24 \\ \text { DFS Fear } & 1.01 & 4.67 & .27 \\ \text { DFS Physio } & 2.32 & 4.66 & .39 \\ \text { DFS Total } & -.89 & 4.40 & -.58 \\ \text { FPQ-III Severe } & -.06 & .53 & -.03 \\ \text { FPQ-III Total } & -.15 & .29 & -.14 \\ \end{array}$

Note. DFS Avoid = Dental Fear Survey Avoidance Subscale; DFS Fear = Dental Fear Survey Fear of Specific Dental Stimuli Subscale; DFS Physio = Dental Fear Survey Physiological Subscale; FPQ-III Severe $=$ Fear of Pain Questionnaire-III Severe Subscale; FPQ-III Total = Fear of Pain Questionnaire-III Total Score. ${ }^{*} p<.05$. 


\section{Figure Captions}

Figure 1. Mean scores on DKI subscales across groups in Experiment 1.

Figure 2. Mean scores on DKI subscales across groups in Experiment 2.

Figure 3. Mean verbal reports of fear for Experiment 2.

Figure 4. Mean verbal reports of pain for Experiment 2.

Figure 5. Mean heart rate change scores for Experiment 2.

Figure 6. Mean verbal reports of fear experienced during treatment and remembered at follow-up.

Figure 7. Mean verbal reports of pain experienced during treatment and remembered at follow-up. 
Figure 1.

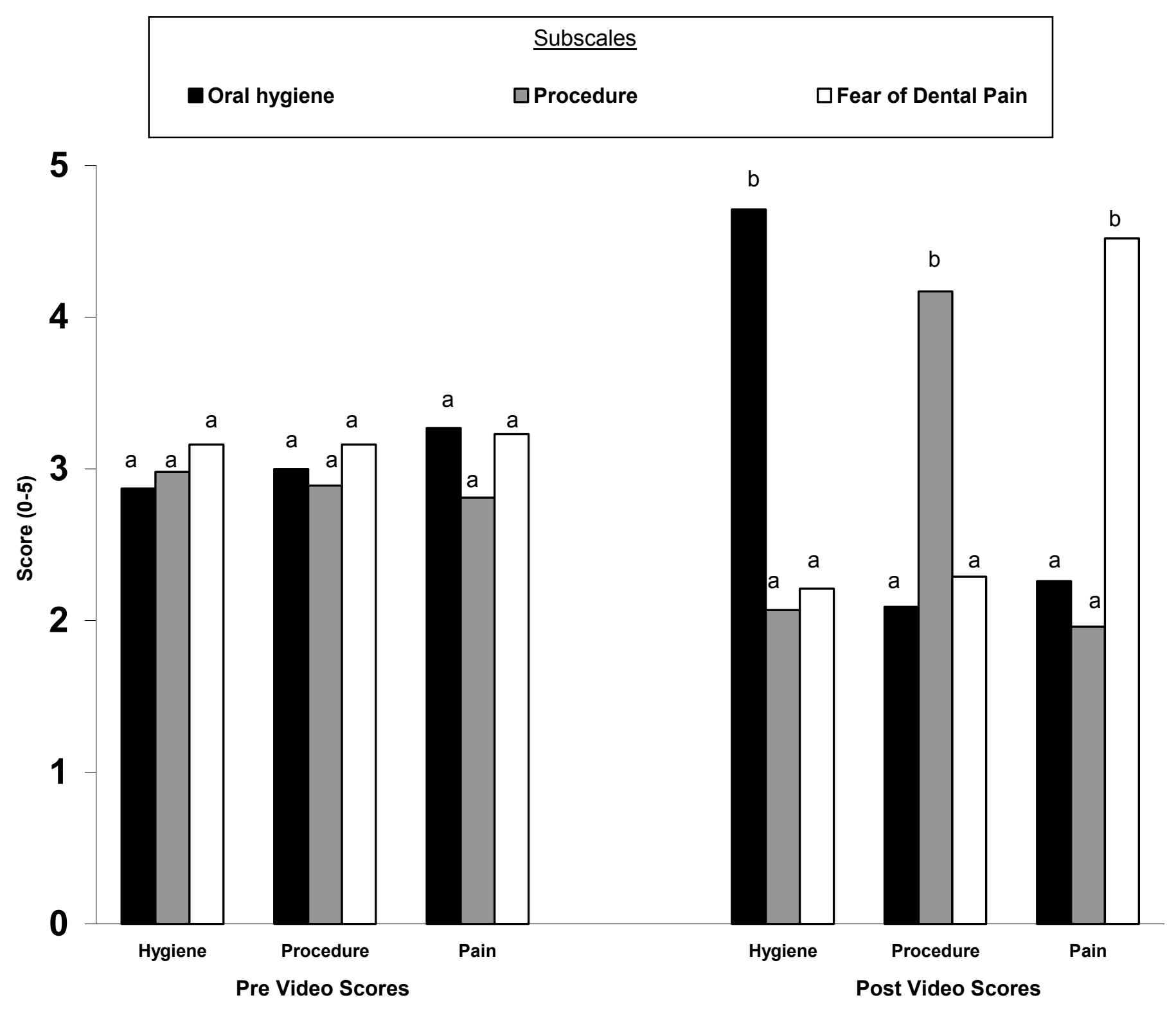

Note: $N=104$. Different superscripts indicate significant differences, $p<.05$. 
Figure 2.

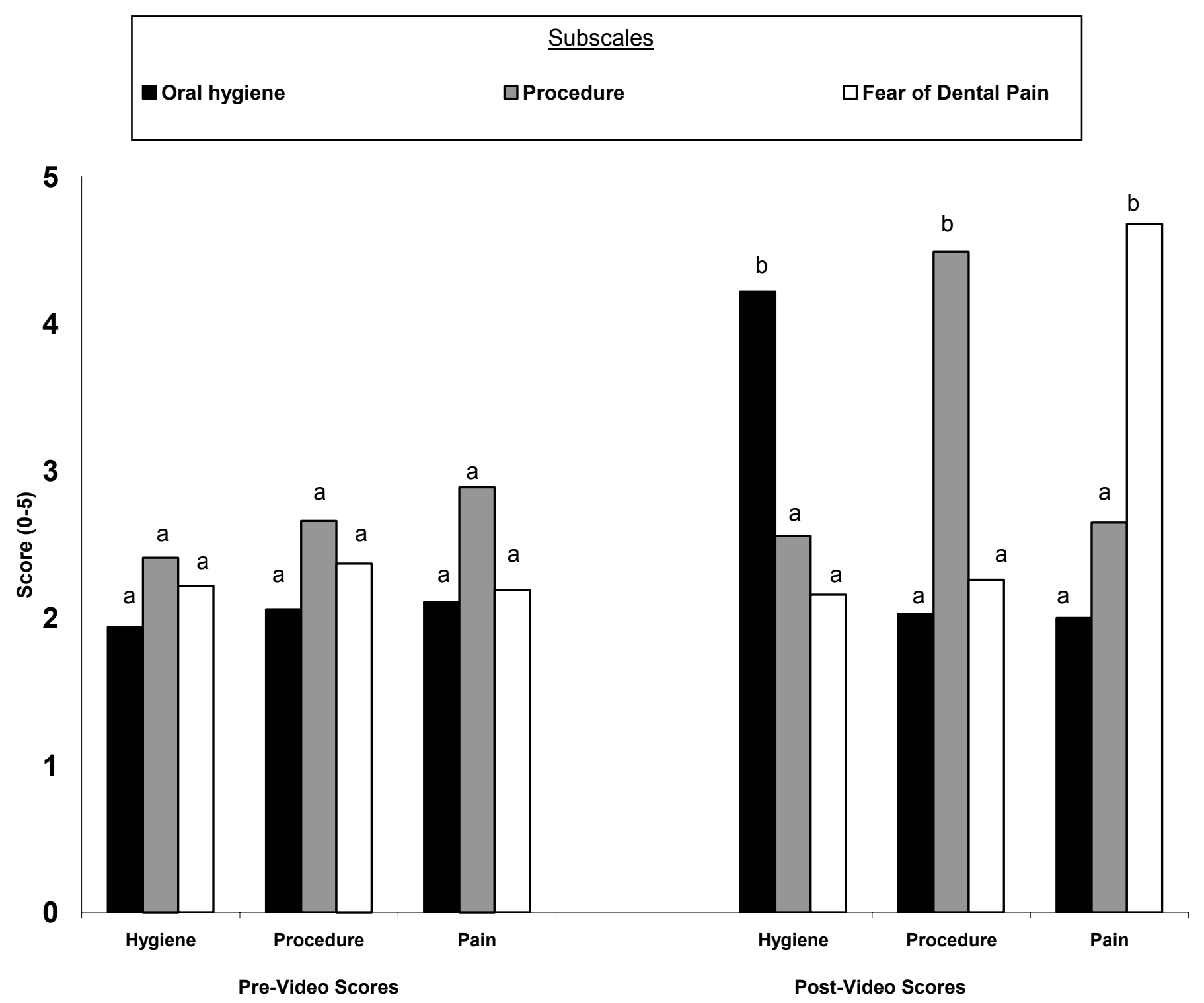

Note: $N=104$. Different superscripts indicate significant differences, $p<.05$. 
Figure 3.

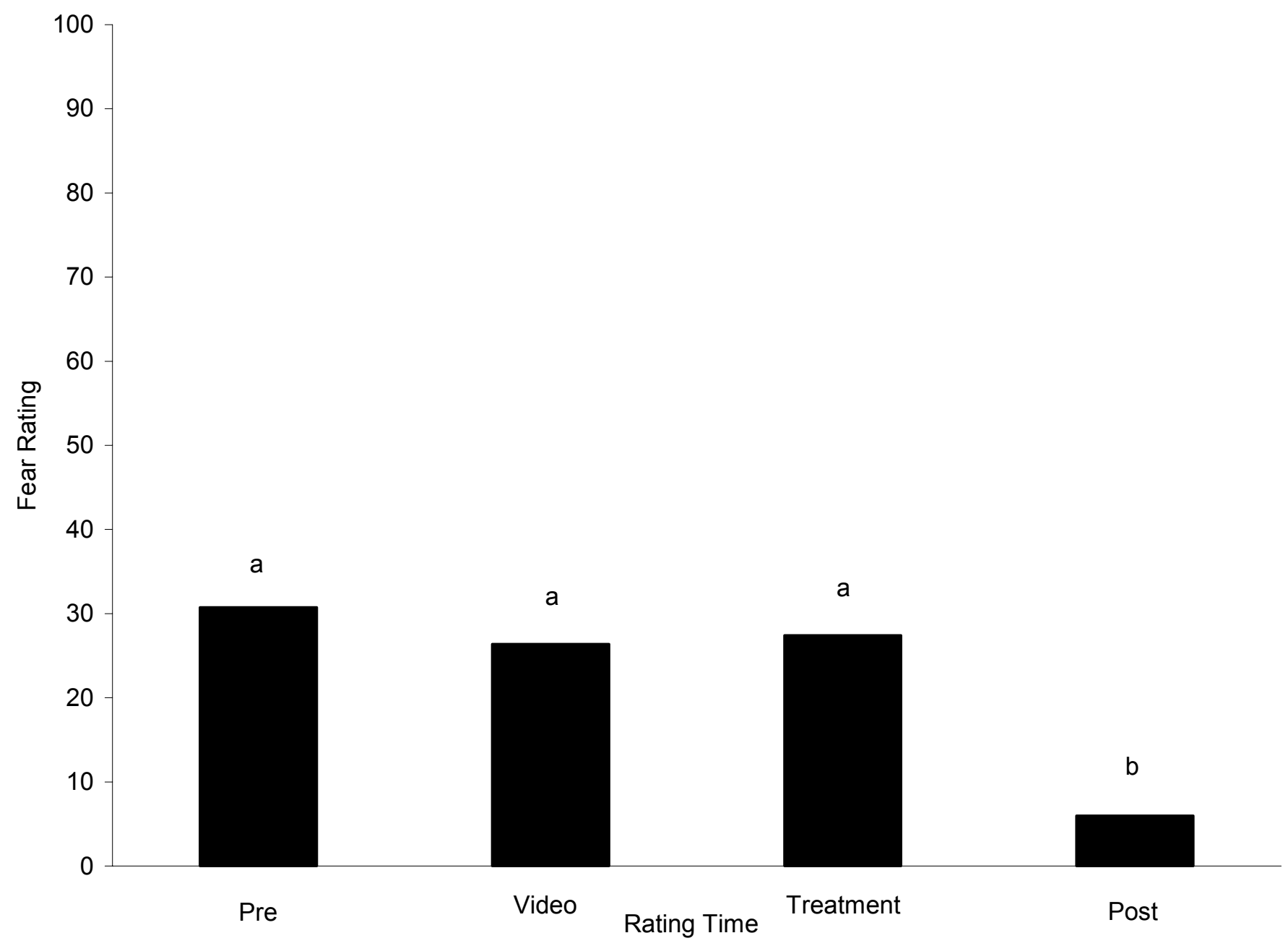

Note: $N=104$. Different superscripts indicate significant differences, $p<.05$. 
Figure 4.

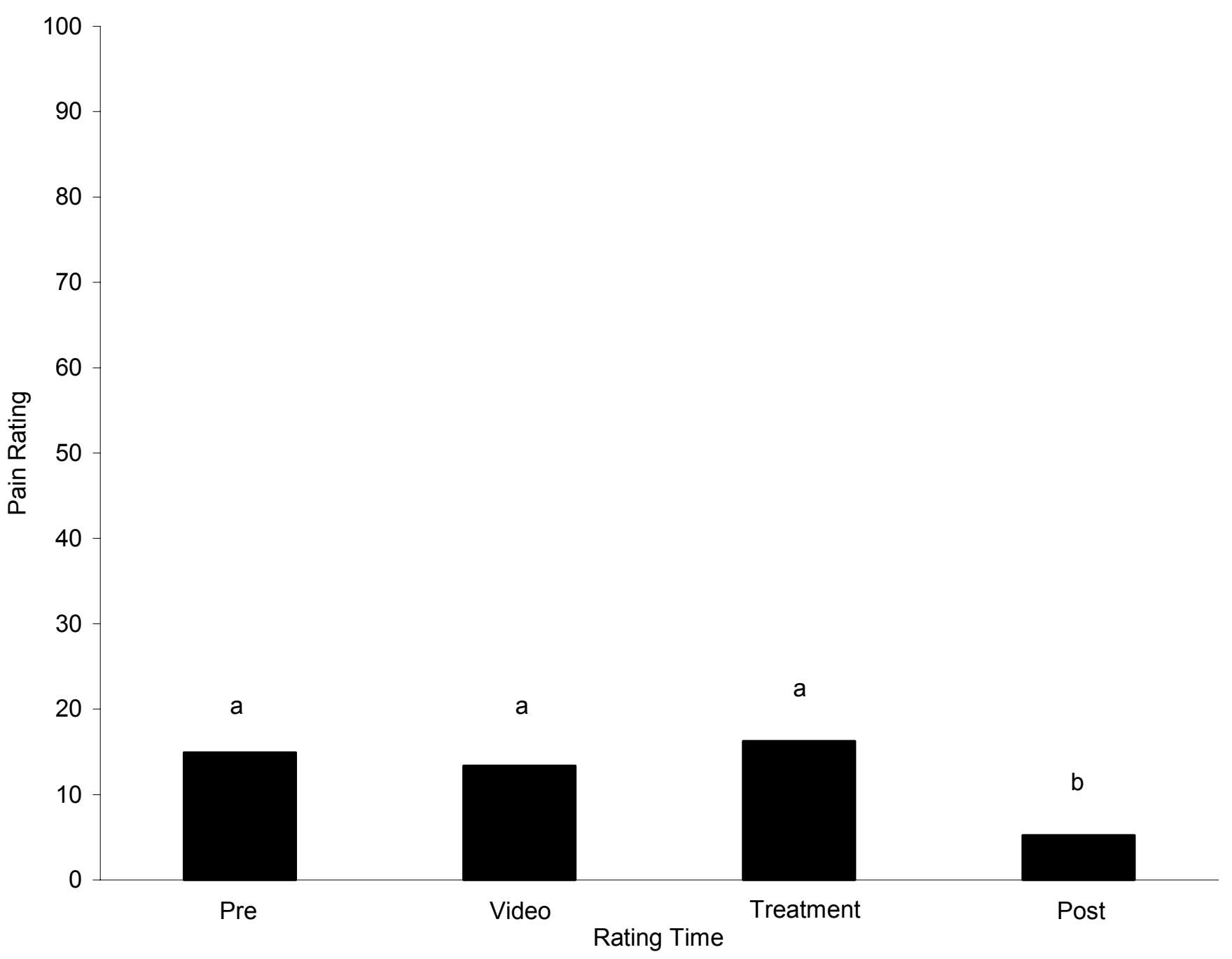

Note: $N=104$. Different superscripts indicate significant differences, $p<.05$. 
Figure 5.

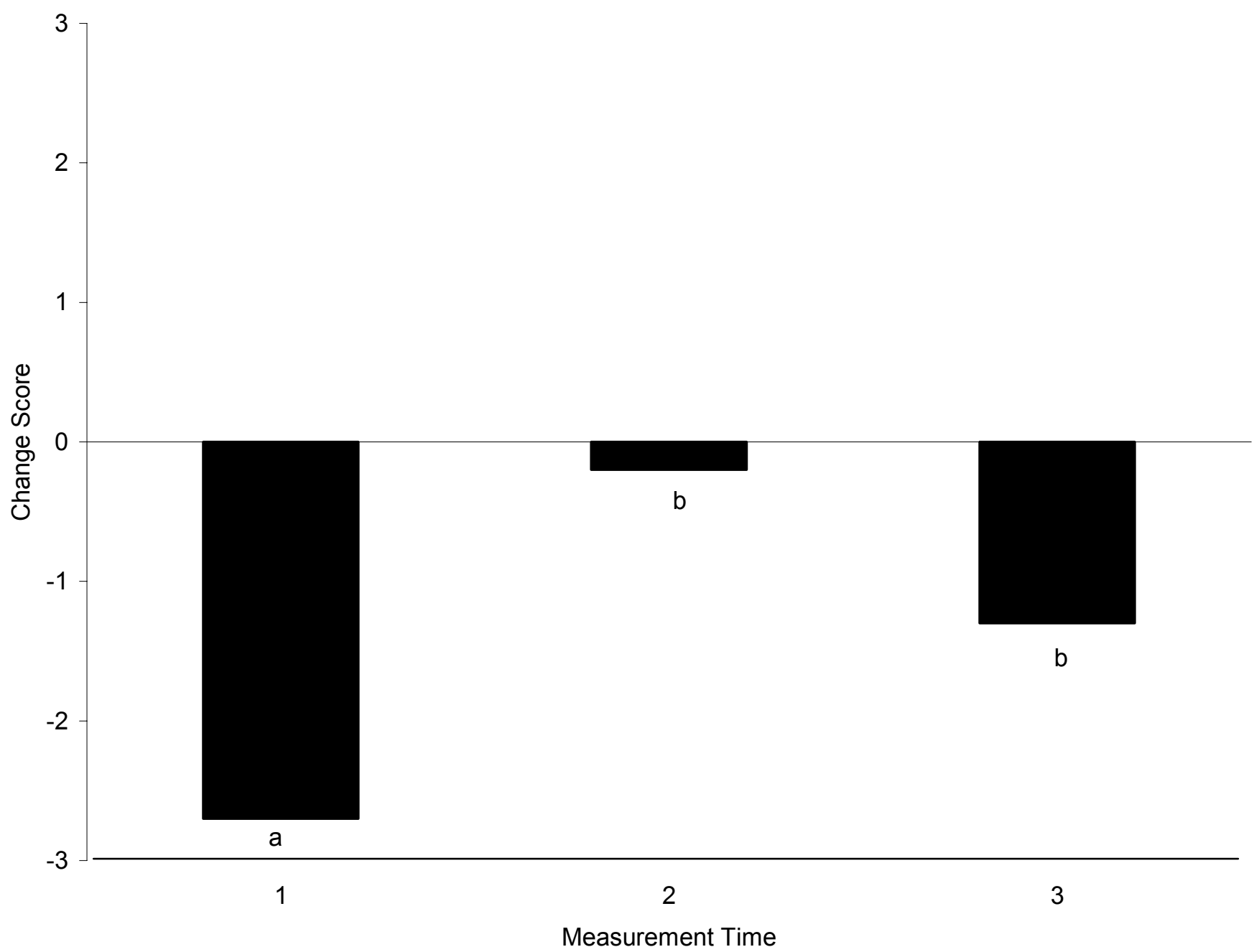

Note: $n=97.1=$ Injection heart rate; $2=$ Drilling heart rate; $3=$ Cleaning and shaping of canal heart rate.

Different superscripts indicate significant differences, $p<.05$. 
Figure 6.

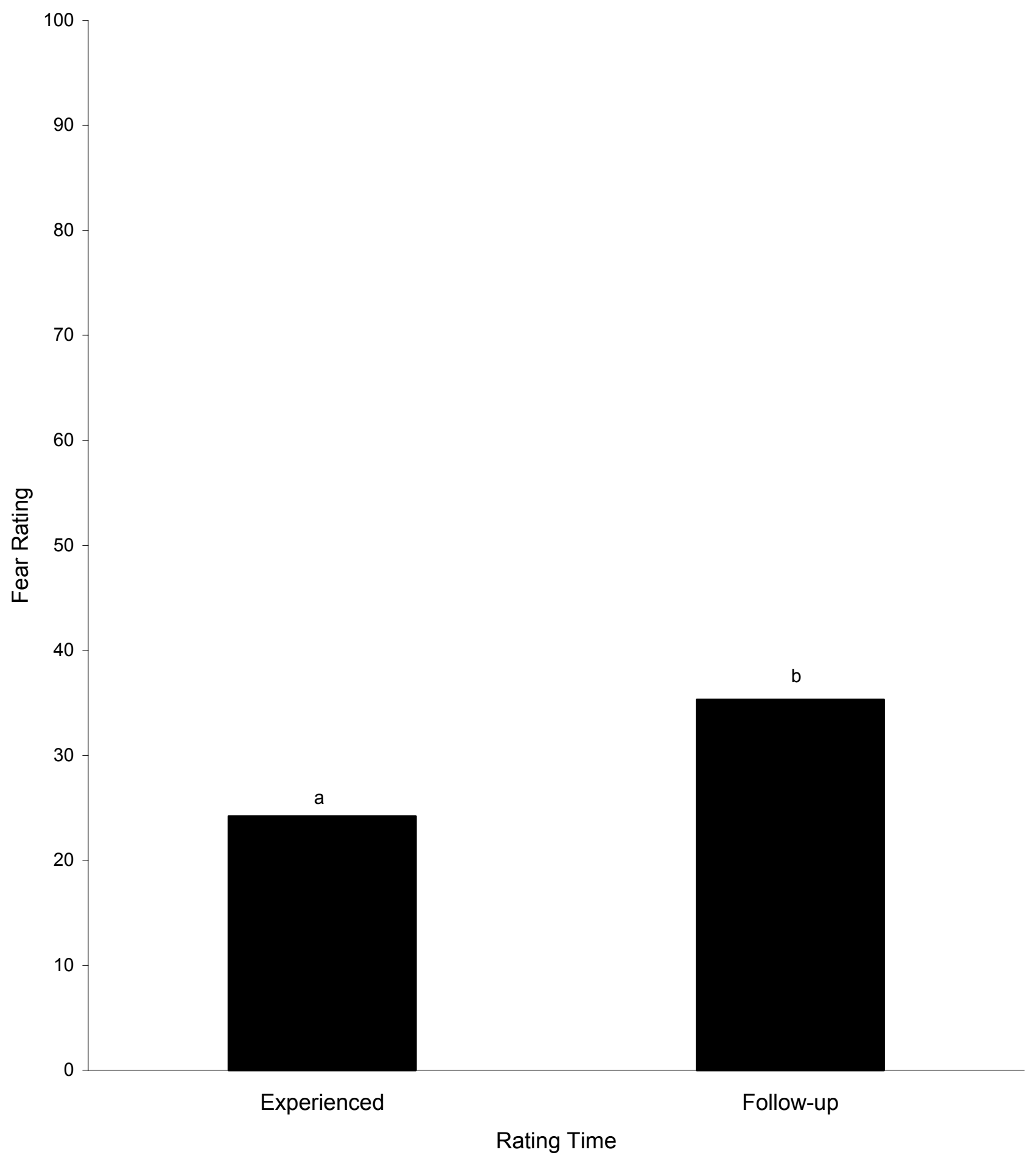

Note: $n=90$. Different superscripts indicate significant differences, $p<.05$. 
Figure 7

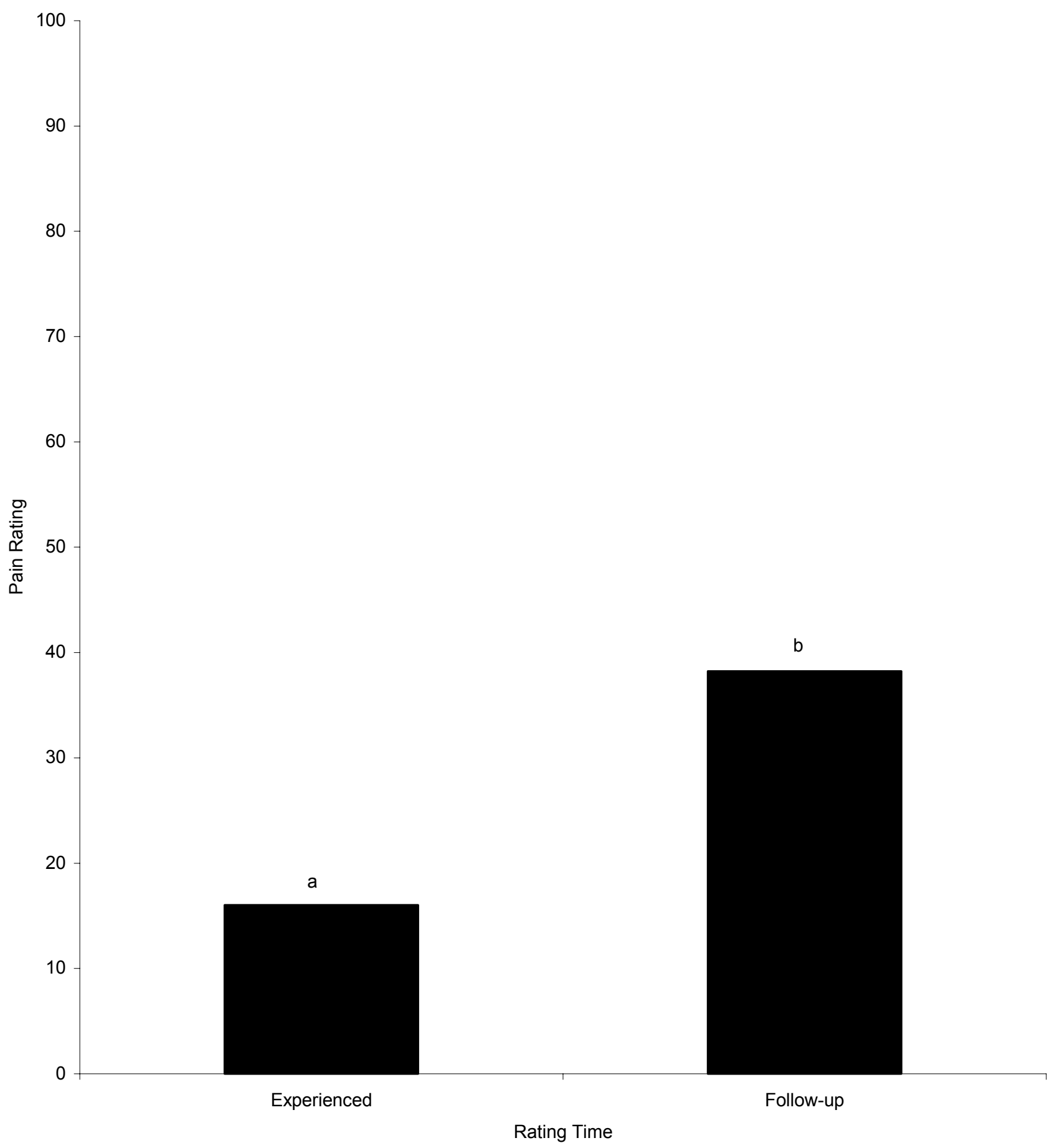

Note: $n=90$. Different superscripts indicate significant differences, $p<.05$. 